\title{
WestVirginiaUniversity
}

THE RESEARCH REPOSITORY @ WVU

Graduate Theses, Dissertations, and Problem Reports

2018

\section{Three Essays on Public Information and Security Prices.}

Chen Gu

Follow this and additional works at: https://researchrepository.wvu.edu/etd

\section{Recommended Citation}

Gu, Chen, "Three Essays on Public Information and Security Prices." (2018). Graduate Theses,

Dissertations, and Problem Reports. 8184.

https://researchrepository.wvu.edu/etd/8184

This Dissertation is protected by copyright and/or related rights. It has been brought to you by the The Research Repository @ WVU with permission from the rights-holder(s). You are free to use this Dissertation in any way that is permitted by the copyright and related rights legislation that applies to your use. For other uses you must obtain permission from the rights-holder(s) directly, unless additional rights are indicated by a Creative Commons license in the record and/ or on the work itself. This Dissertation has been accepted for inclusion in WVU Graduate Theses, Dissertations, and Problem Reports collection by an authorized administrator of The Research Repository @ WVU.

For more information, please contact researchrepository@mail.wvu.edu. 
Three Essays on Public Information and Security Prices

\author{
Chen Gu
}

Dissertation submitted to the

College of Business and Economics

at West Virginia University

in partial fulfillment of the requirements for the degree of

Doctor of Philosophy in Business Administration

\author{
Alexander Kurov, Ph.D., Chair \\ Victor Chow, Ph.D. \\ Ann Marie Hibbert, Ph.D. \\ Eric Olson, Ph.D.
}

Department of Finance

Morgantown, West Virginia

2018

Keywords: Market Efficiency; Informed Trading; Natural Gas Futures; Preannouncement Effect: Brexit; Political Risk; Financial Market Uncertainty; Social Media; Return Predictability 


\section{ABSTRACT \\ Three Essays on Public Information and Security Prices}

\section{Chen Gu}

This dissertation includes three essays examining the role of public information in financial markets. The first essay examines informed trading before natural gas inventory announcements. Natural gas futures prices start moving in the "right" direction about 90 minutes before the announcement. The empirical results show that the difference between the median forecast of analysts with high historical forecasting accuracy and the consensus forecast can be used to predict inventory surprises and some of the pre-announcement drift. Because both individual analyst forecasts and consensus are available to Bloomberg subscribers prior to official release time, our results suggest that informed trading before the announcement may be driven by superior forecasting based on public information rather than by information leakage.

The second essay investigates the effect of public political information on financial markets in the setting of the UK referendum on EU membership. It shows that an increase in the probability of Brexit, as reflected in online betting odds, leads to lower stock prices and higher market uncertainty. However, the likelihood of Brexit moved financial asset prices and volatilities only on days characterized by high investor attention to the Brexit topic. This finding indicates that markets react to new political information only when investors pay attention to it.

The third essay investigates whether and why information extracted from social media moves stock returns. It shows that firm-level Twitter sentiment predicts stock returns without subsequent reversals, suggesting that tweets contain novel information about firms' fundamentals. Furthermore, the paper provides four examples of value relevant information embodied in Twitter

sentiment. Specifically, Twitter sentiment has forecasting power on analyst recommendation revision, target price changes, IPO underpricing and earning surprise. 


\section{ACKNOWLEDGMENTS}

I would like to thank my advisor, Alexander Kurov, and my committee members Victor Chow, Ann Marie Hibbert, and Eric Olson for their help and support. I also thank my fellow doctoral students for many helpful discussions and suggestions. 


\section{TABLE OF CONTENTS}

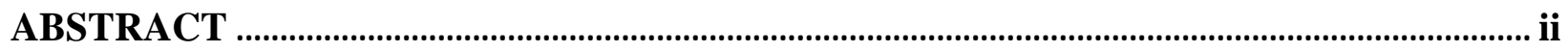

ACKNOWLEDGMENTS.............................................................................................................

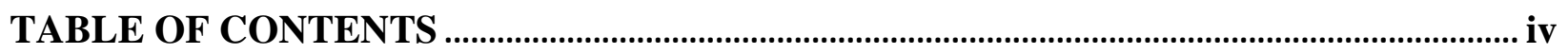

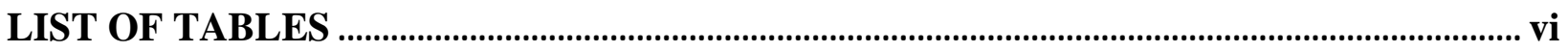

LIST OF FIGURES ........................................................................................................................... viii

INTRODUCTION ................................................................................................................... ix

CHAPTER 1: WHAT DRIVES INFORMED TRADING BEFORE PUBLIC RELEASES? EVIDENCE FROM NATURAL GAS INVENTORY ANNOUNCEMENTS ...........................1

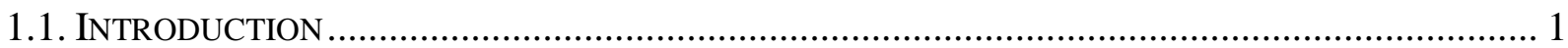

1.2. DATA

1.2.1. The Weekly Natural Gas Storage Report ……………………................................ 4

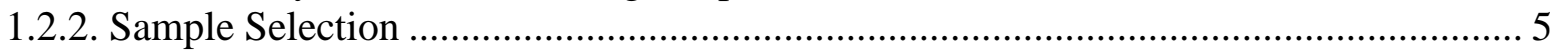

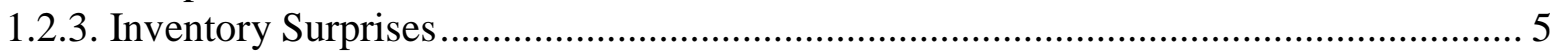

1.3. EVIDENCE OF PRE-ANNOUNCEMENT INFORMED TRADING............................................... 7

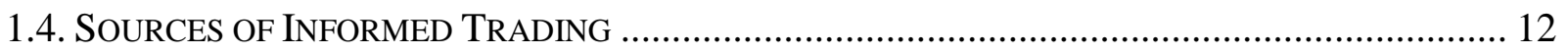

1.4.1 Informed Trading Based on Superior Forecasts ...................................................... 12

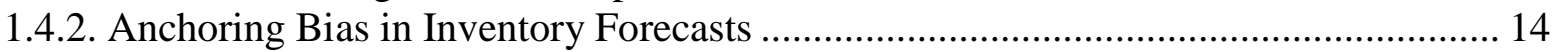

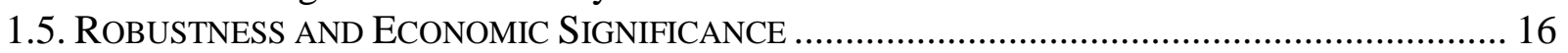

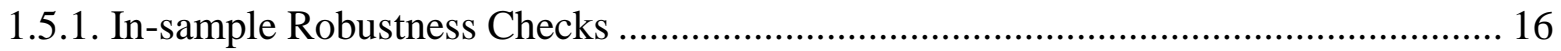

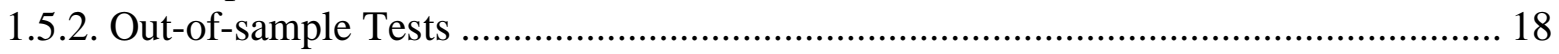

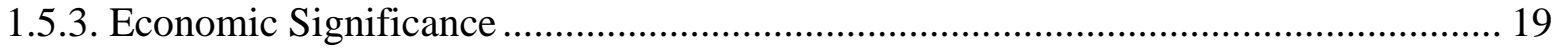

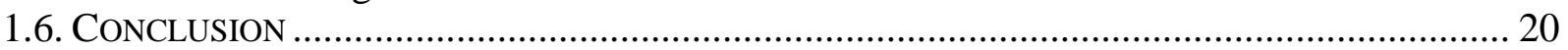

CHAPTER 2: EXPECTATIONS AND FINANCIAL MARKETS: THE CASE OF

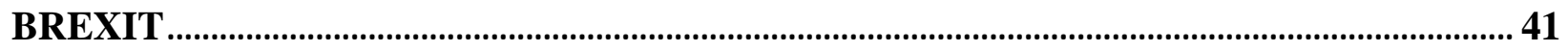

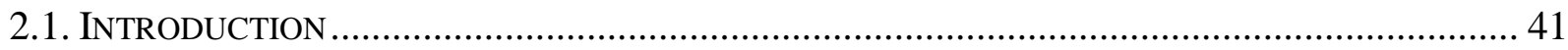

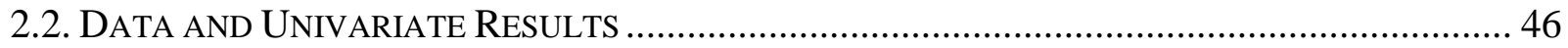

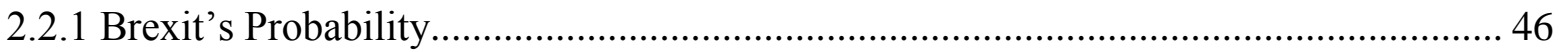

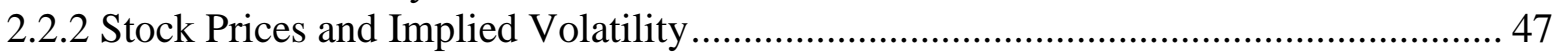

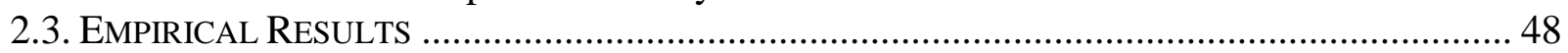

2.3.1 The Impact of the Probability of Brexit on Returns ................................................... 48

2.3.2 The Impact of the Probability of Brexit on Implied Volatilities ................................. 52

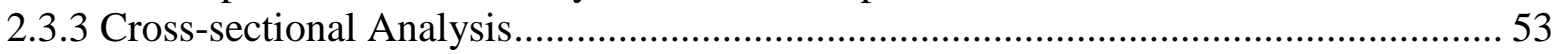

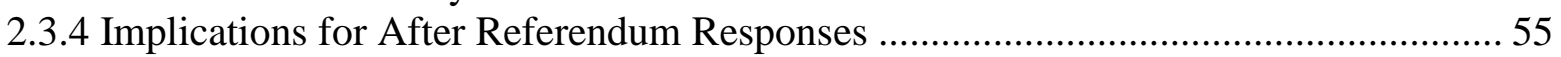

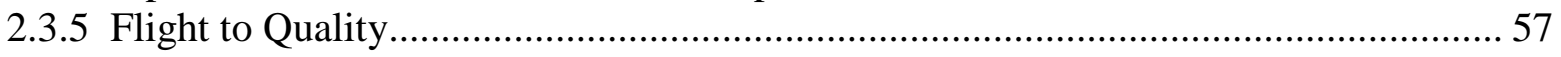

2.4. PROBABILITY OF BREXIT AND INVESTOR ATTENTION ……............................................ 58

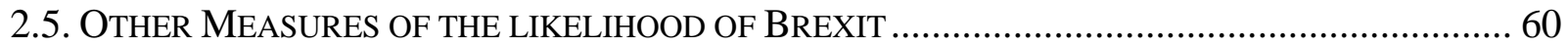

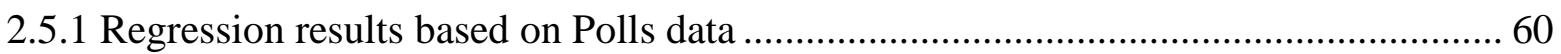

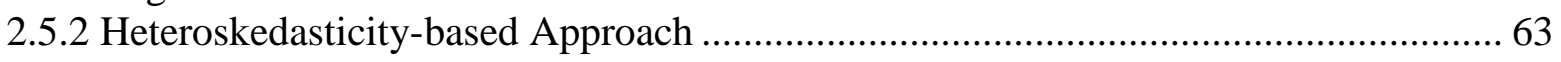

2.6. THE EFFECT OF ARTICLE 50 OF THE LISBON TREATY ON STOCK MARKETS ........................... 65

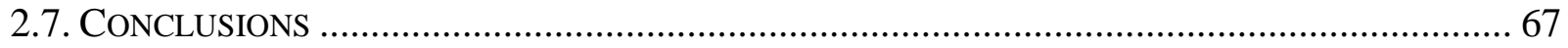




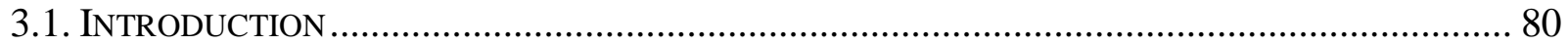

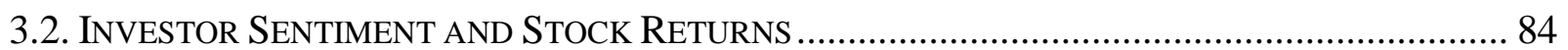

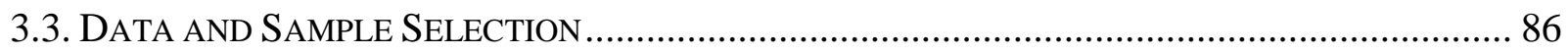

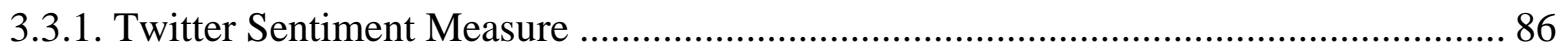

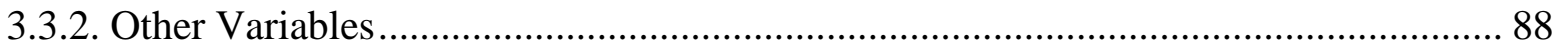

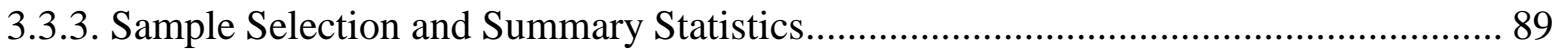

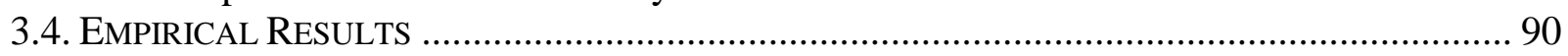

3.4.1. Predicting Stock Returns Using Twitter Sentiment................................................... 90

3.4.2. Is Twitter Sentiment Informative?........................................................................... 92

3.4.3. Twitter Sentiment vs. News Sentiment …………...................................................... 93

3.4.4. Economic Significance of Return Predictability ...................................................... 95

3.5. FundAMENTALS REFLECTED IN TwITTER SENTIMENT ………........................................... 98

3.5.1. Analyst Recommendation Changes ........................................................................ 98

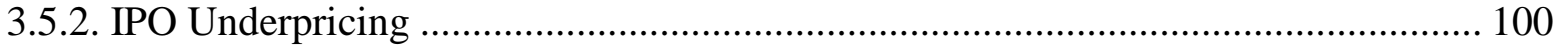

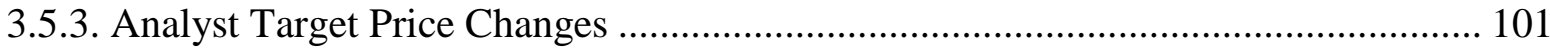

3.5.4. Quarterly Earnings ................................................................................................. 102

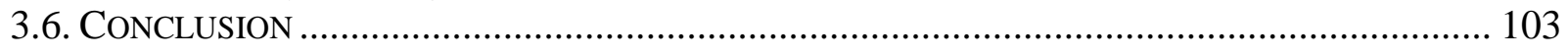

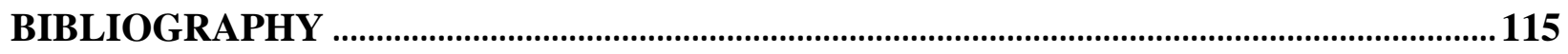




\section{LIST OF TABLES}

\section{CHAPTER 1}

Table 1 Analyst Firms Providing Natural Gas Storage Forecasts .............................................. 22

Table 2 Summary Statistics for Inventory Surprises .................................................................. 23

Table 3 Regression Results for Returns after Inventory Announcements ................................... 24

Table 4 Regression Results for Returns and Order Imbalances before Inventory Announcements

Table 5 Predicting the Inventory Surprise …………………................................................. 26

Table 6 Relation between Predictor of the Inventory Surprise and Returns and Order Imbalances

Table 7 Anchoring Bias in Inventory Forecasts .

Table 7 Anchoring Bias in Inventory Forecasts .................................................................. 28

Table 8 Regression of Pre-announcement Returns on Expected and Unexpected Components of

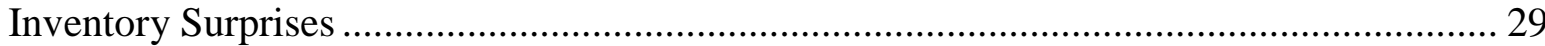

Table 9 Comparison of the Anchoring Bias Predictor and the Predictor Based on Ranked Analyst

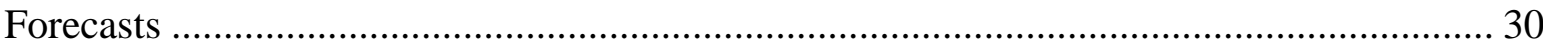

Table 10 Forecasting the Inventory Surprise and Pre-announcement Return with Predictor Based on Shorter Evaluation Periods ....................................................................................... 31

Table 11 Forecasting the Inventory Surprise and Pre-announcement Return with Modified

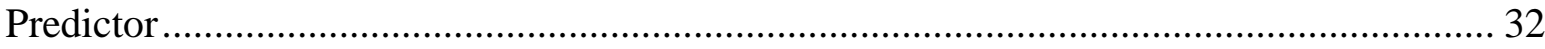

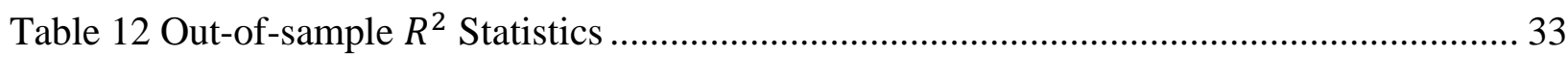

Table 13 Performance of Trading Strategy Based on Predictor of the Inventory Surprise ........... 34

\section{CHAPTER 2}

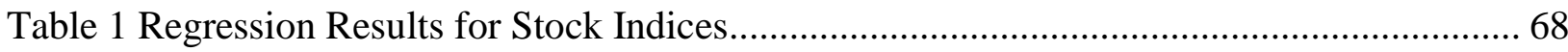

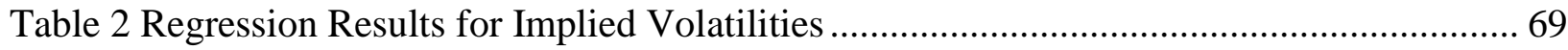

Table 3 Regression results for daily disaggregated stock returns ............................................... 70

Table 4 Regression results for Post-referendum Returns …………………………………........ 71

Table 5 Regression Results for Commodity, Bond and FX markets .......................................... 72

Table 6 Regression Results for Financial Assets Returns and Implied Volatilities with an

Attention Dummy (Betting Odds Data) ........................................................................... 73

Table 7 Regression Results for Financial Assets Returns and Implied Volatilities interacting with Attention Dummy (Polls Data) ........................................................................................ 74

Table 8 Estimated Impact of Increase in the Probability of Brexit (Normalized to cause a 1 basis

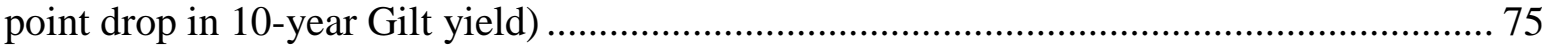

Table 9 Regression Results for the Post Referendum Period ....................................................... 76

\section{CHAPTER 3}

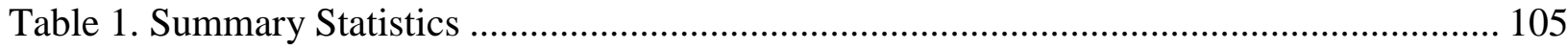

Table 2. Predicting Stock Returns Using Twitter Sentiment................................................... 106

Table 3. Predicting Stock Returns Using Lagged Twitter Sentiment.......................................... 107

Table 4. Predicting Stock Returns Using Twitter Sentiment and News Sentiment..................... 108

Table 5. Returns of Twitter-Based Trading Strategy ............................................................... 109 
Table 6. Predicting Analyst Recommendation Changes and Event Returns Using Twitter

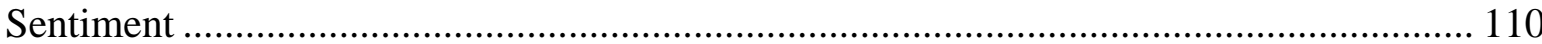

Table 7. Predicting IPO Underpricing Using Twitter Sentiment............................................... 111

Table 8. Predicting Target Price Changes and Event returns Using Twitter Sentiment.............. 112

Table 9. Predicting Earnings Surprises and Event returns Using Twitter Sentiment .................. 113 


\section{LIST OF FIGURES}

\section{CHAPTER 1}

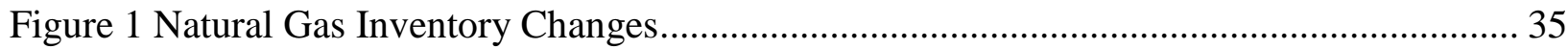

Figure 2 Evidence of Pre-announcement Effect ................................................................. 36

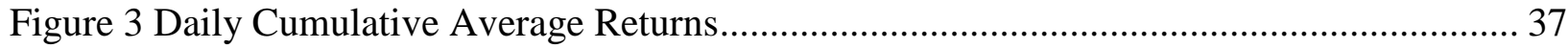

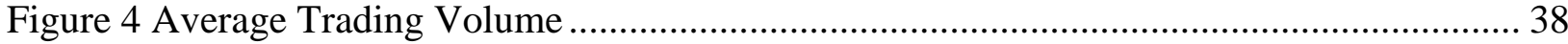

Figure 5 Sensitivity to Event Window Length ................................................................... 39

Figure 6 Moving Average of Pre-announcement Trading Returns ........................................ 40

\section{CHAPTER 2}

Figure 1 The Probability of Brexit vs. the Level of the Stock Indices .................................... 77

Figure 2 Sensitivity of the Slope Coefficient to Sample Period Length ................................... 78

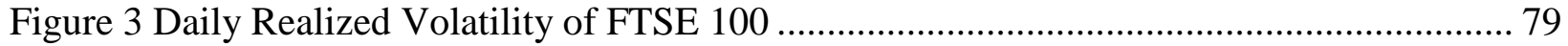

\section{CHAPTER 3}

Figure 1 Time series of monthly returns for the trading strategy based on Twitter sentiment ... 114 


\section{INTRODUCTION}

Public information impacts fundamental values of securities across countries as well as across asset categories. Accordingly, a voluminous literature investigates reaction of financial assets to various types of relevant public information, from macroeconomic news released by governments to online messages posted by individuals. The goal of this dissertation is to improve our understanding of how public information affects financial markets.

Traditional finance believes that public information, in contrast to private information, is incorporated prices before anyone can trade on it. However, a few recent studies find evidence on informed trading before official releases of public information, such as monetary policy (Bernile, Hu and Tang (2016)) and macroeconomic announcements (Kurov, Sancetta, Strasser and Wolfe (2017)). It is important to understand whether informed trading before public announcement is driven by superior forecasting based on public information or by information leakage.

Chapter 1 of this dissertation investigates informed trading before releases of the Weekly Natural Gas Storage Report. It finds that natural gas futures prices begin to drift in the "right" direction prior to the announcement, suggesting pre-announcement informed trading. Furthermore, the paper shows that the difference between the "informed consensus" based on top analyst forecasts and the consensus based on all analyst forecasts has predictive power for inventory surprises and the pre-announcement returns. Because the top analyst forecasts and the overall consensus forecast are available to Bloomberg subscribers, the results suggest that sophisticated traders are able to gain informational advantage through superior analysis of public information.

Political events, from wars to presidential elections, represent another type of market moving public information. This information affects markets by influencing investor expectations. Chapter 2 of this dissertation explores the effect of public political information on European and 
U.S. financial markets in the setting of the U.K. referendum on the country's membership in the E.U. It shows that investors moved capital away from riskier investment vehicles (stocks, crude oil, the British pound) to safer investments (gold, government bonds, the U.S. Dollar and the Japanese Yen) when the probability of Brexit increased. This finding is consistent with the wellknown flight to quality phenomenon usually observed during times of increased fear or uncertainty.

The second important issue examined in Chapter 2 is the effect of investor attention on the connection between the market expectations of Brexit and financial markets. Investor attention facilitates the incorporation of value relevant information into prices. Chapter 2 shows that political risk only influences financial markets when investors pay sufficient attention to related political news. This suggests that investor attention is essential to the incorporation of public information into security prices.

Public information affects financial markets via various communication media. Tetlock (2007) shows that qualitative information in newspapers is value relevant. Social media has become an important communication channel for information about financial markets. Recent research has examined how news from social media, especially Twitter, affects asset prices. However, the role of social media at the firm level is still not well understood due to the difficult task of analyzing massive amounts of social media content.

Chapter 3 of this dissertation examines the relation between information from social media and stock prices at the firm level. The paper shows that firm-level sentiment extracted from Twitter messages does not merely reflect sentiment of unformed traders. Instead, it has a permanent impact on stock returns. This study further finds that Twitter sentiment contains new information about upcoming analyst recommendation revisions, target price changes, IPO first-day opening prices 
and earning surprises. Thus, the results show that public information extracted from social media contains news about firms' fundamentals, which is gradually incorporated into stock prices. 


\section{Chapter 1: What Drives Informed Trading Before Public Releases? Evidence from Natural Gas Inventory Announcements ${ }^{1}$}

\subsection{Introduction}

Security prices contain information. Private information is reflected in prices through trading. Public information is generally believed to be incorporated in prices before anyone can trade on it (e.g., French and Roll, 1986). We examine whether some traders are able to make profitable trades by processing public information. Specifically, we analyze futures returns and trading activity around releases of the Weekly Natural Gas Storage Report. This report contains information about U.S. inventory of natural gas. The report is received by all interested parties simultaneously and can be viewed as typical public information. However, we find evidence of informed trading before the release of the report. About 90 minutes prior to the official announcement time, natural gas futures prices begin to drift in the direction of the eventual market reaction to the announcement. The pre-announcement returns and order flow in natural gas futures are significantly correlated with inventory surprises based on the consensus analyst forecast, suggesting that informed traders correctly anticipate inventory news.

Similar evidence of pre-announcement informed trading has been reported in recent studies of macroeconomic announcements. Bernile, Hu and Tang (2016) show evidence of informed trading during the lockup periods before policy announcements of the Federal Open Market Committee (FOMC). Abnormal order imbalances in the stock index futures market are correlated with the subsequent policy surprise. Kurov, Sancetta, Strasser and Wolfe (2017) find strong

\footnotetext{
${ }^{1}$ This essay is based on a paper coauthored with Alexander Kurov.
} 
evidence of price drift in equity index and Treasury futures prior to the official release of several major U.S. macroeconomic announcements. On average, the pre-announcement price move accounts for almost half of the total price adjustment around the announcement. Similar evidence of price drift before U.K. macroeconomic news has attracted intense media attention. ${ }^{2}$ Our evidence of informed trading before the Weekly Natural Gas Storage Report announcements shows that the pre-announcement effect is not limited to major macroeconomic announcements.

One can think of several channels through which informed traders might obtain informational advantage before the release of the official data. In the first channel, some traders might get advance access to the news due to information leakage. Bernile et al. (2016) show that informed trading before FOMC announcements is associated with the FOMC's embargo practice, suggesting that information about monetary policy decisions may be leaked by parties who have early access to FOMC statements. ${ }^{3}$ Similarly, Kurov et al. (2017) find stronger evidence of informed trading before macroeconomic announcements released under less secure release procedures. This raises the possibility that access to leaked information gives some traders an unfair advantage.

In the second channel, traders may become informed about upcoming announcements by collecting proprietary information. For example, institutional traders may conduct informal surveys of natural gas storage operators and use the collected data to forecast inventory surprises. Finally, traders might be able to predict announcement surprises through the skillful processing of public information. Kim and Verrecchia (1994) contend that some traders can process public information better than others. This increases information asymmetry around public

\footnotetext{
${ }^{2}$ See, for example, Bird (2017) and Binham (2017).

${ }^{3}$ In a related paper, Cieslak, Morse and Vissing-Jorgensen (2018) argue that the Fed tends to release information about future policy decisions through informal communication with the media and the financial sector.
} 
announcements. If some traders are able to use their superior information processing ability to predict inventory surprises and trade on their predictions, we should observe a price drift in the "right" direction before the announcement. Kurov et al. (2017) examine this possibility for macroeconomic announcements but are unable to produce clear evidence that the preannouncement drift is explained by smart reprocessing of publicly available data.

We offer evidence on the public information channel of the pre-announcement informed trading by looking at whether such trading is related to inventory forecasts of analysts with superior historical forecasting ability. Bloomberg assigns ranks to three best analysts based on their past forecasting accuracy. We use the median of the ranked analyst forecasts as a proxy for the "informed" forecast. We then compute a simple predictor of the inventory surprise as the difference between the "informed" forecast and the regular Bloomberg consensus forecast. Individual analyst forecasts and ranks are available to Bloomberg subscribers before the announcement. Thus, our predictor is based on what effectively is public information. ${ }^{4}$ BenRephael, Da and Israelsen (2017) note that Bloomberg subscribers are much more likely to be institutional investors than retail traders. Hendershott, Livdan and Schürhoff (2015) provide evidence that institutional trading predicts news announcements, suggesting that institutions are informed traders. They have expertise and resources to process available information and optimally trade on it.

We show that the predictor discussed above has explanatory power for the natural gas inventory surprises and for the pre-announcement futures returns, both in- and out-of-sample. This finding is consistent with pre-announcement informed trading based on superior forecasts. For example, suppose that the consensus forecast predicts inventory increase of one billion cubic feet,

\footnotetext{
${ }^{4}$ The number of Bloomberg subscribers is about 320,000 globally. It is reasonable to assume that most large futures traders have access to Bloomberg.
} 
while analysts with superior historical forecasting accuracy forecast an increase of two billion cubic feet. The difference between these two forecasts can be viewed as a forecast of what traders relying on the Bloomberg consensus will view as the inventory surprise. If some traders sell futures contracts before the announcement based on this forecast of the inventory shock, prices will decline, leading to a pre-announcement drift. Therefore, we provide evidence that some traders use what effectively is public information to make well-timed trades before public announcements.

It is possible that the pre-announcement informed trading is driven in part by information leakage or by proprietary data collection. However, our results show that informed trading due to superior processing of public information is a plausible explanation for the pre-announcement price drift. We propose a simple trading strategy conditioned on the predictor to capture the preannouncement drift. The trading strategy consists of buying (selling) natural gas futures contracts 90 minutes before the release time if the predictor is negative (positive), and closing the position before the announcement. This strategy produces an annualized Sharpe ratio of 0.84 in the full sample of announcements and an annualized Sharpe ratio of 1.26 on days with large values of the predictor.

\subsection{Data}

\subsubsection{The Weekly Natural Gas Storage Report}

The U.S. Energy Information Administration (EIA) releases its Weekly Natural Gas Storage Report every Thursday at 10:30 a.m. ET. In some weeks, which include holidays, releases are delayed by one day. These reports include estimates of the volume of working natural gas held in underground storage facilities in the lower 48 states and the net change in storage for the week ending the previous Friday. These estimates of working gas are derived from a survey of a sample 
of operators of underground storage facilities. Approximately 140 operators report for their operations at about 400 storage fields. Respondents submit estimates of working gas in storage fields operated by their company as of 9 a.m. on Friday each week by 5 p.m. Eastern Time the following Monday. Several studies show that unexpected changes in gas inventory have a significant impact on natural gas futures prices immediately after the announcement. ${ }^{5}$ In contrast, our study focuses on the natural gas futures prices and trading activity before the official announcement time.

\subsubsection{Sample Selection}

Our sample period is from July 2008 through January 2016. July 2008 serves as the beginning point because in mid-2008 the EIA modified its weekly natural gas storage survey to reflect changes in the industry and improve the accuracy of storage estimates (Halova et al., 2014). The improvement of the information collection process decreased the noise in the natural gas storage estimates. Our sample period includes 387 releases of the Weekly Natural Gas Storage Report. To minimize the potentially confounding effects of the EIA's Weekly Petroleum Status Report on natural gas futures, we exclude 53 occasions when the two reports were released on the same day. ${ }^{6}$ The final sample contains 334 observations.

\subsubsection{Inventory Surprises}

Following previous studies, we use the Bloomberg consensus forecast to measure the market expectation of the changes in inventory. Every week, around 20 analysts submit their forecasts of

\footnotetext{
${ }^{5}$ See, for example, Linn and Zhu (2004), Gay, Simkins and Turac (2009), and Halova, Kurov and Kucher (2014).

${ }^{6}$ The Weekly Petroleum Status Report that includes inventory estimates for crude oil and oil products is released every Wednesday at 10:30 a.m. ET. In some weeks, which include holidays, releases are delayed by one day.
} 
the change in natural gas inventory. ${ }^{7}$ Bloomberg then computes the consensus forecast as the median of the analyst forecasts. ${ }^{8}$ Bloomberg normally ranks the top three analysts based on their forecasting accuracy in the previous 24 months. ${ }^{9}$ Table 1 lists all active analyst firms during the sample period. ${ }^{10}$ As shown in the table, there are substantial cross-sectional differences in forecasting ability measured as the mean standardized absolute forecast error. ${ }^{11}$ In addition, the group of the ranked analysts is quite stable. Only five analysts appeared in the group of the top three forecasters after more than 50 inventory announcements.

\section{[Insert Table 1 here]}

We use the median value of the ranked analyst forecasts to construct the "informed" forecast. The ranking information is updated immediately after the release. To avoid forwardlooking bias, we use the analyst ranks from the previous week. Bloomberg subscribers have access to this information prior to the release of the Weekly Natural Gas Storage Report.

The inventory surprise, $S_{t}$, is computed as the difference between the actual change in inventory and the consensus forecast:

$$
S_{t}=A_{t}-F_{t}
$$

where $A_{t}$ is the actual inventory change and $F_{t}$ is the consensus forecast or the "informed" forecast for week $t .^{12}$

\footnotetext{
${ }^{7}$ The average time between the date of forecast submission and the release date is 1.15 days. If forecasts submitted more than 2 days before the release date are dropped from calculation of the consensus forecast, the empirical results are similar. These results are available upon request.

${ }^{8}$ The empirical results based on the arithmetic average of analyst forecasts, available upon request, are similar.

${ }^{9}$ Bloomberg's analyst ranking methodology is described in section 5.1.

${ }^{10}$ The table only includes 41 analyst firms that submitted more than 50 forecasts during our sample period. There were 85 different forecast submitters during this period.

${ }^{11}$ The standardized absolute forecast error for analyst $i$ in week $t$ is defined as $\left|A_{t}-F_{i, t}\right| / \sigma_{t}$, where $A_{t}$ is the actual announcement, $F_{i, t}$ is the individual forecast and $\sigma_{t}$ is the standard deviation of forecasts for week $t$.

${ }^{12}$ Chang, Daouk and Wang (2009) use a similar approach to measure inventory surprises for crude oil. We also computed inventory surprises scaled by the storage level to control for the potential effects of trends in inventory. The empirical results, available upon request, are similar.
} 
Summary statistics for the inventory surprises are shown in Table 2. The table shows that the standard deviation of the inventory surprises based on ranked analyst forecasts is lower than that of the surprises based on the consensus forecast. Moreover, the inventory surprises based on the "informed" forecast tend to be smaller in absolute value. These statistics indicate that the "informed" forecast tends to be more accurate than the consensus forecast.

[Insert Table 2 here]

Figure 1 shows natural gas inventory and inventory surprises over the sample period. As seen in Panel A of Figure 1, the storage level shows a strong seasonality. It tends to increase from April to October (injection season) and decrease from November to March (withdrawal season). However, Panel B shows that the inventory surprises, which represent unexpected changes in the natural gas inventory, do not have a clear seasonal pattern.

[Insert Figure 1 here]

\subsection{Evidence of Pre-announcement Informed Trading}

To look for evidence of pre-announcement informed trading, we first graph the cumulative average returns (CARs) of the nearby natural gas futures in an intraday event window surrounding the announcement. ${ }^{13}$ Positive surprises represent bad news for natural gas futures prices and negative surprises represent good news. Following Bernile et al. (2016), we invert the sign of returns for bad news. This allows aggregating CARs for positive and negative surprises. Panel A of Figure 2 plots the CAR in the interval from midnight of the announcement day to three hours after the announcement. The figure shows that about 90 minutes before the announcement natural gas futures prices begin moving gradually in the direction of the subsequent post-announcement

\footnotetext{
${ }^{13}$ Since the nearby contract becomes relatively illiquid shortly before expiration, we switch to the next contract in the last three days of trading of the nearby contract.
} 
returns. ${ }^{14}$ As evidenced by the $90 \%$ confidence interval, the pre-announcement returns are statistically significant.

\section{[Insert Figure 2 here]}

We also use second-by-second futures date to examine cumulative order imbalances. If pre-announcement informed trading exists, we should find order imbalances in the "right" direction before the release time. We use the tick rule to classify trading volume as buyer- or sellerinitiated. ${ }^{15}$ Similar to returns, order imbalances for positive inventory surprises are multiplied by minus one. Panel B of Figure 2 plots the average cumulative order imbalances from 90 minutes before to 30 minutes after the release. The figure shows that the pre-announcement order imbalances are in the direction of the subsequent post-announcement trading. The cumulative order imbalance before the release accounts for about one-third of the total order imbalance around the announcement on average.

Informed traders may choose to trade on their forecasts of the announcement surprise days before the announcement. Figure 3 plots daily cumulative average returns in the natural gas futures conditional on the inventory surprise from four days before to the day after the announcement. The CAR is not statistically significant until the announcement day. This suggests that the informed trading is concentrated immediately before the announcement.

\section{[Insert Figure 3 here]}

The Natural Gas Storage Report is released at 10:30 a.m. ET. As shown in Figure 2, the pre-announcement drift begins about 90 minutes before the announcement, which coincides with the beginning of open outcry trading in the natural gas futures market. Although the large majority

\footnotetext{
${ }^{14}$ The correlation of returns in the $[t-90 \mathrm{~min}, t-5 \mathrm{~min}]$ and $[t-5 \mathrm{~min}, t+30 \mathrm{~min}]$ windows, with time $t$ being the announcement time, is positive and statistically significant at the $5 \%$ level.

${ }^{15}$ Specifically, volume in a 1-second bar is classified as buyer-initiated if the price for that bar is higher than the last different price. Otherwise, the volume in the bar is classified as seller-initiated.
} 
of futures trading during our sample period occurred on the 24-hour electronic trading platform called Globex, trading activity increases dramatically after 9:00 a.m. Figure 4 plots the average trading volume around the official release time. As seen in the figure, the volume rises significantly 90 minutes before the announcement. The high level of trading activity on Globex after 9:00 a.m. allows informed traders to hide their trading. Therefore, even if an informed trader receives tradable information several hours before the release of the Natural Gas Storage Report, it may be optimal to trade on it only shortly before the announcement. This is consistent with CollinDufresne and Fos $(2015,2016)$ who show that informed traders are more active when unformed trading is high. It is also possible that investors optimally choose what signals to pay attention to, and the 90 minutes prior to the announcement may be a time when natural gas futures traders process storage information that might have been available before (Admati and Pfleiderer,1988; Kacperczyk, Van Nieuwerburgh, and Veldkamp, 2016). Minimizing risk is another possible reason for delaying trading until shortly before the announcement. Establishing a position long before the announcement would expose the trader to potential losses driven by news unrelated to the inventory announcement.

\section{[Insert Figure 4 here]}

We examine the explanatory power of inventory surprises for the returns around the announcement by estimating the following regression:

$$
R_{t}=a_{0}+a_{1} S_{t}+e_{t}
$$

where $R_{t}$ is the continuously compounded natural gas futures return over a given intraday event window, $S_{t}$ is the inventory surprise, and $e_{t}$ is an i.i.d. error term. ${ }^{16}$

\footnotetext{
${ }^{16}$ As a robustness check, we also run this regression using the return of the U.S. Natural Gas ETF (ticker symbol UNG) as the dependent variable. The results, available upon request, are similar to those based on the futures returns.
} 
We first estimate this regression using the event window from 5 minutes before to 30 minutes after the announcement. Table 3 presents the regression results. Consistent with previous literature, the natural gas futures market negatively reacts to inventory shocks. The table also shows that forecasts of more accurate analysts are given more weight by the market. Specifically, the inventory surprise based on the "informed" consensus forecast explains a larger fraction of variation in the futures returns compared to the surprise based on the Bloomberg consensus. Halova et al. (2014) show that noise in inventory surprises leads to a downward bias in the market response coefficients and lowers the regression $R^{2}$. The larger estimate of the response coefficient and higher $R^{2}$ for the regression using inventory surprises based on the "informed" consensus forecast suggest that these forecasts are less noisy than the regular consensus forecasts computed using data for all analysts.

[Insert Table 3 here]

Since we are interested in the pre-announcement effect, we then estimate the event study regression using futures returns in the interval from 90 minutes before to 5 minutes before the announcement using the inventory surprises based on the Bloomberg consensus. ${ }^{17,18}$ Table 4 provides the regression results. Consistent with the existence of pre-announcement informed trading, futures returns before the announcement are significantly and negatively related to the inventory shocks. We also estimate the same regression using the order imbalance in the preannouncement event window as the dependent variable. Table 4 shows that the coefficient estimate

\footnotetext{
${ }^{17}$ We use 5 minutes before the official release time as the end of the pre-announcement window to minimize the influence of high-frequency traders. Flynn (2012) and Dicolo and Rogow (2012) discuss instances when highfrequency traders send a flood of orders in an effort to trigger large price swings just before the EIA storage data is announced. They then make profits in volatile trading by taking advantage of their superior speed.

${ }^{18}$ The pre-announcement informed trading can also be examined by regressing inventory surprises on preannouncement returns or order imbalances. However, this specification is interchangeable with equation (2) in terms of statistical inference. Following Bernile et al. (2016) and Kurov et al. (2017), we choose to regress the returns and order imbalances on inventory surprises.
} 
on the inventory surprise is negative and statistically significant. This result is consistent with informed trading based on forecasts of inventory surprises.

[Insert Table 4 here]

To investigate the sensitivity of the regression results to the length of the event window, we re-estimate the regression in equation (2) for different event windows. We move the starting point of the window used to compute the futures returns from 150 minutes before the announcement to 10 minutes before the announcement at five-minute increments. The endpoint of the event window is fixed at five minutes before the announcement. As shown in Figure 5, the estimated coefficient of the inventory surprise based on the Bloomberg consensus declines for the pre-announcement windows that start less than 90 minutes before the release time. This is consistent with our finding in Figure 2 showing that the pre-announcement CAR becomes significant about 90 minutes ahead of the announcement.

\section{[Insert Figure 5 here]}

The intercept coefficient estimates in Tables 3 and 4 are negative and statistically significant. This suggests that natural gas futures prices declined in our sample period. This result is mainly driven by a large decline in natural gas prices during first year of our sample. ${ }^{19}$ If we exclude the period from July 2008 to July 2009, the intercept estimates become much smaller but the slope coefficient estimates remain similar to those in Tables 3 and $4 .^{20}$

\footnotetext{
${ }^{19}$ The price of natural gas declined by approximately $70 \%$ between July 2008 and July 2009 and remained low for the rest of our sample period.

20 These results are not tabulated for brevity. In an additional robustness check, we estimate a two-year rolling regression of pre-announcement returns on inventory surprises. The results (not reported but available upon request) show that the relation between the inventory surprises and pre-announcement returns is negative and significant for all two-year sub-periods in our sample.
} 


\subsection{Sources of Informed Trading}

\subsubsection{Informed Trading Based on Superior Forecasts}

A possible explanation for the pre-announcement effect documented in the previous section is that some traders are able to predict inventory surprises by processing available information and trade on their predictions before the announcement. We have shown that forecasts of analysts with best prior forecasting accuracy are superior to the consensus forecast. If the Bloomberg consensus forecast reflects the broad market expectations of natural gas inventory, it is reasonable to use the median value of the ranked analyst forecasts as a proxy for expectations of informed traders. Therefore, the difference between the "informed" and the simple consensus forecasts can be used as a predictor of the inventory surprise:

$$
P_{t}=F_{t}^{I}-F_{t}^{C},
$$

where $F_{t}^{I}$ and $F_{t}^{C}$ are the "informed" and consensus forecasts of inventory change, respectively. Importantly, this predictor uses only information available to Bloomberg subscribers before the announcement.

To formally explore the predictive power of our predictor of the surprise, we run the following OLS regression:

$$
S_{t}=a_{0}+a_{1} P_{t}+\sum_{n=1}^{L} b_{n} S_{t-n}+e_{t} .
$$

Lags of inventory surprises are included in the model to control for potential seasonality. The optimal number of lagged inventory surprises based on the Akaike information criterion is two. In addition to $L=2$, we also use model specifications with one lag, as well as a model with no lags of inventory surprises. As shown in Table 5, the coefficient estimate of the predictor is statistically significant and close to one for all of these models. This indicates that there is a strong relation between the predictor and the inventory surprise. 


\section{[Insert Table 5 here]}

Next, we examine whether the pre-announcement return is related to the predictor. Panel A of Table 6 shows that the predictor has significant explanatory power for the pre-announcement returns. The negative sign of the coefficient of the predictor is consistent with informed trading based on superior forecasts before the announcement. When informed traders believe that the consensus forecast overestimates the increase or underestimates the decrease in inventory, they buy futures contracts before the release time, leading to a positive price drift. When the consensus forecast underestimates the increase or overestimates the decrease in inventory, informed traders sell futures contracts before the announcement, leading to a negative price drift. Panel B reports estimates of a similar regression with the pre-announcement order imbalance used as the dependent variable. These estimates are qualitatively similar to those in Panel A of the table.

\section{[Insert Table 6 here]}

A natural follow-up question is whether the information contained in the predictor is completely incorporated into the market price by the time of the announcement. According to the efficient market hypothesis, since information contained in the predictor is widely available before the announcement, the predictor should be unrelated to price changes after the release of the inventory report. Regression results reported in Table 6 show that the return and order imbalance after the announcement are not significantly related to the predictor. This finding suggests that the information contained in the superior forecast predictor is fully reflected in futures prices before the announcement. This may be due to competition of multiple traders who trade on similar information (Holden and Subrahmanyam, 1992).

Pre-announcement informed trading may be related to other types of public information. For example, $\mathrm{Mu}$ (2007) shows that temperature shocks have a significant impact on returns and 
volatility of natural gas futures. Traders may use temperature shocks to forecast natural gas inventory changes. Traders may also be able to use information about crude oil inventory, which is released one day before the gas storage report, to predict natural gas inventory surprises. In untabulated results, we show that temperature shocks cannot be used to predict natural gas inventory surprises. ${ }^{21}$ Similarly, we find no evidence that crude oil inventory surprises can be used to predict subsequent natural gas inventory surprises.

\subsubsection{Anchoring Bias in Inventory Forecasts}

Campbell and Sharpe (2009) show that consensus forecasts of macroeconomic announcements are anchored to the recent past, which results in the announcement surprises being predictable. The anchoring bias can be illustrated by the following equation:

$$
F_{t}=\lambda E\left[A_{t}\right]+(1-\lambda) \bar{A}_{h}
$$

where $E\left[A_{t}\right]$ is the unbiased forecast and $\bar{A}_{h}$ is the average of the last $h$ realizations. If $\lambda<1$, the forecast is affected by anchoring bias. Substituting $E\left[A_{t}\right]=E\left[S_{t}\right]+F_{t}$ (obtained from equation (1)) produces a simple regression test for anchoring bias:

$$
S_{t}=\gamma\left(F_{t}-\bar{A}_{h}\right)+\varepsilon_{t}
$$

where $\gamma \equiv(1-\lambda) / \lambda$. When the estimate of $\gamma$ is positive and significant (implying $\lambda<1)$, the consensus forecast is systematically biased to historical announcements.

Following Campbell and Sharpe (2009), we use the last actual inventory change $(h=1)$ and the mean of the last three realizations $(h=3)$ to test for anchoring bias in the consensus forecast. The results are reported in Panel A of Table 7 The estimate of $\gamma$ is positive and statistically significant, suggesting that the consensus forecasts contain anchoring bias. Because

\footnotetext{
21 This analysis uses temperature data for Texas, Illinois, Ohio, Michigan, California and New York, which together account for about half of the residential and commercial natural gas consumption in the U.S.
} 
both the consensus forecast and historical actual values of inventory changes are publicly available before the announcement, this result indicates that traders can predict inventory surprises by using public information. Regression results in Panel B of Table 7 show that the "informed" consensus is not affected by anchoring bias.

\section{[Insert Table 7 here]}

Equation (6) shows that inventory surprises include a predictable component $\gamma\left(F_{t}-\right.$ $\bar{A}_{h}$ ) and an unexpected component $\varepsilon_{t}$. Zhou (2015) argues that the predictable component may explain the price drift before macroeconomic announcements. By regressing pre-announcement returns on the two components of the surprise, he finds that the coefficient on the anticipated component is statistically significant. Using a similar regression, we find a similar result. Table 8 shows that the coefficient estimate of the expected component of the inventory surprise is statistically significant. However, when we keep only the expected component of the surprise in the regression, the $R^{2}$ becomes trivial. This finding suggests that most of the information influencing price movement during the pre-announcement window is unrelated to anchoring bias in consensus forecasts. This inference is consistent with the conclusion of Hess and Orbe (2013) that the significant relation between announcement surprises and past announcements is a statistical artifact rather than result of a cognitive bias of analysts. Therefore, the anchoring bias predictor does not contain tradable information.

[Insert Table 8 here]

To further alleviate possible concerns that our predictor based on the "informed" consensus and the anchoring bias predictor have similar information content, we use the two predictors simultaneously to forecast the pre-announcement returns and inventory surprises based on the Bloomberg consensus. The results are reported in Table 9. The predictive power of the anchoring 
bias predictor is dominated by that of our predictor. The estimated coefficient of the anchoring bias predictor is insignificant, while our predictor remains significantly related to the preannouncement returns and inventory surprises. These results show that, although sophisticated traders can use anchoring bias in consensus forecasts to predict storage surprises, this cannot explain the pre-announcement price drift. In addition, we show that the forecasting power of our predictor based on the ranked analyst forecasts is not explained by anchoring bias.

[Insert Table 9 here]

\subsection{Robustness and Economic Significance}

\subsubsection{In-sample Robustness Checks}

In the previous sub-sections, we use economist ranks from Bloomberg to construct a predictor of inventory surprises. Bloomberg normally ranks top three analysts and uses a 24-month evaluation

period. To test the robustness of our empirical results to the changes in the group of the ranked analysts, we replicate Bloomberg's methodology for computing economist ranks. It allows us to test whether our results are robust to changes in the length of evaluation period and the number of forecasts used to compute the "informed" consensus.

To evaluate an economist's forecasting performance for a given period, Bloomberg standardizes each individual forecast error as follows:

$$
Z_{i, t}=\frac{F_{i, t}-A_{t}}{\sigma_{t}}
$$

where $F_{i, t}$ is the forecast of economist $i$ on announcement day $t, A_{t}$ is the announced number, and $\sigma_{t}$ is the standard deviation of all economist forecasts. The distribution of standardized forecast errors is assumed to be normal with a mean of $Z_{A, t}$ and standard deviation of one.

$$
Z_{A, t}=\frac{\mu_{F, t}-A_{t}}{\sigma_{t}}
$$


where $\mu_{F, t}$ is the mean of all economist forecasts for the given period.

The score of a given economist for announcement day $t$ is computed as the probability that the absolute value of a randomly drawn number from the assumed distribution is greater than or equal to the given economist's absolute forecast error $\left|Z_{i, t}\right|$ :

$$
\mathrm{P}\left(\left|\operatorname{Normal}\left(Z_{A, t}, 1\right)\right|>\left|Z_{i, t}\right|\right)=1-\Phi\left(-Z_{A, t}+\left|Z_{i, t}\right|\right)+\Phi\left(-Z_{A, t}-\left|Z_{i, t}\right|\right),
$$

where $\Phi(\cdot)$ is the cumulative standard normal probability function.

Based on this methodology, if an individual forecast error $\left(F_{i, t}-A_{t}\right)$ is zero, the corresponding score is $100 \%$. Conversely, if the forecast error is very high, the score will be low. Bloomberg ranks economists based on their cumulative scores in the past 24 months.

Table 10 reports the forecasting power of the predictor for inventory surprises and preannouncement returns based on shorter evaluation periods $(6,12$ and 18 months, rather than 24 months used by Bloomberg) to rank the top three economists. ${ }^{22}$ The empirical results are similar to those based on the ranks provided by Bloomberg.

\section{[Insert Table 10 here]}

We then compute the predictor based on forecasts of the top five and top 10 economists. The regression results based on this modified predictor are shown in Table 11. Consistent with the results in Tables 5 and 6 , the modified predictor has significant predictive power for inventory surprises and pre-announcement returns.

\section{[Insert Table 11 here]}

In additional robustness checks, we examine whether the predictor of inventory surprises performs differently in injection and withdrawal seasons to address the concern about the impact

\footnotetext{
${ }^{22}$ As before, to avoid forward-looking bias, we use the economist ranks from the previous week. For economists who did not provide a forecast in the previous week, we use the most recent ranks before the previous week.
} 
of the seasonality of consumption of natural gas. We also use the weighted least squares method of Yohai (1987) to estimate our regressions. This so-called MM estimator is robust in the presence of outliers. To alleviate the potential concerns about small-sample issues, we use a simple bootstrap exercise following Lucca and Moench (2015). The results of these robustness checks, available upon request, are similar to the reported results.

\subsubsection{Out-of-sample Tests}

Welch and Goyal (2008) find that return predictive regressions with good in-sample performance tend to provide little forecasting power out-of-sample. Specifically, popular equity premium predictors cannot beat an unconditional historical average equity premium. We perform an out-ofsample test to examine whether our superior forecast predictor provides incremental predictive power for the pre-announcement returns and storage surprises relative to the prevailing mean benchmarks.

Following Rapach, Strauss and Zhou (2010), we use an expanding estimation window to calculate out-of-sample forecasts of the inventory surprise and of the pre-announcement return:

$$
\widehat{Y}_{m+1}=\hat{a}_{0, m}+\hat{a}_{1, m} P_{m+1},
$$

where $m$ is the number of observations in the estimation window, $\hat{a}_{0, m}$ and $\hat{a}_{1, m}$ are the coefficient estimates generated by regressing $\left\{Y_{t}\right\}_{t=1}^{m}$ on a constant and $\left\{P_{t}\right\}_{t=1}^{m} . Y_{t}$ is either the natural gas inventory surprise or the pre-announcement return. To make sure that the results are robust to the choice of the estimation window, we alternatively pick 2010, 2012, and 2014 as the starting point of the out-of-sample period.

We then compute the out-of-sample $R^{2}$ statistic, $R_{O S}^{2}$, as the proportional reduction in the mean square forecast error (MSFE) for the predictive regression based on our predictor vis-á-vis the mean benchmark forecast: 


$$
R_{O S}^{2}=1-\frac{\sum_{k=q_{0}+1}^{q}\left(Y_{m+k}-\hat{Y}_{m+k}\right)^{2}}{\sum_{k=q_{0}+1}^{q}\left(Y_{m+k}-\bar{Y}_{m+k}\right)^{2}},
$$

where $\bar{Y}_{m+k}$ is the historical average of the pre-announcement return or of the inventory surprise before period $m+k \cdot q_{0}$ and $q$ are the endpoints of the in-sample period and the full sample period, respectively. A positive $R_{O S}^{2}$ indicates that our predictor outperforms the prevailing mean.

We use the Clark and West (2007) out-of-sample MSPE-adjusted statistic to test the null hypothesis that $R_{O S}^{2} \leq 0$ against the alternative hypothesis that $R_{O S}^{2}>0$. Panel A of Table 12 shows the results. The positive and significant $R_{O S}^{2}$ statistics suggest that our predictor outperforms the prevailing mean benchmarks for both the inventory surprise and the pre-announcement return.

We further analyze out-of-sample predictability of inventory surprises and preannouncement returns using a variety of autoregressive models as baseline forecasting models. For consistency, we use the same number of lags as in section 1.4.1. For each AR model, the competing forecasting model includes our predictor as an additional regressor. Panel B of Table 12 shows that models with the predictor consistently outperform baseline models out-of-sample. Therefore, our predictor has significant predictive power both in- and out-of-sample.

[Insert Table 12 here]

\subsubsection{Economic Significance}

In section 1.4.1, we show that the price drift before the announcement is related to the predicted value of the inventory surprise. Therefore, it may be worthwhile to use this predictor as a trading indicator during the pre-announcement period. Among the 334 announcements in the sample, there are 63 events with a zero predictor. Therefore, we have 271 announcements with tradable values of the predictor. Panel A of Table 13 shows that a simple trading strategy that consists of buying (selling) a futures contract 90 minutes before the release time if the predictor is negative (positive), 
and closing the position 5 minutes ahead of the announcement would have earned an annualized Sharpe ratio of $0.84 .{ }^{23}$ Investors are primarily concerned about downside risk. Therefore, we also compute the Sortino ratio as follows:

$$
\text { Sortino Ratio }=\frac{\bar{R}-T}{\sqrt{\frac{1}{N} \sum_{i=1}^{N}\left(\min \left(0, R_{i}-T\right)\right)^{2}}},
$$

where $\bar{R}$ is the average per-event return, $T$ is the target rate of return that we assume to be equal to zero, $R_{i}$ is the return for event $i$, and $N$ is the total number of events in the sample. Our trading strategy would have yielded an annualized Sortino ratio of $1.40 .^{24}$

[Insert Table 13 here]

Small values of the predictor may not provide informed traders with profitable trading opportunities. Using the sample of announcements with non-zero values of the predictor, we classify values of the predictor in the first and fourth quartiles as large and the remaining values as small. Panel B in Table 13 reports that the simple trading strategy discussed above would have yielded an annualized Sharpe ratio of 1.26 and an annualized Sortino ratio of 2.12 in the large predictor subsample. Figure 6 depicts the 24-month moving average of the pre-announcement trading returns. This moving average is positive for the entire sample period, suggesting that the positive average returns are persistent.

\section{[Insert Figure 6 here]}

\subsection{Conclusion}

This paper documents informed trading in the natural gas futures market before the Weekly Natural Gas Storage Report announcements. We find significant price changes and order imbalances in

\footnotetext{
${ }^{23}$ We compute the annualized Sharpe ratio as the per-event Sharpe ratio multiplied by the square root of the average number of announcements per year.

${ }^{24}$ The Sortino ratio is annualized the same way as the Sharpe ratio.
} 
the "right" direction relative to the subsequent inventory news. The results show that the preannouncement informed trading can be explained, at least in part, by processing of easily available information. We construct a predictor of the inventory surprise by using the difference between the median forecast of ranked analysts and the overall consensus of analysts in the Bloomberg survey. We propose a simple trading strategy conditioned on this predictor. The strategy involves buying (selling) futures contracts 90 minutes ahead of the announcement when the predictor is negative (positive), and closing the position right before the announcement. This strategy would have yielded a large Sharpe ratio. Traders may use public information from a variety of sources and employ sophisticated forecasting models or forecast combinations. Such market participants may be able to predict announcement surprises more accurately, which should translate into even better trading performance.

Our results have two important implications. First, our predictor is based on information that is common knowledge before the announcement, suggesting that careful analysis of public information can lead to informational advantage. This finding may alleviate concerns of traders and regulators that pre-announcement informed trading is necessarily driven by information leakage. Second, we relate the pre-announcement returns to superior forecasting, suggesting that trading based on such superior forecasts facilitates price discovery in financial markets and improves market efficiency. Although we look only at the natural gas futures market around the weekly releases of the Natural Gas Storage Report, our findings should be of interest to academics interested in the sources of informed trading in general. 
Table 1 Analyst Firms Providing Natural Gas Storage Forecasts

\begin{tabular}{|c|c|c|c|c|c|}
\hline \multirow[b]{2}{*}{ Analyst Firm } & \multicolumn{2}{|c|}{ Time Period } & \multicolumn{2}{|c|}{ Obs. } & \multirow{2}{*}{$\begin{array}{c}\text { Mean Standardized } \\
\text { Absolute Forecast } \\
\text { Error }\end{array}$} \\
\hline & From & To & $\begin{array}{l}\text { Total } \\
\text { Obs. }\end{array}$ & $\begin{array}{c}\text { Ranked } \\
\text { Obs. }\end{array}$ & \\
\hline Societe Generale & $01 / 08 / 09$ & $10 / 10 / 13$ & 205 & 13 & 0.94 \\
\hline Strategic Energy \& Economic Research & $08 / 12 / 10$ & $01 / 04 / 13$ & 92 & 12 & 0.94 \\
\hline JP Morgan Chase Bank & $07 / 03 / 08$ & $01 / 14 / 16$ & 333 & 323 & 0.94 \\
\hline Macquarie Energy & $02 / 17 / 11$ & $01 / 14 / 16$ & 216 & 78 & 0.96 \\
\hline SunTrust Robinson Humphrey & $07 / 17 / 08$ & $09 / 02 / 10$ & 95 & 23 & 0.96 \\
\hline Noble Americas & $03 / 31 / 11$ & $08 / 08 / 13$ & 94 & 39 & 0.98 \\
\hline IAF Advisors & 07/03/08 & $01 / 14 / 16$ & 299 & 119 & 0.99 \\
\hline Louis Capital Markets & $02 / 05 / 09$ & $01 / 06 / 11$ & 77 & 0 & 1.01 \\
\hline Conoco Phillips & 07/03/08 & $01 / 14 / 16$ & 310 & 157 & 1.03 \\
\hline Macquarie Bank & 04/09/09 & $02 / 10 / 11$ & 82 & 0 & 1.03 \\
\hline RBC Capital Markets & 07/03/08 & $03 / 25 / 10$ & 63 & 8 & 1.04 \\
\hline Citigroup Global Markets & $02 / 16 / 12$ & $01 / 14 / 16$ & 155 & 49 & 1.05 \\
\hline DTE Energy Trading Inc & $09 / 13 / 12$ & $10 / 08 / 15$ & 129 & 7 & 1.10 \\
\hline ICAP Energy & $07 / 10 / 08$ & $12 / 31 / 15$ & 282 & 5 & 1.12 \\
\hline SG Americas Securities & $05 / 22 / 14$ & $01 / 07 / 16$ & 61 & 0 & 1.13 \\
\hline Wells Fargo Securities & 07/03/08 & $01 / 07 / 16$ & 304 & 76 & 1.14 \\
\hline Credit Suisse & $02 / 17 / 11$ & $03 / 20 / 14$ & 126 & 0 & 1.15 \\
\hline Energy Aspects Ltd & $09 / 11 / 14$ & $01 / 14 / 16$ & 53 & 0 & 1.16 \\
\hline Mitsui \& Co Commodity Risk & $06 / 06 / 13$ & $09 / 03 / 15$ & 92 & 0 & 1.17 \\
\hline Raymond James \& Associates & $07 / 03 / 08$ & $08 / 11 / 11$ & 115 & 3 & 1.18 \\
\hline Tradition Financial & $03 / 24 / 11$ & $04 / 24 / 14$ & 57 & 0 & 1.20 \\
\hline Cormark Securities & 09/17/09 & $01 / 14 / 16$ & 255 & 0 & 1.22 \\
\hline Johnson Rice \& Co & $01 / 10 / 13$ & $01 / 14 / 16$ & 127 & 0 & 1.22 \\
\hline Morgan Keegan \& Co. Inc. & 07/03/08 & $05 / 05 / 11$ & 110 & 0 & 1.25 \\
\hline Asset Risk Management & $05 / 02 / 13$ & $01 / 14 / 16$ & 120 & 0 & 1.29 \\
\hline Ritterbusch \& Assoc. & $07 / 03 / 08$ & $03 / 26 / 15$ & 279 & 0 & 1.31 \\
\hline UBS & 07/03/08 & $06 / 04 / 15$ & 280 & 10 & 1.32 \\
\hline FirstEnergy Capital & 07/03/08 & $01 / 14 / 16$ & 309 & 0 & 1.33 \\
\hline Hencorp & 07/03/08 & $04 / 09 / 15$ & 269 & 0 & 1.37 \\
\hline Fellon-McCord & $09 / 23 / 10$ & $04 / 02 / 15$ & 127 & 0 & 1.39 \\
\hline Summit Energy & $07 / 03 / 08$ & $05 / 09 / 13$ & 198 & 0 & 1.44 \\
\hline Prestige Economics & 09/03/09 & $12 / 19 / 13$ & 184 & 0 & 1.44 \\
\hline MF Global & 07/03/08 & $03 / 15 / 12$ & 98 & 0 & 1.47 \\
\hline Ecova Inc & $07 / 06 / 12$ & $01 / 14 / 16$ & 134 & 0 & 1.50 \\
\hline Tuohy Brothers & $02 / 04 / 10$ & $01 / 14 / 16$ & 236 & 0 & 1.56 \\
\hline Gelber \& Associates & 07/0308 & $11 / 13 / 15$ & 212 & 0 & 1.56 \\
\hline Energy Overview & $01 / 27 / 11$ & $04 / 30 / 15$ & 148 & 0 & 1.66 \\
\hline Citi Futures Perspective & 07/03/08 & $01 / 14 / 16$ & 313 & 0 & 1.74 \\
\hline Wavelength CTA & $07 / 24 / 08$ & $03 / 01 / 12$ & 71 & 0 & 1.76 \\
\hline C.H. Guernsey & $07 / 03 / 08$ & $12 / 31 / 15$ & 321 & 0 & 1.91 \\
\hline
\end{tabular}

The table lists all analyst firms that provided storage forecasts to Bloomberg more than 50 times during the period from July 2008 through January 2016. The firms are sorted by their mean standardized absolute forecast error. Ranked analysts are those ranked by Bloomberg among the top three based on their forecasting accuracy. 
Table 2 Summary Statistics for Inventory Surprises

\begin{tabular}{cccccc}
\hline \hline & Mean & Median & $1^{\text {st }}$ Quartile & $3^{\text {rd }}$ Quartile & St. deviation \\
\hline$S_{t}^{C}$ & 0.42 & 0.00 & -5.00 & 5.00 & 7.38 \\
$S_{t}^{I}$ & 0.65 & 1.00 & -4.00 & 5.00 & 6.51 \\
$\left|S_{t}^{C}\right|$ & 5.78 & 5.00 & 3.00 & 7.00 & 4.59 \\
$\left|S_{t}^{I}\right|$ & 5.20 & 4.50 & 2.00 & 7.00 & 3.96 \\
$\left|S_{t}^{I}\right|-\left|S_{t}^{C}\right|$ & $-0.58^{* * *}$ & & & & \\
\hline \hline
\end{tabular}

This table presents summary statistics for inventory surprises based on the Bloomberg consensus forecast $\left(S_{t}^{C}\right)$ and on the "informed" consensus $\left(S_{t}^{I}\right)$. The "informed" consensus is the median value of ranked analyst forecasts. The sample period is from July 2008 to January 2016 and contains 334 observations. *, $* *, * * *$ indicate statistical significance at $10 \%, 5 \%$, and $1 \%$ levels, respectively. 
Table 3 Regression Results for Returns after Inventory Announcements

\begin{tabular}{lcc}
\hline \hline & Bloomberg Consensus & "Informed" Consensus \\
\hline Panel A: Full Sample & & \\
Intercept $\left(a_{0}\right)$ & $-0.42(0.11)^{* * *}$ & $-0.34(0.10)^{* * *}$ \\
Slope $\left(a_{1}\right)$ & $-0.17(0.02)^{* * *}$ & $-0.22(0.02)^{* * *}$ \\
$R^{2}$ & 0.32 & 0.44 \\
\hline \hline
\end{tabular}

The table reports estimates for the following model: $R_{t}=a_{0}+a_{1} S_{t}+e_{t}$, where $R_{t}$ is the continuously compounded futures return (expressed in percent) in the event window from 5 minutes before to 30 minutes after the announcement and $S_{t}$ is the natural gas inventory surprise for day. The inventory surprises are computed using either the Bloomberg consensus or the "informed" consensus. The "informed" consensus is the median value of ranked analyst forecasts. The sample period is from July 2008 to January 2016 and contains 334 observations. The regressions are estimated using OLS with the White (1980) heteroskedasticity consistent covariance matrix. Standard errors are shown in parentheses. $*, * *, * * *$ indicate statistical significance at $10 \%, 5 \%$, and $1 \%$ levels, respectively. 
Table 4 Regression Results for Returns and Order Imbalances before Inventory Announcements

Return in [-90min, $-5 \mathrm{~min}]$ window

Order Imbalance in [-90min, $-5 \mathrm{~min}]$ window

\begin{tabular}{lcc}
\hline Intercept $\left(a_{0}\right)$ & $-0.17(0.05)^{* * *}$ & $-137.73(57.78)^{* * *}$ \\
Slope $\left(a_{1}\right)$ & $-0.04(0.01)^{* * *}$ & $-27.24(7.46)^{* * *}$ \\
$R^{2}$ & 0.09 & 0.04 \\
\hline \hline
\end{tabular}

The table reports estimates for the following model: $Y_{t}=a_{0}+a_{1} S_{t}+e_{t}$, where $Y_{t}$ is the continuously compounded futures return (expressed in percent) or the order imbalance in the window from 90 minutes before to 5 minutes before the announcement and $S_{t}$ is the natural gas inventory surprise for day $t$. The inventory surprises are computed using the Bloomberg consensus forecast. The sample period is from July 2008 to January 2016 and contains 334 observations. The regressions are estimated using OLS with the White (1980) heteroskedasticity consistent covariance matrix. Standard errors are shown in parentheses. $*, * *, * * *$ indicate statistical significance at $10 \%, 5 \%$, and $1 \%$ levels, respectively. 
Table 5 Predicting the Inventory Surprise

\begin{tabular}{cccc}
\hline \hline & No lags of surprise & $\mathrm{L}=1$ & $\mathrm{~L}=2$ \\
\hline Intercept $\left(a_{0}\right)$ & $0.64(0.36)^{*}$ & $0.65(0.36)^{*}$ & $0.65(0.32)^{* *}$ \\
$P_{t}\left(a_{1}\right)$ & $0.95(0.12)^{* * *}$ & $0.96(0.12)^{* * *}$ & $0.94(0.10)^{* * *}$ \\
adj $R^{2}$ & 0.22 & 0.22 & 0.22 \\
\hline \hline
\end{tabular}

The table reports estimates for the following regression model: $S_{t}=a_{0}+a_{1} P_{t}+\sum_{n=1}^{L} b_{n} S_{t-n}+e_{t}$. $S_{t}$ is the natural gas inventory surprise for day $t$. The predictor, $P_{t}$, is the difference between the "informed" and the Bloomberg consensus forecasts. The "informed" consensus is the median value of ranked analyst forecasts. The sample period is from July 2008 to January 2016 and contains 334 observations. The regression is estimated using OLS with the White (1980) heteroskedasticity consistent covariance matrix. Standard errors are shown in parentheses. *,**,*** indicate statistical significance at $10 \%, 5 \%$, and $1 \%$ levels, respectively. 
Table 6 Relation between Predictor of the Inventory Surprise and Returns and Order Imbalances

\begin{tabular}{|c|c|c|}
\hline & [-90min, $-5 \mathrm{~min}]$ window & [-5min, 30min] window \\
\hline \multicolumn{3}{|c|}{ Panel A. Return in [-90min, $-5 \mathrm{~min}]$ window } \\
\hline Intercept $\left(a_{0}\right)$ & $-0.20(0.05)^{* * *}$ & $-0.31(0.12)^{* *}$ \\
\hline$P_{t}\left(a_{1}\right)$ & $-0.06(0.02) * * *$ & $0.02(0.04)$ \\
\hline$R^{2}$ & 0.05 & 0.00 \\
\hline \multicolumn{3}{|c|}{ Panel B. Order Imbalance in [-90min, $-5 \mathrm{~min}]$ window } \\
\hline Intercept $\left(a_{0}\right)$ & $-157.21(57.74)^{* * *}$ & $-322.14(132.3)^{* *}$ \\
\hline$P_{t}\left(a_{1}\right)$ & $-35.47(13.99) * *$ & $30.11(35.00)$ \\
\hline$R^{2}$ & 0.02 & 0.00 \\
\hline
\end{tabular}

Panel A reports estimates for the following model: $R_{t}=a_{0}+a_{1} P_{t}+e_{t}$, where $R_{t}$ is the continuously compounded futures return (expressed in percent) in a given event window and $P_{t}$ is the difference between the "informed" consensus and the Bloomberg consensus. The "informed" consensus is the median value of ranked analyst forecasts. Panel B reports estimates of the same regression with the order imbalance used as the dependent variable. The sample period is from July 2008 to January 2016 and contains 334 observations. The regressions are estimated using OLS with the White (1980) heteroskedasticity consistent covariance matrix. Standard errors are shown in parentheses. *, **, *** indicate statistical significance at $10 \%, 5 \%$, and $1 \%$ levels, respectively. 
Table 7 Anchoring Bias in Inventory Forecasts

$$
h=1 \quad h=3
$$

Panel A: Surprise based on the consensus forecast

$$
\begin{array}{ccc}
\gamma & 0.048(0.014)^{* * *} & 0.004(0.002)^{*} \\
R^{2} & 0.066 & 0.006
\end{array}
$$

Panel B: Surprise based on the "informed" consensus forecast

$\begin{array}{ccc}\gamma & 0.014(0.013) & 0.001(0.002) \\ R^{2} & -0.002 & -0.008\end{array}$

The table reports estimates for the following model: $S_{t}=\gamma\left(F_{t}-\bar{A}_{h}\right)+\varepsilon_{t}$, where $S_{t}$ is the inventory surprise, $F_{t}$ is the consensus forecast, and $\bar{A}_{h}$ represents the historical average of the last $h$ realizations of inventory changes. The "informed" consensus is the median value of ranked analyst forecasts. The sample period is from July 2008 to January 2016 and contains 334 observations. The regressions are estimated using OLS with the White (1980) heteroskedasticity consistent covariance matrix. Standard errors are shown in parentheses. *, **, *** indicate statistical significance at $10 \%, 5 \%$, and $1 \%$ levels, respectively. 
Table 8 Regression of Pre-announcement Returns on Expected and Unexpected Components of Inventory Surprises

\begin{tabular}{ccc}
\hline \hline & $(1)$ & $(2)$ \\
\hline$a_{0}$ & $-0.17(0.05)^{* * *}$ & $-0.19(0.05)^{* * *}$ \\
$a_{1}$ & $-0.04(0.02)^{*}$ & $-0.04(0.02)^{*}$ \\
$a_{2}$ & $-0.04(0.01)^{* * *}$ & \\
$R^{2}$ & 0.09 & 0.01 \\
\hline \hline
\end{tabular}

Column (1) reports estimates for the following model: $R_{t}=a_{0}+a_{1} S_{t}^{e}+a_{2} S_{t}^{u}+e_{t}$, where $R_{t}$ is the continuously compounded futures return in the event window from 90 minutes before to 5 minutes before the announcement, and $S_{t}^{e}$ and $S_{t}^{u}$ are the anticipated and unanticipated components of natural gas inventory surprises. $S_{t}^{e} \equiv \gamma\left(F_{t}-\bar{A}_{1}\right)$ and $S_{t}^{u} \equiv S_{t}-\gamma\left(F_{t}-\bar{A}_{1}\right) . S_{t}$ is the inventory surprise, $F_{t}$ is the consensus forecast, and $\bar{A}_{1}$ is the previous realization of inventory change. $\gamma=0.048$, as estimated in Table 7 Column (2) reports results for the regression with $S_{t}^{e}$ only. The sample period is from July 2008 to January 2016 and contains 334 observations. The regressions are estimated using OLS with the White (1980) heteroskedasticity consistent covariance matrix. Standard errors are shown in parentheses. *, **, *** indicate statistical significance at $10 \%, 5 \%$, and $1 \%$ levels, respectively. 
Table 9 Comparison of the Anchoring Bias Predictor and the Predictor Based on Ranked Analyst Forecasts

\begin{tabular}{ccc}
\hline \hline & $\begin{array}{c}\text { Dependent variable: } \\
\text { Return in [-90min, -5min] window }\end{array}$ & $\begin{array}{c}\text { Dependent variable: } \\
\text { Inventory surprise }\end{array}$ \\
\hline$a_{0}$ & $-0.20(0.05)^{* * *}$ & $0.66(0.36)^{*}$ \\
$a_{1}$ & $0.00(0.03)$ & $0.02(0.02)$ \\
$a_{2}$ & $-0.06(0.02)^{* * *}$ & $0.86(0.12)^{* * *}$ \\
$R^{2}$ & 0.05 & 0.22 \\
\hline \hline
\end{tabular}

The table reports estimates for the following model: $Y_{t}=a_{0}+a_{1} S_{t}^{e}+a_{2} P_{t}+e_{t}$, where $Y_{t}$ is the continuously compounded futures return in the window from 90 minutes before to 5 minutes before the announcement or the inventory surprise based on the Bloomberg consensus, $S_{t}^{e}$ is the anchoring bias predictor, and $P_{t}$ is the predictor based on ranked analyst forecasts. $S_{t}^{e} \equiv \gamma\left(F_{t}-\bar{A}_{1}\right)$, where $F_{t}$ is the Bloomberg consensus forecast and $\bar{A}_{1}$ is the previous realization of inventory change. $\gamma=0.048$, as estimated in Table 7. The sample period is from July 2008 to January 2016 and contains 334 observations. The regressions are estimated using OLS with the White (1980) heteroskedasticity consistent covariance matrix. Standard errors are shown in parentheses. *, **, *** indicate statistical significance at $10 \%, 5 \%$, and $1 \%$ levels, respectively. 
Table 10 Forecasting the Inventory Surprise and Pre-announcement Return with Predictor Based on Shorter Evaluation Periods

\begin{tabular}{lccc}
\hline \hline & 6 months & 12 months & 18 months \\
\hline Panel A. Inventory Surprise & & & \\
Intercept $\left(a_{0}\right)$ & $0.38(0.38)$ & $0.47(0.39)$ & $0.42(0.38)$ \\
Slope $\left(a_{1}\right)$ & $1.15(0.24)^{* * *}$ & $1.16(0.28)^{* * *}$ & $1.18(0.25)^{* * *}$ \\
$R^{2}$ & 0.09 & 0.08 & 0.09 \\
\hline Panel B. Return in [-90min, $-5 \mathrm{~min}]$ window & & \\
Intercept $\left(a_{0}\right)$ & $-0.18(0.05)^{* * *}$ & $-0.29(0.05)^{* * *}$ & $-0.19(0.05)^{* * *}$ \\
Slope $\left(a_{1}\right)$ & $-0.07(0.03)^{* *}$ & $-0.06(0.03)^{*}$ & $-0.07(0.03)^{* *}$ \\
$R^{2}$ & 0.02 & 0.01 & 0.02 \\
\hline \hline
\end{tabular}

Panel A reports estimates for the following model: $S_{t}=a_{0}+a_{1} P_{t}^{M}+e_{t}$, where $S_{t}$ is the natural gas inventory surprise based on Bloomberg consensus for day $t . P_{t}^{M}$ is the difference between the median value of the top three economist forecasts and the Bloomberg consensus. Economists are ranked based on forecasting accuracy in the past 6,12 and 18 months, respectively. Panel B reports estimates for the following model: $R_{t}=a_{0}+a_{1} P_{t}^{M}+e_{t}$, where $R_{t}$ is the continuously compounded futures return (expressed in percent) from 90 minutes to 5 minutes before the announcement. The sample period is from July 2008 to January 2016 and contains 334 observations. The regressions are estimated using OLS with the White (1980) heteroskedasticity consistent covariance matrix. Standard errors are shown in parentheses. *,**, *** indicate statistical significance at $10 \%, 5 \%$, and $1 \%$ levels, respectively. 
Table 11 Forecasting the Inventory Surprise and Pre-announcement Return with Modified Predictor

$M=5 \quad M=10$

\begin{tabular}{lcc}
\hline Panel A. Inventory Surprise & & \\
Intercept $\left(a_{0}\right)$ & $0.53(0.36)$ & $0.48(0.37)$ \\
Slope $\left(a_{1}\right)$ & $1.08(0.14)^{* * *}$ & $1.16(0.18)^{* * *}$ \\
$R^{2}$ & 0.20 & 0.15 \\
\hline Panel B. Return in [-90min, -5min] window & \\
Intercept $\left(a_{0}\right)$ & $-0.19(0.05)^{* * *}$ & $-0.19(0.05)^{* * *}$ \\
Slope $\left(a_{1}\right)$ & $-0.07(0.02)^{* * *}$ & $-0.06(0.02)^{* * *}$ \\
$R^{2}$ & 0.05 & 0.03 \\
\hline \hline
\end{tabular}

Panel A reports estimates for the following model: $S_{t}=a_{0}+a_{1} P_{t}^{M}+e_{t}$, where $S_{t}$ is the natural gas inventory surprise based on Bloomberg consensus for day $t . P_{t}^{M}$ is the difference between the median value of the top $M$ economist forecasts and the Bloomberg consensus. Panel B reports estimates for the following model: $R_{t}=a_{0}+a_{1} P_{t}^{M}+e_{t}$, where $R_{t}$ is the continuously compounded futures return (expressed in percent) from 90 minutes to 5 minutes before the announcement. The sample period is from July 2008 to January 2016 and contains 334 observations. The regressions are estimated using OLS with the White (1980) heteroskedasticity consistent covariance matrix. Standard errors are shown in parentheses. *,**, *** indicate statistical significance at $10 \%, 5 \%$, and $1 \%$ levels, respectively. 
Table 12 Out-of-sample $R^{2}$ Statistics

\begin{tabular}{lcc}
\hline \hline & Inventory Surprise & Return in [-90min, -5min] window \\
\hline Panel A. Mean Benchmark & & \\
Out-of-sample period: & & $3.43^{* * *}$ \\
January 2010-January 2016 & $14.42^{* * *}$ & $2.90^{* *}$ \\
January 2012-January 2016 & $13.51^{* * *}$ & $17.68^{* * *}$ \\
January 2014-January 2016 & $21.77^{* * *}$ & \\
Panel B. AR Benchmark & & $6.39^{* * *}$ \\
AR(1) & $15.31^{* * *}$ & $7.69^{* * *}$ \\
AR(2) & $14.56^{* * *}$ & \\
\hline \hline
\end{tabular}

Panel A reports the proportional reduction in mean square forecast error $\left(R_{O S}^{2}\right)$ for predictive regression for the natural gas inventory surprise and the pre-announcement return based on the mean benchmark vis-ávis competing forecast based on the predictor.

Panel B reports the proportional reduction in mean square forecast error $\left(R_{O S}^{2}\right)$ for predictive regression for the natural gas inventory surprise and the pre-announcement return based on an AR model vis-á-vis the competing forecasting model including the predictor as an additional repressor. The out-of-sample period in Panel B is from January 2010 to January 2016.

Statistical significance is based on the Clark and West (2007) statistic for testing the null hypothesis that the MSFE of the baseline model is less than or equal to the competing model MSFE against the alternative hypothesis that the MSFE of the baseline model is greater than the competing model MSFE. The full sample period is from July 2008 to January 2016. *, **, *** indicate statistical significance at 10\%, 5\%, and $1 \%$ levels, respectively. 
Table 13 Performance of Trading Strategy Based on Predictor of the Inventory Surprise

\begin{tabular}{lcc}
\hline \hline & Full Sample $(\mathrm{N}=271)$ & Large Values of Predictor $(\mathrm{N}=153)$ \\
\hline Sharpe Ratio & 0.84 & 1.26 \\
Sortino Ratio & 1.40 & 2.12 \\
\hline \hline
\end{tabular}

The table reports performance of the trading strategy that consists of buying (selling) a futures contract 90 minutes before the announcement if the predictor is negative (positive), and closing the position 5 minutes before the announcement. The predictor is defined as the difference between the "informed" consensus and the Bloomberg consensus forecast. The "informed" consensus is the median value of ranked analyst forecasts. The sample period is from July 2008 to January 2016 and contains 334 observations, including 271 announcements with non-zero values of the predictor. We classify non-zero values of the predictor in the $1^{\text {st }}$ and $4^{\text {th }}$ quartiles as large and the remaining values as small. We compute the annualized Sharpe ratio and Sortino ratio as the per-event ratio times the square root of the average number of events per year. 
Figure 1 Natural Gas Inventory Changes

Panel A: Natural Gas Inventory

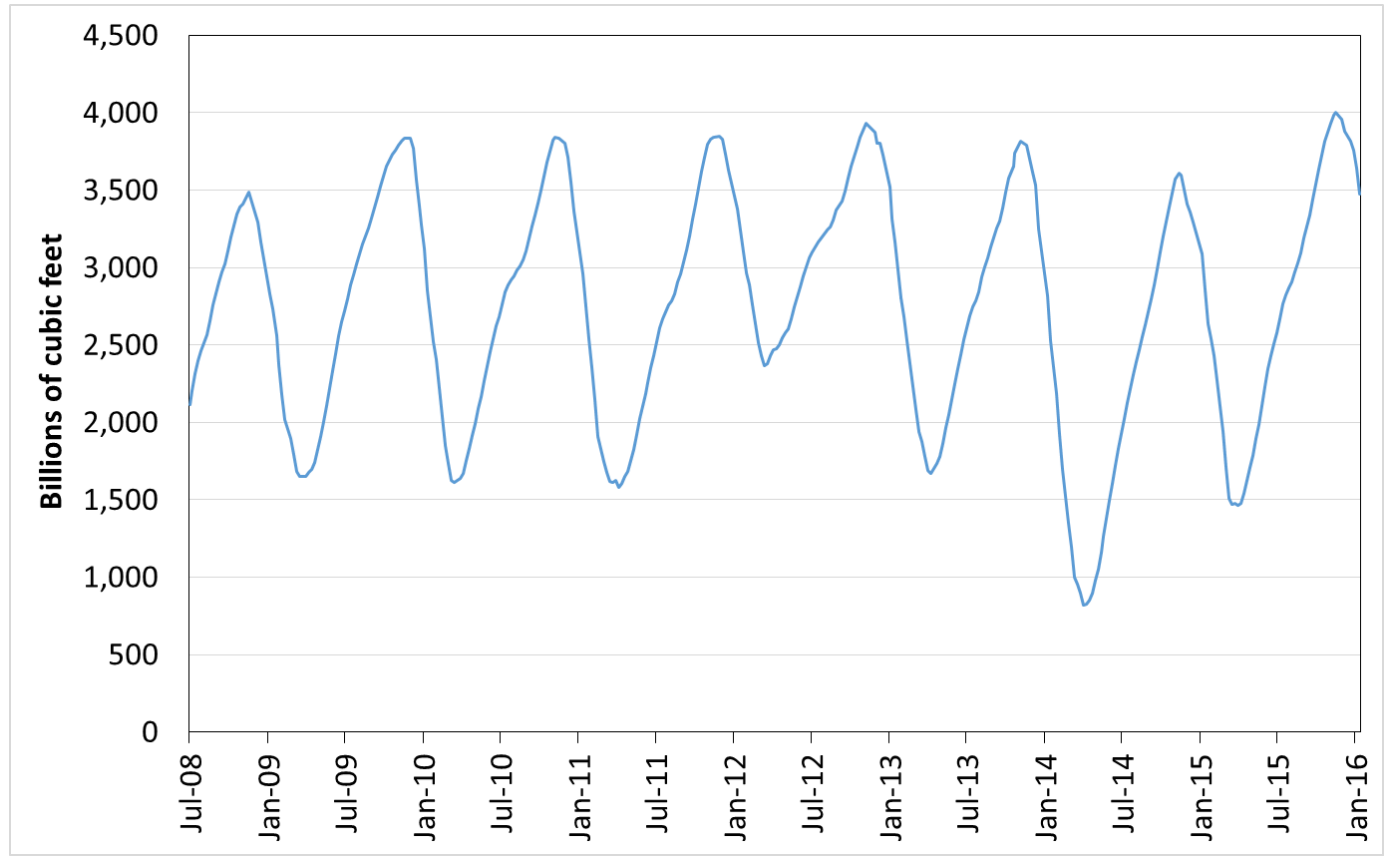

Panel B: Natural Gas Inventory Surprises

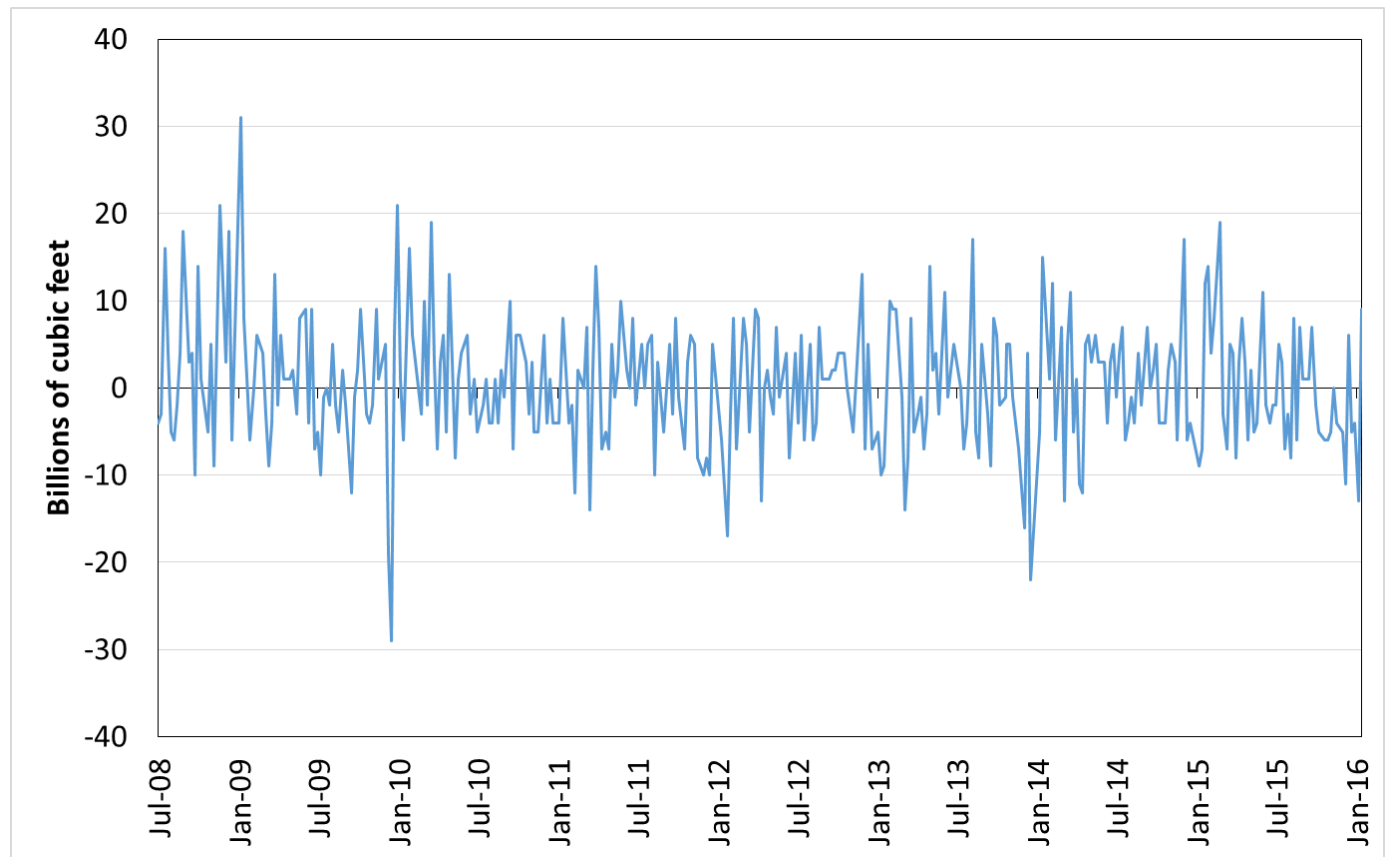

Panel A depicts the natural gas inventory level. Panel B shows the weekly natural gas storage surprises. The surprise is the difference between the announced change in inventory and the Bloomberg consensus. The sample period is from July 2008 to January 2016 and contains 334 announcements. 
Figure 2 Evidence of Pre-announcement Effect

Panel A. Cumulative Average Returns

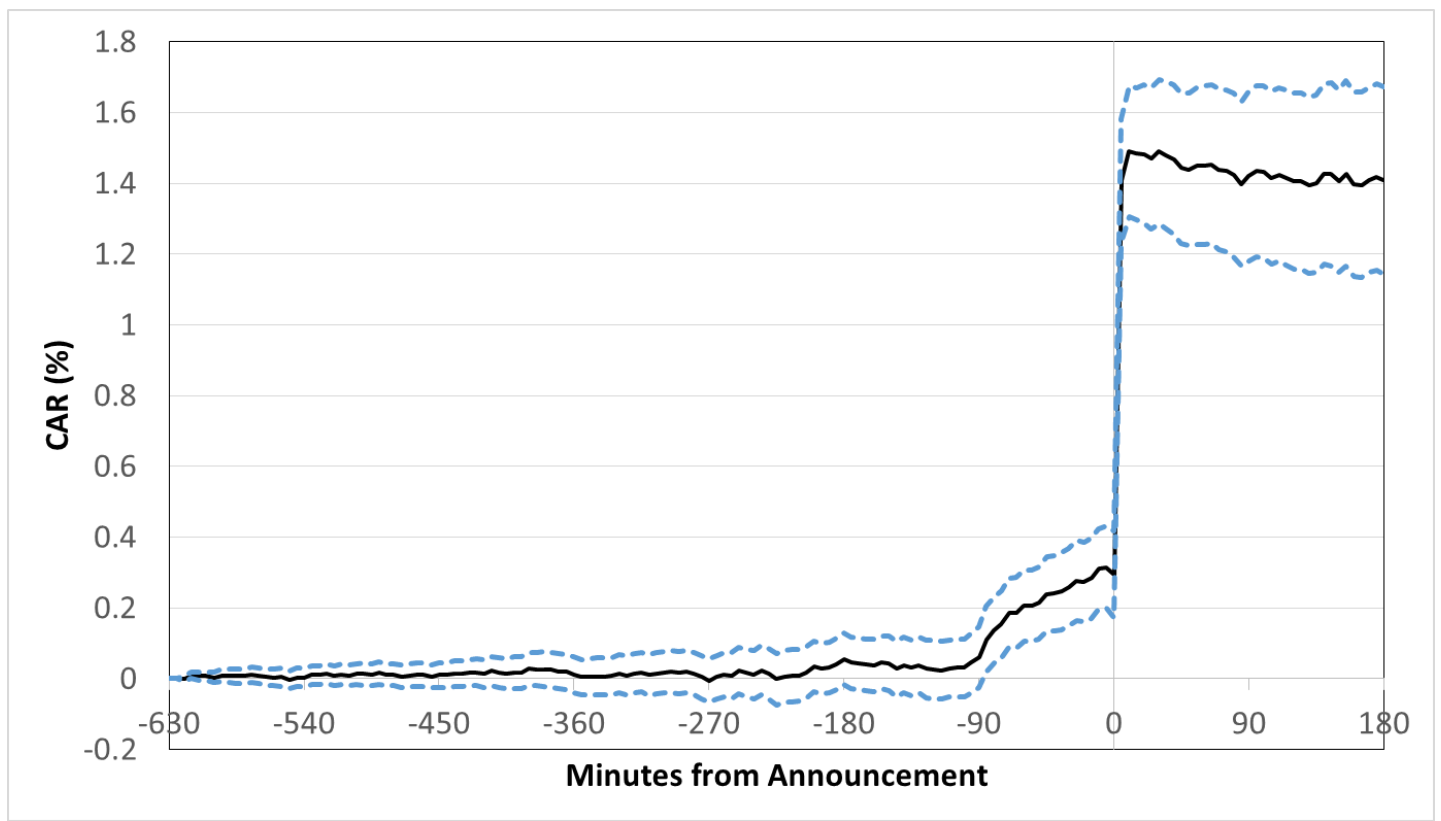

Panel B. Cumulative Order Imbalances

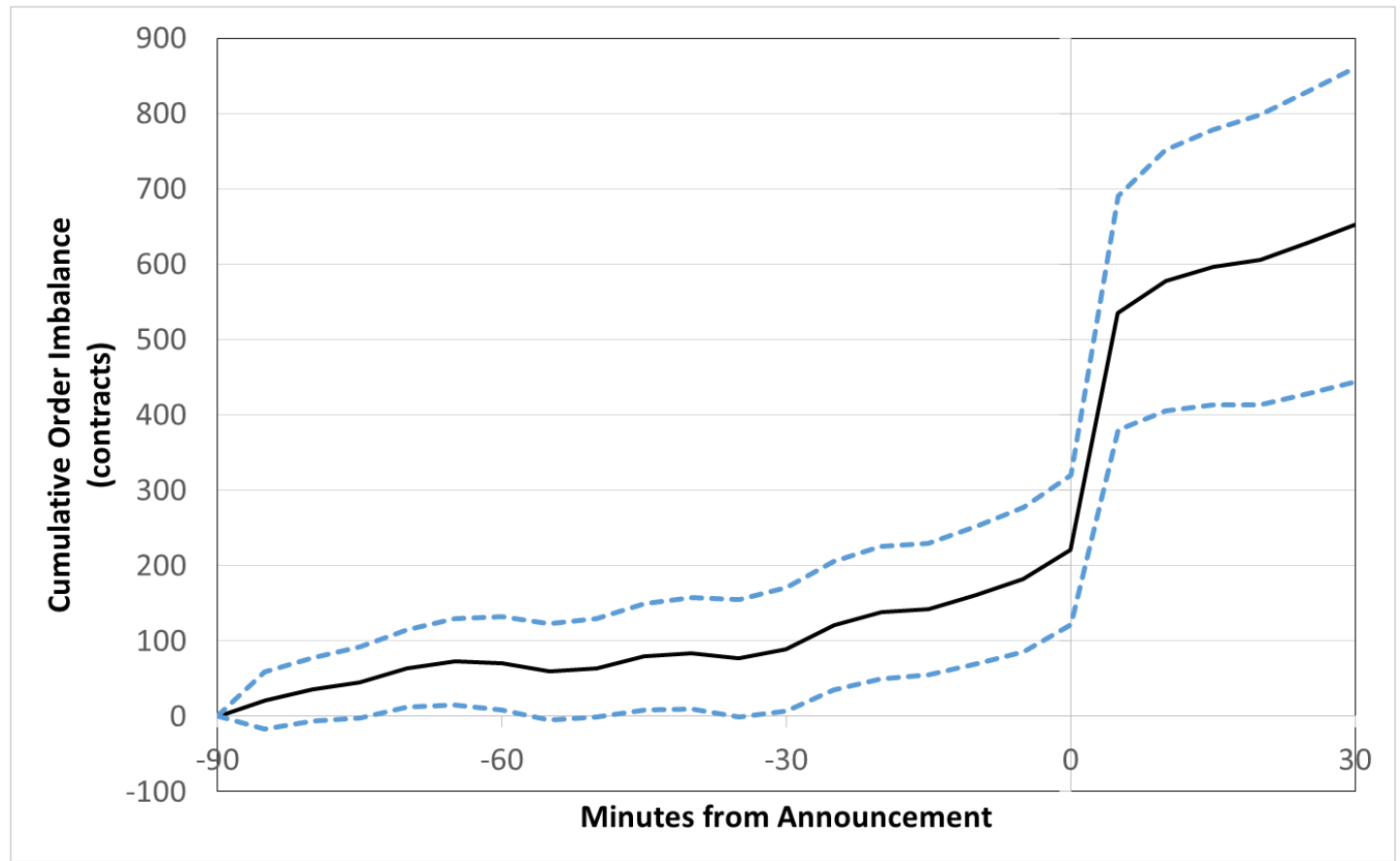

Panel A shows the average cumulative returns of the nearby natural gas futures contract around the release of the Weekly Natural Gas Storage Report. Panel B shows the average cumulative order imbalances in the same futures contract. The dashed lines represent $90 \%$ confidence interval. The sample period is from July 2008 through January 2016 and contains 334 announcements. 
Figure 3 Daily Cumulative Average Returns

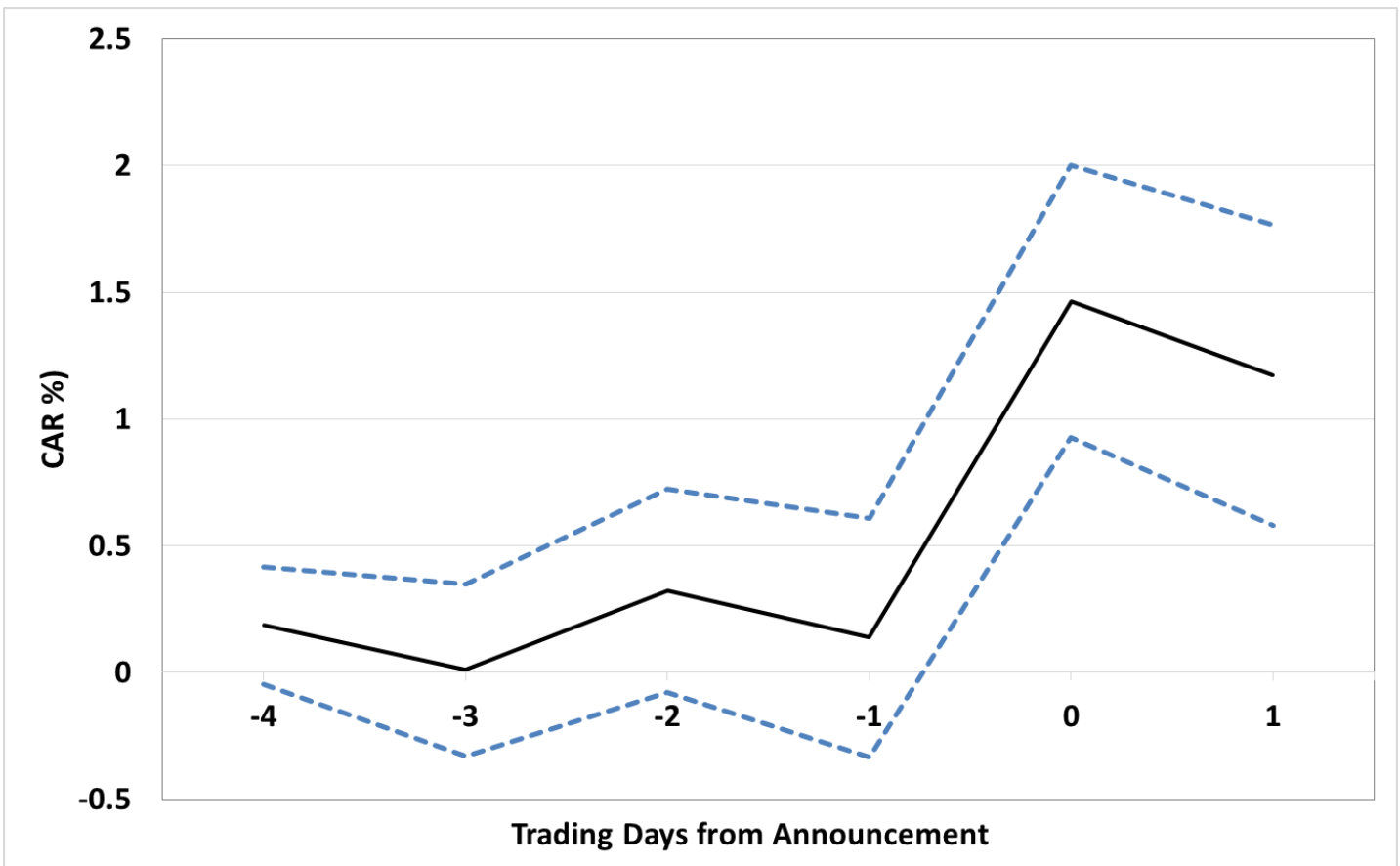

The Figure shows the daily cumulative average returns of the nearby natural gas futures contract around releases of the Weekly Natural Gas Storage Report. Day 0 on the horizontal axis is the day of the announcement. The dashed lines represent $95 \%$ confidence interval. The sample period is from July 2008 through January 2016 and contains 334 announcements. 
Figure 4 Average Trading Volume

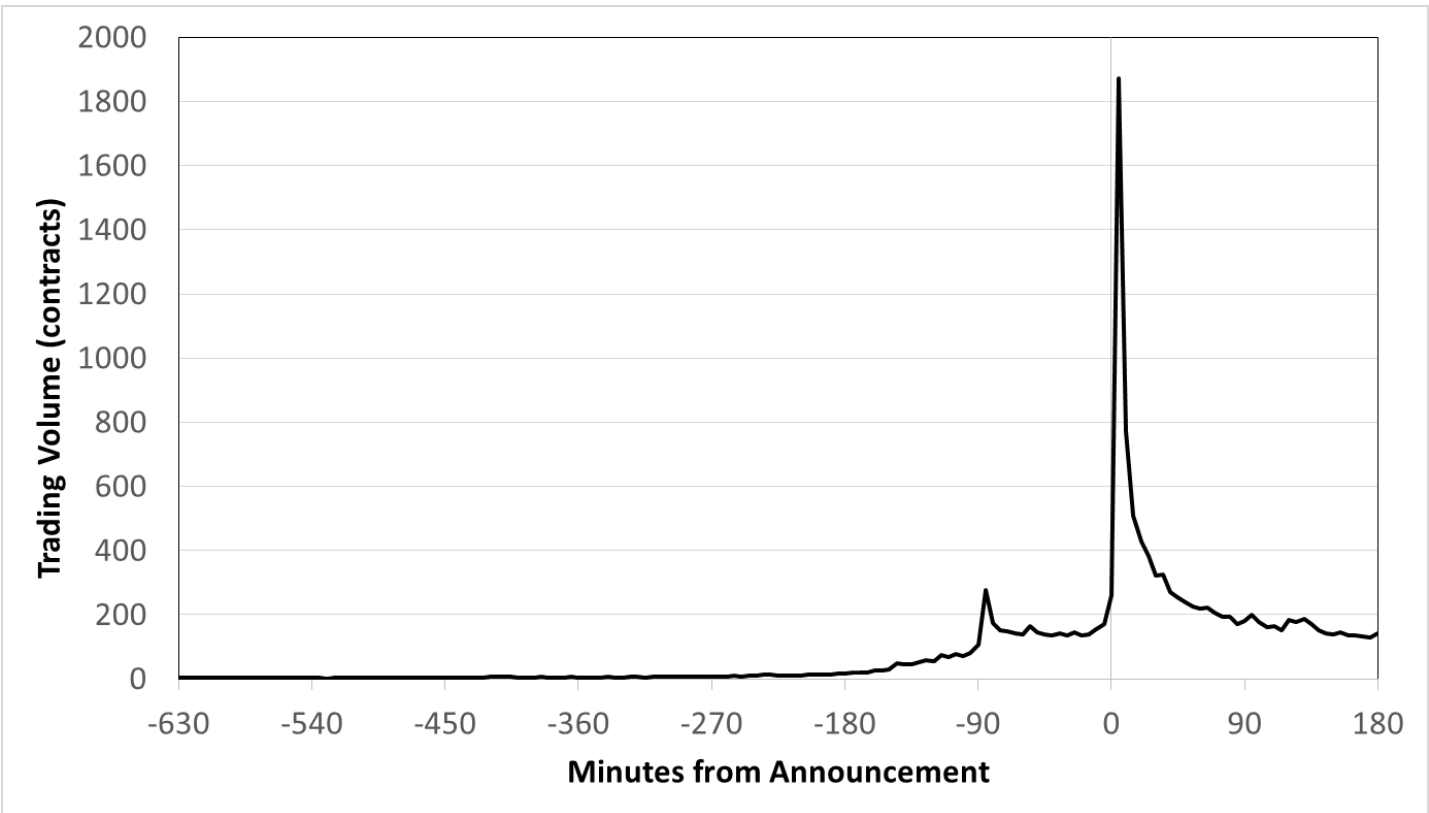

The figure plots the average trading volume per minute in the nearby natural gas futures contract around the release of the Weekly Natural Gas Storage Report. The sample period is from July 2008 through January 2016 and contains 334 announcements. 
Figure 5 Sensitivity to Event Window Length

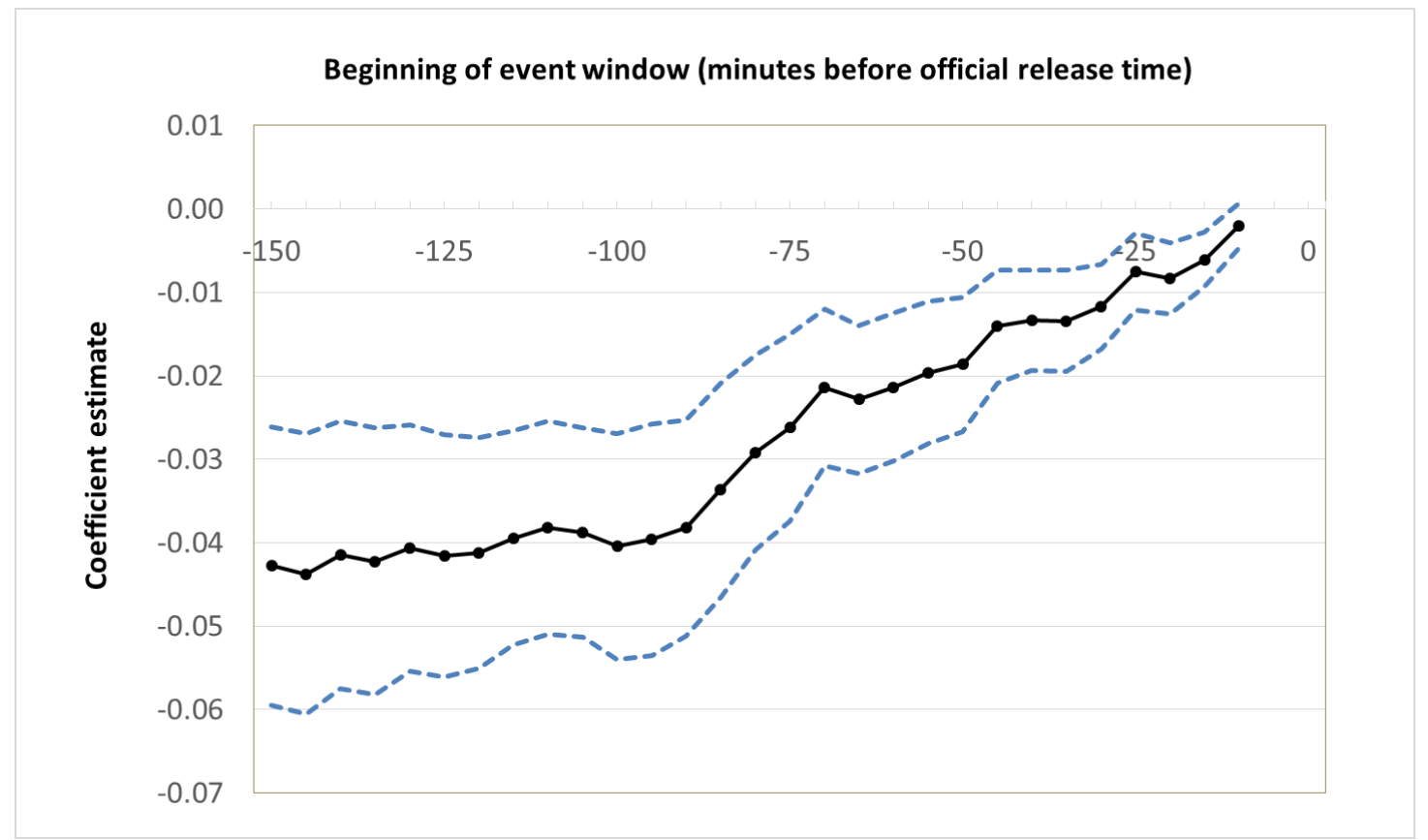

The figure plots the slope coefficient estimates from the event study OLS regression of natural gas futures returns on inventory surprises. The inventory surprise is computed using the Bloomberg consensus forecasts. The natural gas futures return is computed in the event window from the time shown on the horizontal axis to five minutes before the announcement. The dashed lines represent $95 \%$ confidence interval. The sample period is from July 2008 through January 2016 and contains 334 announcements. 
Figure 6 Moving Average of Pre-announcement Trading Returns

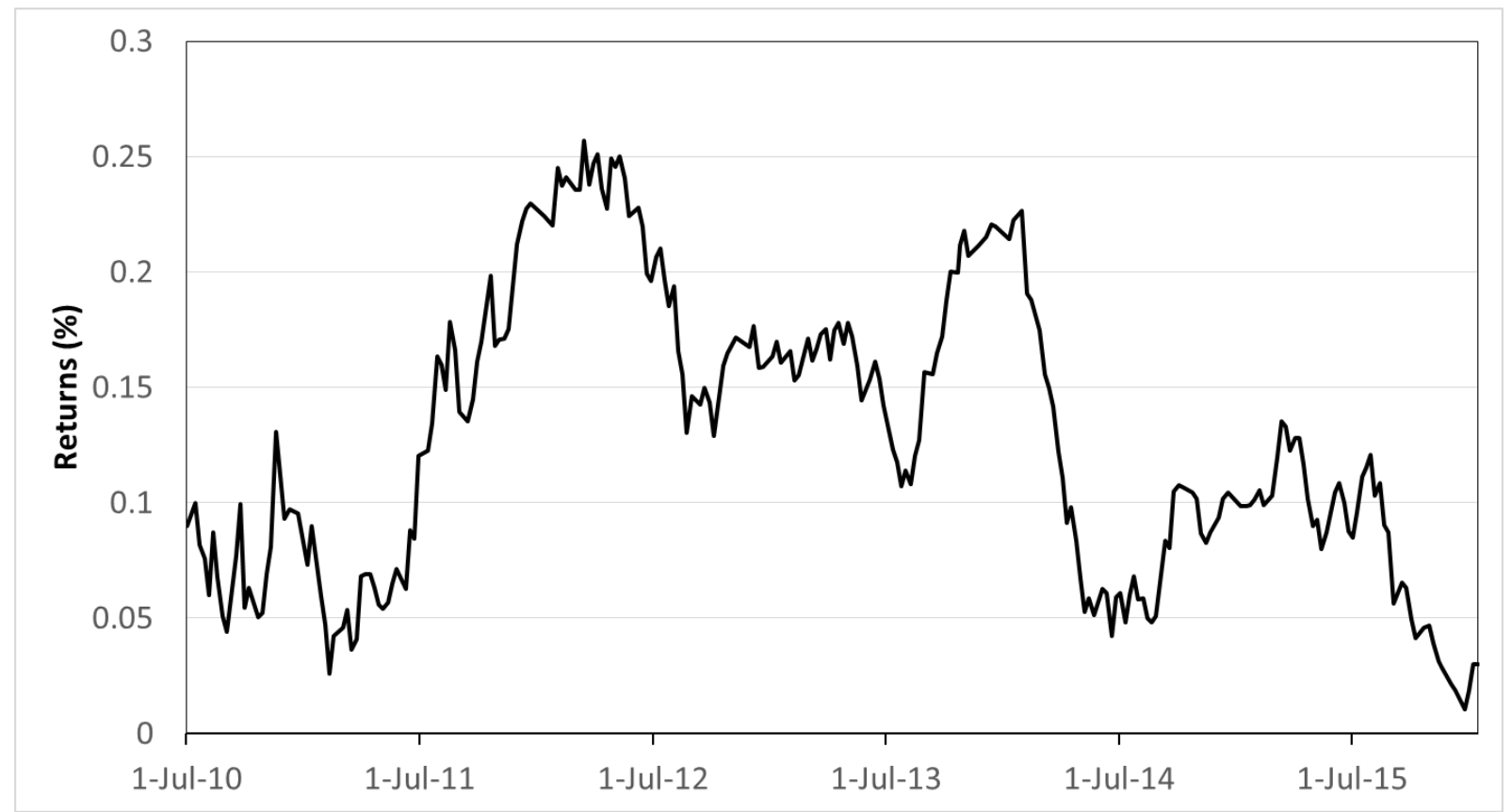

The figure plots the 24-month moving average returns of the trading strategy that consists of buying (selling) a futures contract 90 minutes before the announcement if the predictor is negative (positive), and closing the position 5 minutes before the announcement. The predictor is defined as the forecast difference between the "informed" consensus and the Bloomberg consensus. The "informed" consensus is the median value of ranked analyst forecasts. The sample period is from July 2008 to January 2016 and contains 334 observations, $\mathrm{i}$ 


\section{Chapter 2: Expectations and Financial Markets: The Case of Brexit ${ }^{25}$}

\subsection{Introduction}

On June 23, 2016, British voters went to the polls to determine if their country should leave the European Union, the so-called "British Exit" or more popularly referred to as Brexit. Prior to the vote, most polls had indicated that Britons would vote against Brexit (i.e. Leave), and in favor of Remain. The betting odds also showed that the market's expectation about the probability of Brexit was just over $20 \%$ before the referendum. Surprisingly, the British public voted to leave the European Union by a 52 to 48 percent margin. In the following two trading days, the French CAC 40 and German DAX, which are the main European stock indices for blue-chip companies, crumbled over $10 \%$. The UK and US equities did not fare much better; with the FTSE 100 decreasing by $5.8 \%$ and the S\&P 500 declining by $5.5 \%$ in the two days following the referendum. ${ }^{26}$ During this time, investors were piling into government bond markets; yields on the 10-year UK Gilt and US note fell by 35 bps and 28 bps, respectively. Clearly, the shocking referendum result roiled financial markets. In this paper we investigate how changes in the market's expectations of Brexit in the period immediately preceding the referendum vote, affected US and European financial markets.

Financial markets hinge on expectations. The fundamental values of risky assets are largely determined by discounting their expected future cash flows under different scenarios. An asset

\footnotetext{
25 This essay is based on a paper coauthored with Ann Marie Hibbert.

${ }^{26}$ US blue chips reacted in a similar manner, with the Dow Jones Industrial Average falling 4.3\% during the two trading days after the referendum.
} 
which has a good or improving outlook usually attracts more buyers, which results in an increase in price. Conversely, an asset with a bad or deteriorating outlook will attract more sellers than buyers, which can result in lower prices. Analysts, fund managers, and others who are involved in asset allocation decisions usually analyze both historical information such as financial reports, as well as current and anticipated new information, such as macroeconomic news, expectations about firm-specific or industry events, and other national or global events. Information that influences these expectations has the potential to drive market movements. Our primary goal is to investigate to what extent the expectations of Brexit was impounded into market prices.

The main challenge faced by researchers who investigate the impact of the public's expectations about political (and other) events on financial markets, is that expectation as a variable is unobservable and difficult to quantify. Amihud and Wohl (2004) use marketdetermined betting odds to measure the market's expectations of the probability of Saddam's fall before and after the outbreak of the second Gulf War. ${ }^{27}$ They find that the projected likelihood of Saddam's fall explained over 40\% of the variation in the S\&P 500 index during a 20-day post war period. In a similar vein, Goodell and Vähämaa (2013) employ futures prices from the Iowa Electronic Markets to capture changes in beliefs about future macroeconomic policy before presidential elections. Besides these market-based expectations, poll data has also been used to investigate the effect of the public's anticipation of election results on financial market returns and volatility (Gemmill, 1992; Li and Born, 2006). If people vote consistent with their response to surveys, poll results can provide reasonable proxies for the prospects of future events. Rigobon and Sack (2005) propose a heteroskedasticity-based estimation technique to investigate the effect

\footnotetext{
${ }^{27}$ The probability of Saddam's fall was derived from the price of a futures contract called "Saddam Securities". The contract was traded on Tradesports.com, an online betting exchange market. The investor would receive $\$ 10$ if Saddam was ousted before the expiration of the contract.
} 
of war risk on US financial markets. This methodology allows for the identification of the impact of unobservable political news, without measuring the news itself directly. For our empirical tests, we mainly use the Brexit betting odds based expectations about the probability of Britain leaving the European Union, but we also use polls data and the heteroskedasticity-based approach as robustness checks.

A rise in the probability of Brexit was related to the public's anxiety about greater political and economic uncertainties after the referendum. Uncertainty increases the value of waiting to invest (Bernanke, 1983). Julio and Yook (2012) empirically show that firms reduce expenditures during times of high political uncertainty. An increase in the probability of Brexit could cause firms and rational investors to defer their new investment in risky assets (e.g. stocks and commodities), and increase their investment portfolio weights in traditionally safe and liquid assets (e.g. treasuries and gold). An increased likelihood of Brexit could also induce investors to demand a higher risk premium due to greater expected political uncertainty (Pastor and Veronesi, 2012, 2013; Amihud and Wohl, 2004) and potential economic slowdown (Amihud and Wohl, 2004). Overall, it is expected that a rise in the probability of Brexit should have negative effects on stock prices and a positive impact on market uncertainty.

These expectations are confirmed by our empirical results. Changes in the likelihood of Brexit were negatively related to stock prices but positively related to implied volatilities. Furthermore, the pre-referendum response across individual stocks was positively correlated with their respective performance after the referendum, i.e. stocks that were more sensitive to changes in the likelihood of Brexit experienced a larger price decline after the referendum. This suggests that there exists political betas that drive the heterogeneity in stock price movements around political events. This finding has implications for investors. For example, sophisticated traders can 
identify stocks that over- or under-react to political events by observing a stock's sensitivity to changes in expected political risks in the pre-event period and trade accordingly.

In addition, we find that relative to the UK stock market, continental European markets were more sensitive to changes in the likelihood of Brexit. We find this result surprising since the political crisis originated in the UK. This observation is possibly caused by differences in the ownership structure of listed firms among the stock markets we study. The UK stock market has more multi-national firms, which would benefit from a weakening pound after Brexit. Alternatively, investors may have more confidence in the UK prospects, vs. that of the continental European countries, in a post-Brexit era. For example, the UK has a more flexible and independent monetary policy, which could facilitate an easy recovery of their economy. From a trading perspective, the UK's current significant trade deficit with other European countries suggests that the UK would have a more balanced trading account after leaving the EU.

The economic impact of Brexit was not confined to stock markets. An analysis of commodity, government bond and foreign exchange markets suggests that they too tend to include a premium for the risk of potential market turmoil in the event of a Leave vote. Specifically, changes in the probability of Brexit were negatively associated with the value of the British pound and bond yields; whereas these changes had positive explanatory power for dollar and gold values. All these findings are consistent with the well-known flight to quality phenomenon around high uncertainty periods.

A growing body of literature shows that investor attention is crucial to returns and volatilities formation. ${ }^{28}$ Dellavigna and Pollet (2009) show that stock markets underreact to

\footnotetext{
${ }^{28}$ For examples of studies that analyze the effect of investor attention on asset returns, see Da, Engelberg and Gao, (2011); and Ben-Rephael, Da and Israelsen (2016) and for similar studies regarding the effect of investor attention on asset volatilities, see Vlastakis and Markellos (2012); and Basistha, Kurov and Wolfe (2016).
} 
earning announcements on Fridays due to limited attention, and Gervais, Kaniel and Mingelgrin (2001) and Seasholes and $\mathrm{Wu}$ (2007) show that high attention stocks tend to have positive returns. Basistha, Kurov and Wolfe (2016) report that a Google search volume based attention measure has predictive power for volatility in the financial and commodity markets. We reexamine the role of attention in the context of the association between financial markets and expectations about Brexit. Following Liu, Sherman and Zhang (2009) and Ben-Rephael, Da and Israelsen (2016), we use news coverage to identify days on which the UK referendum appeared to have attracted investor attention. We define high attention days as days when the number of news stories published on Bloomberg on the Brexit topic is above the median level for the sample period. Our results show that the negative relation between the probability of Brexit and stock market movements strengthened on high attention days, but disappeared on low attention days.

Our paper joins the literature on the association between political events and financial markets. Cutler, Poterba and Summers (1989) show that war news has very little explanatory power for market movements. However, Leigh, Wolfers and Zitzewitz (2003) and Amihud and Wohl (2004) find that changes in the probability of Saddam's fall from power, as reflected in the futures price of the "Saddam Contract", explain a large portion of stock variation. Similarly, Rigobon and Sack (2005) show that stock prices are negatively related to war risk, and Li and Born (2006) report that presidential election uncertainty significantly influences stock markets. In a study that investigates the effect of political uncertainty on implied volatility, Goodell and Vähämaa (2013) show that the VIX is positively related to changes in beliefs about future macroeconomic policy before presidential elections. Our study employs market-based expectations about Brexit to do an ex-ante assessment of the economic consequences of a British 
Leave vote on financial markets. Our findings support the notion that market fluctuations are significantly associated with political news.

Our finding that investor attention on the Brexit topic played a crucial role in building the connection between the market's expectations about Brexit and financial markets contributes to the literature on (in)attention in finance. High investor exposure to news causes stock prices to respond to information about Brexit. The projected chance of Brexit had no significant effect on asset returns and implied volatilities during low investor attention days. This is consistent with Huberman and Regev (2001), who point out that markets react to new information only when investors pay attention to it.

\subsection{Data and Univariate Results}

\subsubsection{Brexit's Probability}

Amihud and Wohl (2004) find that the market's expectation about the probability of Saddam's fall, as reflected in market-determined betting odds, has strong explanatory power for stock returns. We follow Amihud and Wohl (2004) and use Brexit online betting odds data obtained from Betdata.io to investigate the reaction of financial asset returns to the public's belief about the likelihood of Brexit.

The UK referendum betting was initiated on February 26, 2016 by Betfair, the world's largest internet betting exchange with an open limit order book. Betfair is also the only political prediction market in the world that has a very liquid and efficient market. For example, the total bets for the UK referendum on EU membership, was over 100 million GBP. Referendum results' shares were traded identical to how stocks are traded in the stock market. Betdata.io converts the 
prices on the Betfair platform to probabilities of Leave and Remain. ${ }^{29}$ We collect the daily probability of Leave as of 24:00, London time (BST), from February 26, 2016 to June 23, 2016, a total of 85 weekday observations. ${ }^{30}$

\subsubsection{Stock Prices and Implied Volatility}

To investigate the relation between the likelihood of Brexit and financial markets, we focus on the major European and US stock indices. Specifically, we include the London FTSE 100 index, the Paris CAC 40 index, the Frankfurt DAX index, and the New York S\&P 500 index. The spot prices of these indices are obtained from Bloomberg.

We use implied volatility to measure market uncertainty. For the S\&P 500 index, we use the Chicago Board Options Exchange (CBOE) Volatility Index (VIX), which is a measure of the market's expectations of 30-day volatility conveyed by S\&P 500 index option prices. For the European stock indices, we use the VFTSE, the VCAC and the VDAX to reflect the implied volatilities of the FTSE 100 index, the CAC 40 index and the DAX index options, respectively. These implied volatility indices follow the CBOE VIX methodology and have become the investor fear gauge in the British, French and German stock markets. The VFTSE and the VCAC are published by Euronet while the VDAX is released by the Frankfurt stock exchange.

Figure 1 shows the level of each stock index vs. the probability of Brexit over our sample period. As the probability of Brexit increased (decreased), there was a corresponding decrease (increase) in the level of each index, suggesting a negative relation between the projected

\footnotetext{
${ }^{29}$ The formula used is: Probability (Brexit/Remain) $=1 /\left(\frac{B i d+A s k}{2}\right)$. The sum of Leave and Remain probabilities is close to $100 \%$.

${ }^{30}$ There are 86 weekdays in the sample period, but no data is available for June 20, 2016.
} 
likelihood of Brexit and stock returns. The association is consistent across all stock markets and seems to strengthen as the referendum day approached.

[Insert Figure 1 about here]

\subsection{Empirical Results}

\subsubsection{The Impact of the Probability of Brexit on Returns}

In this section we test whether the public's belief about the likelihood of Brexit move stock prices. We start our econometric tests by estimating the following model:

$$
R_{t}=a_{0}+a_{1} \Delta \text { Brexit }_{t}+\varepsilon_{t}
$$

where $R_{t}$ is the daily return on each of the stock index and $\Delta$ Brexit $_{t}$ is the first difference of the probability of Brexit derived from online betting odds. We also extend this model by adding the one-day lagged change in the Brexit's probability to capture any potential non-contemporaneous association:

$$
R_{t}=a_{0}+a_{1} \Delta \text { Brexit }_{\mathrm{t}}+a_{2} \Delta \text { Brexit }_{\mathrm{t}-1}+e_{t}
$$

Panels A and B of Table 1 reports the results of models (1) and (2) respectively, estimated separately for each of the four stock indices. ${ }^{31}$

[Insert Table 1 about here]

Panel A shows that all stock indices were negatively associated with changes in the probability of Brexit. On average, a hypothetical 10 percent increase in the probability of Brexit was associated with a decline of: $1.0 \%$ in the FTSE 100, $1.6 \%$ in the CAC 40, $1.5 \%$ in the DAX and $0.5 \%$ in the S\&P 500. These results should not be interpreted as changes in Brexit betting odds resulting in market movements. Instead, the more appropriate interpretation is, for example, that

\footnotetext{
${ }^{31}$ The t-statistics in all the reported tables employ White's (1980) standard errors. We also use Newey and West's (1987) correction of standard error for heteroskedasticity and autocorrelation in residuals. The results are unchanged.
} 
news about the UK referendum that cause a $10 \%$ increase in the probability of Brexit also cause a $1 \%$ decline in the FTSE 100. A similar interpretation applies for the CAC 40, the DAX and the S\& P500..$^{32}$

The results of model (2), reported in Panel B of Table 1 show that the lagged probability of Brexit had significant explanatory power only for US stock market returns. A $10 \%$ increase in the probability of Brexit was associated with a $0.5 \%$ decrease in the S\&P 500 index the following day. This is most likely due to the closing time mismatch between the betting market and the US (spot) stock markets. ${ }^{33}$ For the European stock markets, the one day lagged probability of Brexit lacked significant explanatory power for the return variables, but the sign of the coefficient estimates are all negative. As the referendum day approached, the negative relation between stock returns and the Brexit probability is more evident in Figure 1. Therefore, in addition to the static models (1) and (2), we also investigate the sensitivity of the regression results to the length of the sample period. We re-estimate the regression in equation (1) for different sample period lengths by varying the sample start date but keeping the end date fixed at June 23, 2016. The starting date for each of these (variable-length) sub-periods is from February 26, 2016 to 10 trading days before the referendum day, in ten-day increments. For example, the first sub-period is identical to our full sample period, i.e. from February 26 to June 23, 2016; the second sub-period is from March 8 to June 23, 2016, the third is from March 18 to June 23, 2016, etc. Figure 2, which plots the average of the coefficient estimates over all the sub-periods, shows that as the referendum day approached, the magnitude of the estimated slope coefficients for all stock indices increased monotonically.

\footnotetext{
${ }^{32}$ In addition to the OLS regressions reported in Table 1, we re-estimate model (1) using the weighted least squares method of Yohai (1987) for each asset, to address any potential concern about the effect of outliers on inferences. This so-called MM estimator is robust in the presence of outliers. The results, available upon request, are similar to those in Table 1.

${ }^{33}$ The closing time of the betting market is 24:00 BST, which is 19:00 EST. Thus, news between 16:30 BST and 24:00 BST is reflected in the FTSE 100, CAC 40 and DAX indices the following day; information between 16:00 EST and 19:00 EST is reflected in the S\&P 500 index the following day.
} 
After June 1, a hypothetical ten percent increase in the probability of Brexit was associated with roughly a three percent decrease in the European stock indices.

\section{[Insert Figure 2 about here]}

The magnitude of the coefficients in Table 1 indicates that the European stock markets were more sensitive to the variability in the projected chance of Brexit relative to the US stock market. This is not surprising. However, inspection of the results for each of the European stock markets, reveal the counterintuitive finding that information about Brexit caused less movement in the UK stock index compared to the stock indices of the countries in mainland Europe. There are at least three potential explanations for this finding. The first explanation is based on the fact that the UK stock market has a high percentage of international ownership. A weakening pound, which is positively related to the probability of Brexit, would be a positive factor for international investors buying into the FTSE. ${ }^{34}$ Analysts at Deutsche Bank, Germany's biggest bank, are quoted in a June 21, 2016 Bloomberg article as saying, "In Europe equities, we prefer UK over Germany regardless of the Brexit referendum outcome. The UK has become a more defensive player and should outperform going forward." 35

Another potential explanation for the weaker reaction of the British stock market, relative to that of Germany and France, is that some investors expected that relative to other European countries, the UK would recover more easily from Brexit. Interest rates set by the European Central Bank (ECB) has been in a negative zone for a long period. Yields on short- and medium-term government bonds for Germany and France have also decreased to negative levels after several rounds of quantitative easing $(\mathrm{QE})$. Hence, the ECB has very limited ability to stop economic

\footnotetext{
${ }^{34}$ One unreported result is that the probability of Brexit had no statistically significant impact on the EUR/USD exchange rate.

35 https://www.bloomberg.com/news/articles/2016-06-21/deutsche-prefers-u-k-stocks-to-germany-s-brexit-or-nobrexit
} 
decay via monetary policy tools. In contrast, the Bank of England has more room to stimulate the economy by using monetary policy. In addition, if the UK leaves the EU, Germany and France, as the remaining main leaders in the EU, would have to assume more political, as well as financial responsibility to tackle the other existing challenges within the EU, e.g. the Greek rescue, the Ukraine conflict, and the refugee crisis.

A third possible reason for the greater link between the probability of Brexit and the German and French stock markets vis-⿳亠㐅冋-vis that of Britain, is that Germany and France benefit more from the EU market than does the UK, and would therefore be more adversely impacted by a Brexit vote. UK has trade deficits with almost all EU members except Ireland. In 2015 alone, the UK had goods and services trade deficits of $£ 25,468$ million with Germany, $£ 5,244$ million with France, $£ 10,102$ million with Spain, $£ 7,603$ million with Netherlands and $£ 28,512$ million with the rest of the EU excluding Ireland. In comparison, the UK had $£ 29,968$ million trade surpluses with non-EU countries. ${ }^{36}$ Moreover, since 1999, the percentage of UK total goods exported to the EU areas has been decreasing, whereas the percentage of UK total goods exported to the non-EU areas has been increasing. The value of UK exports of goods to non-EU countries exceeded goods exported to the EU in the four years preceding the referendum vote (2012-2015).

In unreported results, we perform several additional tests to ensure that our findings in Table 1 are robust to the methodology used and are not due to omitted variables. First, we conducted a bootstrap exercise similar to Lucca and Moench (2015), in which randomly draw with replacement 1,000 samples of changes in the probability of Brexit's and returns for each stock index. The size of the random sample for each index is equal to its respective number of observations in Panel A of Table 1. Second, we extend our Model (1) to include key

\footnotetext{
${ }^{36}$ Date source: Office of National statistics, The Pink Book 2016, Figure 9\&10.
} 
macroeconomic variables such as the CBOE VIX and the Eurodollar futures rate with 8-9 quarters to expiration, ${ }^{37}$ both of which have been shown to move asset prices globally. Third, we estimate the regressions separately for sub-sectors, small-cap indices and mid-cap indices. ${ }^{38}$ The results from all these additional tests are similar to those reported in Table 1.

\subsubsection{The Impact of the Probability of Brexit on Implied Volatilities}

Information regarding the probability of Brexit is related to the market's expectation about political and economic uncertainties. If the UK leaves the EU, the UK needs to renegotiate trade deals with all countries, especially those within the EU. It is not clear whether new deals would be better than current ones. Brexit may also change the political map, by for example causing the resignation of Prime Minister David Cameron, which would lead to leadership and policy uncertainty. ${ }^{39}$ In light of the potential economic slowdown, the central bank needs to adjust current monetary policy in order to stimulate the economy and increase market confidence. Mark Carney, governor of the Bank of England, has promised that the Bank of England will do "whatever it takes" to support growth. But with interest rates at historical lows, and questions being raised about the viability of additional quantitative easing, it is unclear that the Bank of England has the tools to meet the challenges ahead. Overall, it is expected that changes in the probability of Brexit should be positively associated with market uncertainty. Accordingly, we hypothesize that an increase in the

\footnotetext{
${ }^{37}$ Eurodollar futures rates can be viewed as the market's forecasts of the 3 -month LIBOR expected to prevail at expiration of the futures contract.

${ }^{38}$ For the sector indices, we include seven supersector sub-indices of the STOXX 600 index; for small-cap indices, we include the FTSE small, the CAC Small 90, the DAX Small and the S\&P 600; and for mid-cap indices, we include the FTSE 250, the CAC Mid 60, the DAX Mid-Cap and the S\&P 400.

${ }^{39}$ Although Cameron had pledged before the vote to stay in office whatever the results, Brexit would be an astonishing blow to his authority. The voters would have rejected his stance on the biggest political question Britain had faced in decades. The shock of Brexit might be enough to make him abandon his previous promise to stay on. Unsurprisingly, Cameron announced his resignation as soon as it was clear that the vote was in favor of Leave.
} 
likelihood of Brexit engenders financial market uncertainty. To test this proposition, we reestimate Model (2) with the change in implied volatility for each market as the dependent variable.

[Insert Table 2 about Here]

Table 2 shows that the estimated slope coefficients are positive and statistically significant for all stock indices, suggesting that implied volatilities in these stock markets increased as the probability of Brexit increased. On average, a $10 \%$ increase in the likelihood of Brexit was associated with a $7.9 \%, 12.2 \%, 9.2 \%$ and $12.1 \%$ increase in the FTSE 100, CAC 40, DAX and S\&P 500 implied volatility indices, respectively. This finding supports the hypothesis that market anxiety about political and economic uncertainty strengthened when the public expected that Brexit was more likely to occur.

\subsubsection{Cross-sectional Analysis}

In subsections 2.3.1 and 2.3.2, we provide robust evidence that an increase in the likelihood of Brexit lead to a drop in stock prices and a rise in financial market uncertainty. In this section, we use a two-step approach to test the hypothesis that changes in the probability of Brexit affect stock prices, in part, through its effect on financial market uncertainty. We first measure the sensitivity of firm-level stock returns to fluctuations in financial market uncertainty, and then regress uncertainty factor loadings on the response of firm-level stock returns to changes in the probability of Brexit. If the null hypothesis is true, we would expect a positive relationship between Brexit factor loadings and uncertainty factor loadings. In other words, stocks that are more sensitive to uncertainty shocks should be more sensitive to changes in the likelihood of Brexit.

In step one, we estimate the following model for each stock:

$$
R_{i t}^{a b}=\alpha_{0}+\beta_{i}^{V I X} \Delta V I X_{t}+\varepsilon_{i t}
$$


where $R_{i t}^{a b}$ is firm i's risk-adjusted abnormal return on day t, estimated as the residual from the Fama-French five-factor model (2015). ${ }^{40} \Delta V I X_{t}$ is the first difference of the VIX index. The coefficients $\beta_{i}^{V I X}$ measures the sensitivity of firm-level stock returns to changes in the VIX. The model is estimated over our sample period for S\&P 500 component stocks as at December 2016. Next we estimate Model (2) using firm-level daily returns for each S\&P 500 firm. Firm-specific reactions, the sum of $a_{1}$ and $a_{2}$, reflect the heterogeneity in firm-level response to revisions in the likelihood of Brexit.

In step two, we estimate the following cross sectional regression model:

$$
\beta_{i}^{\text {Brexit }}=\alpha_{0}+\alpha_{1} \beta_{i}^{V I X}+\sum_{\text {industries }} \alpha_{\text {Industries }} D_{\text {industries }}+\varepsilon_{i},
$$

where $\beta_{i}^{\text {Brexit }}$ is the sum of $a_{1}$ and $a_{2}$ in Model (2) estimated respectively for each firm $\mathrm{i}$, and $\beta_{i}^{V I X}$ is the financial market uncertainty factor loadings from Model (3). We normalize $\beta_{i}^{\text {Brexit }}$ and $\beta_{i}^{V I X}$ using their sample means and standard deviations. To control for industrial heterogeneity in the effect of changes in the likelihood of Brexit on stock returns, we add industry dummies in Model (4). We apply the first two digits of the North American Industry Classification System (NAICS) code to classify firms into industries and use the mining industry as the base industry.

The results of Model (4) are reported in Table 3. Consistent with the null of uncertaintybased hypothesis, Table 3 shows a positive relation between responses to VIX changes and the response to changes in market expectation of the probability of Brexit. Stocks that are more affected by stock market uncertainty react more strongly to changes in the likelihood of Brexit. On average, a one standard deviation increase in $\beta_{i}^{V I X}$ lead to a $14 \%$ standard deviation increase in $\beta_{i}^{\text {Brexit }}$.

\footnotetext{
${ }^{40}$ Daily values of the market excess return, size, value, profitability and investment factors are obtained from Kenneth French's data library.
} 
[Insert Table 3 about Here]

Table 3 also shows some heterogeneity in the reaction of industries to Brexit related information. The coefficient estimates for most industry dummies are positive and statistically significant. This suggests that stocks in those industries generally react less strongly to changes in the likelihood of Brexit than those in the mining industry. On the other hand, the sensitivity of five industries (Construction, Transportation and Warehousing, Finance and Insurance, Management of Companies and Enterprises and Health Care and Social Assistance) to changes in the likelihood of Brexit is not statistically different from that of the mining industry.

\subsubsection{Implications for After Referendum Responses}

In this section, we investigate the relation between the response of stock prices to changes in the likelihood of Brexit before the referendum vote to the stock daily returns after the referendum vote. If post-referendum stock returns are caused by the referendum result, stocks that are more sensitive to the Brexit probability changes would decrease more dramatically when the referendum result is announced. To measure the sensitivity of post-referendum returns to the sensitivity of prereferendum reaction to fluctuations in Brexit probability, we estimate the following cross-sectional regression separately for each of the six trading days immediately after the UK referendum date:

$$
R_{i t}=\alpha_{0}+\alpha_{1} \beta_{i}^{\text {Brexit }}+\sum_{\text {sectors }} \alpha_{\text {Industries }} D_{\text {industries }}+\varepsilon_{i}
$$

where $R_{i t}$ is the S\&P 500 component stock i return on day t. $\beta_{i}^{\text {Brexit }}$ is the sum of $a_{1}$ and $a_{2}$ in Model (2) estimated respectively for each firm i, $\beta_{i}^{\text {Brexit }}$ is standardized by using its sample mean and standard deviation.

The results of model (5) are reported in Table 4. As expected, the coefficient estimate on $\beta_{i}^{\text {Brexit }}$ on the day of the referendum, June 24,2016 , is positive and statistically significant. A one 
standard deviation decrease in $\beta_{i}^{\text {Brexit }}$ leads to $1.22 \%$ decrease in stock returns. ${ }^{41}$ Interestingly, we find $\beta_{i}^{\text {Brexit }}$ is positively related to cross-sectional returns on June 27 , one trading day after the referendum, but negatively related to returns on June 28 and June 29. This reaction pattern suggests that investors underreacted to Brexit in the first trading day after the referendum but overreacted to Brexit in the second trading day. Prices are adjusted to fundamental levels in the next two trading days. Afterwards, the pre-referendum cross-sectional response has no explanatory power for crosssectional returns. Overall, the last column of Table 4 shows that stocks that were more affected by changes in the probability of Brexit, decreased more during the six trading period following the release of the referendum result.

\section{[Insert Table 4 about Here]}

Our finding that the pre -referendum response has predictive power for post-referendum response is supported by Pastor and Veronesi (2012) who document that stocks which are more sensitive to political uncertainty require higher risk premium. The UK referendum on EU membership is just the first in a series of foreseeable political blows related to the EU. Similar votes would occur in other European countries. ${ }^{42}$ Trading consistency reported in this section indicates that experienced traders are likely to identify stocks that overreact and those that underreact, according to observed pre-event relations between returns and expectations of political events. Arbitrageurs could devise profitable trading strategies by exploiting temporary post-event market inefficiency. Hedgers could use pre-event relations to determine optimal hedge ratios for different stock portfolios in order to minimize overall exposure to potential risks related to political events.

\footnotetext{
${ }^{41}$ Stock prices react negatively to changes in the likelihood of Brexit. So a decrease in $\beta_{i}^{\text {Brexit }}$ means an increase in the sensitivity of returns to changes in the likelihood of Brexit.

${ }^{42}$ Italian voters turned down a pro-EU constitutional referendum on December 4, 2016.
} 


\subsubsection{Flight to Quality}

In the preceding subsections our analyses employ stock markets only. However, it is possible that changes in the market's expectations about the probability of Brexit is also related to other markets, e.g. commodities, bonds and exchanges rates. Caballero and Krishnamurthy (2008) theoretically show that uncertainty shock leads to flight to quality. We investigate this using Brent Crude Oil futures, Bloomberg commodity index and gold, for commodity markets; the ten-year UK, Euro and US government bonds for fixed income markets; and the Dollar Index, GPB/USD exchange rate, GPB/JPY exchange rate and GPB/CHF exchange rate for foreign exchange markets. We obtain all data from Bloomberg. For brevity, we only tabulate regression results based on Model (2) in Table 5 and mainly interpret the cumulative effects of Brexit's probability on various assets.

Panel A of Table 5 shows that an increase in the probability of Brexit bolstered the US Dollar Index. Conversely, a rise in the chance of Brexit resulted in the Pound depreciating relative to the US Dollar, Japanese Yen and Swiss Franc. A hypothetical $10 \%$ increase in the probability of Brexit was associated with: a $0.4 \%$, change in the Dollar Index, a $-1.6 \%$ change in the GBP/USD, a $-2.4 \%$ change in the GBP/JPY and a $-1.8 \%$ change in the GBP/CHF. The slope coefficient estimates consistently exhibit safe haven characteristics of US Dollar, Japanese Yen and Swiss Franc (Grisse and Nitschka, 2015).

For the government bond markets reported in Panel B of Table 5, yields decreased with the probability of Brexit. Put differently, bond prices were positively associated with the projected chance of Brexit. A hypothetical 10\% increase in the probability of Brexit was associated with an 8.6, a 3.9 and a 6.2 bp decrease in the ten-year UK, European and U.S government bond yields, 
respectively. This finding indicates that the more concerned the public was about a pending Brexit vote, the more capital was transferred into 'risk free' bond markets.

Panel $\mathrm{C}$ of Table 5 shows that the likelihood of Brexit was not associated with the Bloomberg commodity index nor Brent Crude oil prices, but there was a positive contemporaneous relation between the probability of Brexit and the price of gold. This finding provides further support for the "safe haven" theory. ${ }^{43}$

[Insert Table 5 about here]

Overall, the empirical results so far strongly support our hypothesis that the market's beliefs about the probability of Brexit significantly influenced investors' asset allocation decisions. Increased signals of Britain's intention to leave the EU sent global stock markets into turmoil. Investors moved their capital away from riskier investment vehicles (stocks, crude oil, GBP) to safer investments (gold, government bonds, US Dollar and Yen). This finding confirms the wellknown flight to quality phenomenon that is usually observed during times of increased fear or uncertainty.

\subsection{Probability of Brexit and Investor Attention}

A growing body of empirical evidence shows that investor attention plays a crucial role in returns and volatilities formation (Ben-Rephael, Da and Israelsen, 2016). We examine the role of attention by comparing the market's reaction to information about Brexit on high and low attention days. It is expected that the market's response should be stronger when investors' attention to the UK referendum was high.

\footnotetext{
${ }^{43}$ In unreported results based on a shorter sample period, we find a significant negative association between the prospect of Brexit and oil prices. The negative relation is consistent with a strengthened dollar value after a decrease in the probability of Brexit.
} 
Following previous papers (Liu, Sherman and Zhang, 2009; and Ben-Rephael, Da and Israelsen, 2016), we use the number of news stories to identify days on which the UK referendum appeared to have attracted investors' attention. The news data is from Bloomberg. Every day, Bloomberg records the number of news stories published on Bloomberg on the Brexit topic. BenRephael, Da and Israelsen, (2016) argue that the number of Bloomberg articles is a good measure to capture attention of institutional investors. High attention days are defined as ones on which the number of news stories was above the median level in the sample period. To do the econometric test, we regress daily asset returns on the changes in the probability of Brexit interacted with a dummy variable that is meant to capture a shift in the relationship between asset returns and the probability of Brexit during the high attention days:

$$
R_{t}=a_{1}+\left(b_{1} \Delta \text { Brexit }_{t}\right) D_{t}^{H}+\left(b_{2} \Delta \text { Brexit }_{t}\right)\left(1-D_{t}^{H}\right)+\varepsilon_{t},
$$

where $D_{t}^{H}$ is a dummy variable that is equal to one during the high attention days, and zero otherwise.

[Insert Table 6 about here]

The results of the model in equation (6) are presented in Panel A of Table 6. The table shows that on high attention days, change in the probability of Brexit was strongly related to stock returns. As expected, the magnitude of the slope coefficients on high attention days and regression R-squareds increased for all stock indices compared to the results in Panel A of Table 1. However, on low attention days the relationship between stock returns and the likelihood of Brexit disappeared. Panel B of Table 6 reports the role attention played in the relation between implied volatilities and the probability of Brexit. Similar to the findings for stock returns, we see that implied volatilities respond to the information about Brexit only on high attention days. The slope 
coefficient estimates are all positive and statistically significant. In contrast, on low attention days there was no association between implied volatilities and changes in the likelihood of Brexit.

We also test the robustness of the results in Table 6 to the choice of news source by using the major U.S traditional news media as contained in Factiva, as an alternative source of data for the Brexit attention variable. ${ }^{44} \mathrm{Da}$, Engelberg, and Gao (2011) use the number of articles in the print editions of major newspapers as a proxy for retail investor attention. We count the daily number of news items which contain the keyword "Brexit" and use the median number to split the full sample into high and low attention subsamples. The results using this alternative measure of attention are very similar to those in Table 6 and available upon request. Overall, these results suggest that when the Brexit topic was not widely reported in the media, the market's belief about Brexit had no effect on financial markets.

A possible argument is that the lack of association on low attention days may be due to the smaller magnitude of changes in the probability of Brexit. However, this is unlikely the cause as there was no significant difference in the absolute value of the changes in Brexit's likelihood between high and low attention days. This further supports our proposition that investor attention was crucial to the impact of the projected chance of Brexit on asset returns and volatilities.

\subsection{Other Measures of the likelihood of Brexit}

\subsubsection{Regression results based on Polls data}

"The markets have been responsive to changes in the polls, clearly, so the vote could certainly bring on significant volatility," Jerome H. Powell, governor of the Federal Reserve, told "Squawk Box."

CNBC, June 22, 2016

\footnotetext{
${ }^{44}$ The data source includes The Wall Street Journal, The New York Times, The Washington Post, Los Angeles Times, Chicago Tribune, USA Today, The Atlanta Journal-Constitution, Tampa Bay Times, Barron's and Forbes.
} 
In sections 2.3 and 2.4, we show that the odds-determined measure of the likelihood of Brexit was negatively related to stock returns and positively associated with implied volatilities. In this section, we use trial-heat polls data to measure the market's expectation about the probability of Brexit.

Our polls data is the Bloomberg composite indicator of UK EU referendum voter intention surveys. The Bloomberg indicator consists of three sub-indices: Leave, Remain and Undecided. These indices are the simple averages of polls data revealed by poll agencies including BMG, ComRes, ICM, Ipsos MORI, ORB, Survation and YouGov. The question on the surveys is the same as the referendum question, i.e. "should the United Kingdom remain a member of the European Union or leave the European Union?” Bloomberg only updated and reported data when a new poll result was released. The polls, which do not report a value for the Undecided/Don't know question are not included in the indices. We define the market's expectation about the probability of Brexit as the difference between the Leave and Remain indices. ${ }^{45}$

Bloomberg started to release the composite indicator of the UK EU referendum voter intention surveys in September, 2015. We restrict the empirical analysis to the sample period from February, 2016 to the referendum day. February, 2016 is the month when the referendum day was decided. Since then, Brexit polls were more frequently conducted by various social research companies. In our sample period, there are 60 observations of the Leave and Remain indices. Because polls results were usually released to the public at night or during weekends, the information embodied in polls data was mainly reflected in stock markets the following day. To

\footnotetext{
45 The level of the Unknown index was not trivial. Thus it is not appropriate to use the Leave index directly as a proxy for the probability of Brexit. The difference between the Leave and Remain indices is an indirect measure of the probability of Brexit.
} 
account for this, we combine changes in the likelihood of Brexit for Friday, Saturday and Sunday together as one observation, this results in a final sample of 55 observations.

In section 2.4 we find that the market's expectation about the probability of Brexit based on betting odds data, mainly influenced asset returns and implied volatilities on high investor attention days. To empirically examine asset price movement in response to changes in polls-data based likelihood of Brexit, we estimate the event study regression with an attention dummy variable as:

$$
R_{t}=a_{1}+\left(b_{1} \Delta \text { Brexit }_{t-1}^{\text {polls }}\right) D_{t}^{H}+\left(b_{2} \Delta \text { Brexit }_{t-1}^{\text {polls }}\right)\left(1-D_{t}^{H}\right)+\varepsilon_{t}
$$

where $\Delta$ Brexit $_{t-1}^{\text {polls }}$ is the first difference of the probability of Brexit derived from polls data.

[Insert Table 7 about here]

Panel A of Table 7 shows the role of investor attention in the association between the trialheat polls data based probability of Brexit and asset returns. For all stock indices, there is strong evidence that when investor attention was high, Britain's intention to leave, as reflected in polls, has significant explanatory power for asset returns the following day. Stock indices decreased with the likelihood of Brexit. A $10 \%$ increase in the probability of Brexit was related to a 1.0\%, $1.1 \%$, $1.2 \%$ and $0.5 \%$ decrease in the FTSE 100, the CAC 40, the DAX and the S\&P 500 indices, respectively.

Panel B of Table 7 reports the effect of polls data based likelihood of Brexit on implied volatilities. The magnitude of the coefficients shows that on high attention days, a ten percent increase in the probability of Brexit was related to about a three percent increase in each of the implied volatility index.

Overall, the results based on polls data are qualitatively similar to those based on betting odds data. There was a negative (positive) association between stock returns (implied volatilities) 
and the projected chance of Brexit. Further, the information contained in polls data was not incorporated into markets when investor attention was low.

\subsubsection{Heteroskedasticity-based Approach}

Rigobon and Sack (2005) show that the response of stock returns to war risk can be identified using days with elevated variance caused by war news. We use the same approach to measure the effect of the public's belief about the probability of Brexit on stock indices. We designate the last 10 trading days (from June 10, 2016 to June 23, 2016) before the referendum vote as high variance days, and the previous 10 trading days (from May 26, 2016 to June 9, 2016) as low variance days. 46,47

Figure 3 shows the realized volatilities of the FTSE 100 index during the last 20 trading days before June 24, 2016. Prior to June 10, 2016, the market was quiet in terms of realized volatility. The market consensus was that the probability of Brexit would be very low. Thereafter, the volatility increased significantly and stayed at a high level as a new opinions poll revealed that the campaign to take Britain out of the EU had opened up a remarkable 10-point lead over the "Remain" camp on June 10, 2016. Within the 20 sample days, there were no other big events or important news, except those on the Brexit topic. Therefore, it is reasonable to assume that the increased variance in the financial markets over the last 10 trading days before the referendum vote was driven largely (if not exclusively) by the market's elevated attention on the probability of Brexit.

\section{[Insert Figure 3 about here]}

\footnotetext{
${ }^{46}$ In Rigobon and Sack (2005) there are 17 observations in the sample of high variance days.

${ }^{47}$ We obtain qualitatively similar results using the 20 and 30 trading days with the lowest realized volatilities of the FTSE 100 index during the sample period, as the low variance sample days.
} 
The relationship between stock returns and the Brexit's probability factor can be expressed in a reduced form model as:

$$
R=D Z+\varepsilon_{t}
$$

$R$ is a vector of asset returns, and

$$
\mathrm{D}=\left[\left(\begin{array}{ccc}
1 & \cdots & d_{1 m} \\
\vdots & \ddots & \vdots \\
d_{51} & \cdots & d_{5 m}
\end{array}\right)\right]
$$

where $d_{i j}$ represents the impact of the $\mathrm{j}^{\text {th }}$ factor on the $\mathrm{i}^{\text {th }}$ asset return. We use changes in the yield (bps) on the ten-year Gilt and log returns of the FTSE 100, CAC40, DAX and S\&P 500 indices in R. Assuming that the first factor of $\mathrm{Z}\left(z_{1}\right)$ is the Brexit's probability factor, the first column of $\mathrm{D}$ measures the effect of the likelihood of Brexit on all financial variables. After normalizing the impact of the Brexit factor on the bond $\left(d_{11}\right)$ to unity, we are interested in estimating $d_{21}, d_{31}$, $d_{41}$ and $d_{51}$, which capture the effect of the market's expectation about Brexit on the FTSE 100, CAC 40, DAX and S\&P 500, respectively.

The variance-covariance matrix can be modeled as:

$$
\Omega=D \Sigma_{Z} D^{\prime}+\Sigma_{\varepsilon}
$$

where $\Sigma_{Z}$ and $\Sigma_{\varepsilon}$ are the variance-covariance matrices of $\mathrm{Z}$ and $\varepsilon$, repectively. If the shift in the variance/covariance between high and low variance sample periods is caused solely by changes in the variance of the Brexit's probability factor, the changes in variance-covariance can be denoted as:

$$
\Delta \Omega=\lambda\left[\begin{array}{ccccc}
1 & d_{21} & d_{31} & d_{41} & d_{51} \\
d_{21} & d_{21}^{2} & d_{21} d_{31} & d_{21} d_{41} & d_{21} d_{51} \\
d_{31} & d_{21} d_{31} & d_{31}^{2} & d_{31} d_{41} & d_{31} d_{51} \\
d_{41} & d_{21} d_{41} & d_{31} d_{41} & d_{41}^{2} & d_{41} d_{51} \\
d_{51} & d_{21} d_{51} & d_{31} d_{51} & d_{41} d_{51} & d_{51}^{2}
\end{array}\right]
$$


where $\lambda$ is $\Delta \sigma^{2}\left(z_{1}\right)$. The five parameters $\left(\lambda, d_{21}, d_{31}, d_{41}\right.$ and $\left.d_{51}\right)$ can be estimated using the generalized method of moments (GMM). Since fifteen moment conditions can be used to estimate these five unknown parameters, we implement a standard test of overidentifying restrictions.

[Insert Table 8 about here]

We normalize the impact of the Brexit's probability factor on the first financial variable, the yield on the ten-year Gilt, to -1 . Table 8 shows that the FTSE 100, CAC 40, DAX and S\&P 500 indices tended to decrease $0.40 \%, 0.46 \%, 0.40 \%$ and $0.08 \%$, respectively, in response to an increase in the probability of Brexit that was able to depress the ten-year UK government bond yield by 1 bps. These results are quantitatively similar to our empirical findings based on betting odds data. ${ }^{48}$ The test of overidentifying restrictions indicates that our identification assumptions are not rejected.

\subsection{The effect of Article 50 of the Lisbon treaty on stock markets}

The UK referendum on EU membership result is merely "advisory' and is not legally binding. In theory, a parliamentary vote is needed before the British government can trigger Article 50 of the Lisbon treaty to launch the formal EU leaving process. ${ }^{49}$ After the trigger, Britain will have two years to negotiate its withdrawal from the EU. Thus, in the post-referendum period, the market's expectation about when or whether the UK will leave the EU, are directly related to the market's expectation about when Article 50 will be invoked.

\footnotetext{
${ }^{48}$ Based on Model (2), the cumulative slope coefficient estimate $\left(a_{1}+a_{2}\right)$ ratios between the ten-year Gilt yield (bps) and the FTSE 100, CAC 40, DAX and S\&P 500 during the last ten trading days before the referendum vote in percentage points were $0.32,0.42,037$ and 0.13 , respectively.

${ }^{49}$ On August 31, 2016 UK Prime Minister Theresa May's cabinet concluded that Article 50 can be invoked without a parliamentary vote. On January 24, 2017 the UK Supreme Court ruled that Brexit article 50 must be authorized by parliament. On February 8, 2017, Britain's lower house of parliament authorized Prime Minister Theresa May to begin the Brexit process, whereas the upper house of parliament voted to amend PM Theresa May's bill to trigger Brexit talks on March 1, 2017.
} 
In this section, we use betting odds regarding the probability that Article 50 will not be triggered in 2016, to test the effect of the expectation of the realization of Brexit on stock indices. Betting on Article 50 being triggered in 2016 was initiated on July 12, 2016 by Betfair. We obtain daily betting odds data from Betdata.io. The empirical results based on the model in (2) are presented in Table 9.

\section{[Insert Table 9 about here]}

As shown in Panel A of Table 9, there was a negative and statistically significant relation between stock prices and changes in the probability that Article 50 will be triggered in 2016. A 10 percent increase in the trigger probability was related to a $0.7 \%, 0.7 \%, 0.9 \%$ and $0.2 \%$ decrease in the FTSE 100, CAC 40, DAX and S\&P 500, respectively, the following day. ${ }^{50}$

Panel B of Table 9 reports the association between changes in the projected chance of Article 50 being triggered in 2016, and implied volatilities of the stock indices. These changes had strong impact on the VFTSE and the VDAX. A $10 \%$ increase in the trigger probability was related to a $7.6 \%$ increase in the FTSE 100 implied volatility index and a $2.9 \%$ increase in that of the DAX the next trading day. Although the probability of Article 50 being triggered in 2016 lacked significant explanatory power for the VCAC and the VIX, the signs of the coefficient estimates are as expected, the greater the chance that Article 50 would be triggered in 2016, the greater the level of stock market uncertainty. Overall, the results in Table 9 show that during the post referendum period, the market's expectation about the realization of Brexit is an influential factor for stock markets.

\footnotetext{
${ }^{50}$ The insignificant contemporaneous relationship may be caused by a slower response of the stock markets to changes in expectation, or the difference in closing time between the betting market and stock markets.
} 


\subsection{Conclusions}

The finance literature suggests that people with money at stake are good at predicting the outcome of events, from Federal Reserve actions to wars (Kuttner, 2001; Amihud and Wohl, 2004). Changes in their expectations constitute shocks that drive market movement. This paper studies the effect of changes in the public's projected chance of Brexit, as reflected in market determined betting odds, on financial markets. We find that the value of European and US stocks decreased when the probability of Brexit increased, with the association strengthening as the referendum day approached. The negative economic effect of a rise in the expectation of Britain's intention to leave the EU was not confined to the stock markets. The price of oil and the value of the British Pound were also depressed. On the other hand, the value of (seemingly) safer assets, i.e. gold, Government bonds, the U.S dollar, and the Japanese Yen, were positively related to the prospect of Brexit. Stock market uncertainty, measured by implied volatility, also increased with the likelihood of Brexit. However, all associations disappeared when investors had low exposure to news on the Brexit topic. This finding suggests that investor attention is crucial to the relation between the public's expectation about political events, and asset returns or market uncertainty. 
Table 1 Regression Results for Stock Indices

\begin{tabular}{|c|c|c|c|c|c|c|}
\hline & Intercept & $\Delta$ Brexit $_{\mathrm{t}}\left(a_{1}\right)$ & $\Delta$ Brexit $_{\mathrm{t}-1}\left(a_{2}\right)$ & $a_{1}+a_{2}$ & $\mathrm{~N}$ & $R^{2}$ \\
\hline \multicolumn{7}{|c|}{ Panel A: Basic Regression } \\
\hline FTSE100 & $0.05(0.10)$ & $-0.10(0.05)^{*}$ & & & 81 & 0.07 \\
\hline CAC40 & $0.00(0.13)$ & $-0.16(0.05)^{* * *}$ & & & 83 & 0.10 \\
\hline DAX & $0.09(0.13)$ & $-0.15(0.05) * * *$ & & & 82 & 0.09 \\
\hline S\&P500 & $-0.50(0.07)$ & $-0.05(0.02)^{*}$ & & & 83 & 0.03 \\
\hline \multicolumn{7}{|c|}{ Panel B: Regression with lags } \\
\hline FTSE100 & $0.02(0.10)$ & $-0.09(0.05)^{*}$ & $-0.05(0.04)$ & $-0.14(0.06)^{* *}$ & 80 & 0.09 \\
\hline CAC40 & $0.01(0.12)$ & $-0.15(0.05) * * *$ & $-0.07(0.05)$ & $-0.22(0.06) * * *$ & 82 & 0.12 \\
\hline DAX & $0.07(0.14)$ & $-0.15(0.05) * * *$ & $-0.02(0.04)$ & $-0.18(0.06)^{* * *}$ & 81 & 0.09 \\
\hline S\&P500 & $0.10(0.07)$ & $-0.04(0.02)^{*}$ & $-0.05(0.02)^{* *}$ & $-0.09(0.03) * * *$ & 82 & 0.06 \\
\hline
\end{tabular}

Panel A reports results of the following model:

Panel B reports results of the following models:

$$
R_{t}=a_{0}+a_{1} \Delta \text { Brexit }_{\mathrm{t}}+e_{t} .
$$

$$
R_{t}=a_{0}+a_{1} \Delta \text { Brexit }_{\mathrm{t}}+a_{2} \Delta \text { Brexit }_{\mathrm{t}-1}+e_{t},
$$

where $R_{t}$ is the daily returns of each stock index (i.e. the FTSE100, CAC40, DAX and S\&P500). $\Delta$ Brexit $_{\mathrm{t}}$ is the first difference of Leave betting odds, and $\Delta$ Brexit $_{\mathrm{t}-1}$ is its one-day lagged value. The regressions are estimated using OLS with the White (1980) heteroskedasticity consistent covariance matrix. Standard errors are shown in parentheses. *, **, *** indicate statistical significance at the $10 \%$, 5\%, and 1\% level, respectively. The sample period is from February 26, 2016 to June 23, 2016. 
Table 2 Regression Results for Implied Volatilities

\begin{tabular}{lllllll}
\hline \hline & Intercept & $\Delta$ Brexit $_{\mathrm{t}}\left(a_{1}\right)$ & $\Delta$ Brexit $_{\mathrm{t}-1}\left(a_{2}\right)$ & $a_{1}+a_{2}$ & $\mathrm{~N}$ & $R^{2}$ \\
\hline FTSE 100 & 0.34 & 0.52 & 0.27 & 0.79 & 80 & 0.05 \\
& $(0.75)$ & $(0.29)^{*}$ & $(0.31)$ & $(0.40)^{* *}$ & & \\
CAC 40 & 0.14 & 0.70 & 0.52 & 1.22 & 82 & 0.14 \\
& $(0.60)$ & $(0.30)^{* *}$ & $(0.26)^{*}$ & $(0.41)^{* * *}$ & & \\
DAX & 0.21 & 0.61 & 0.30 & 0.92 & 81 & 0.09 \\
& $(0.61)$ & $(0.25)^{* *}$ & $(0.26)$ & $(0.34)^{* * *}$ & & \\
S\&P 500 & 0.03 & 0.74 & 0.50 & 1.21 & 82 & 0.12 \\
& $(0.68)$ & $(0.35)^{* *}$ & $(0.28)^{*}$ & $(0.49)^{* *}$ & & \\
\hline \hline
\end{tabular}

This table reports results of the following model:

$$
\Delta I V=a_{0}+a_{1} \Delta \text { Brexit }_{\mathrm{t}}+a_{2} \Delta \text { Brexit }_{\mathrm{t}-1}+e_{t}
$$

where $\triangle I V$ is the daily change in the implied volatility of each of the four stock indices (i.e. the FTSE100, CAC40, DAX and S\&P500). $\Delta$ Brexit $_{t}$ is the first difference of Leave betting odds, and $\Delta$ Brexit $_{t-1}$ is its one-day lagged value. The regressions are estimated using OLS with the White (1980) heteroskedasticity consistent covariance matrix. Standard errors are shown in parentheses. *, **, *** indicate statistical significance at the $10 \%, 5 \%$, and $1 \%$ level, respectively. The sample period is from February 26, 2016 to June 23, 2016. 
Table 3 Regression results for daily disaggregated stock returns

Intercept $\left(\mathrm{a}_{0}\right)$

$-0.68(0.18)^{* * *}$

$\beta^{V I X}$

$0.14(0.04)^{* * *}$

Sector dummies

Utilities

$1.98(0.25)^{* * *}$

Construction

$0.00(0.45)$

Manufacturing

$0.73(0.19)^{* * *}$

Wholesale Trade

$0.74(0.30)^{* *}$

Retail Trade

$0.64(0.23)^{* * * *}$

Transportation and Warehousing

$0.44(0.28)$

Information

$0.85(0.23) * * *$

Finance and Insurance

$0.24(0.21)$

Real Estate Rental and Leasing

$0.71(0.28)^{* *}$

Professional, Scientific, and Technical Services

$0.65(0.29)^{* *}$

Management of Companies and Enterprises

$0.79(0.95)$

Administrative and Support and Waste Management and Remediation Services

$0.53(0.28)^{*}$

Health Care and Social Assistance

$0.16(0.42)$

Arts, Entertainment, and Recreation

$1.75(0.94)^{*}$

Accommodation and Food Services

$1.16(0.36)^{* * * *}$

Other

$1.16(0.37)^{* * *}$

$\mathrm{N}$

500

$R^{2}$

0.17

The table reports estimates for the following regression model:

$\beta_{i}^{\text {Brexit }}=\alpha_{0}+\alpha_{1} \beta_{i}^{V I X}+\sum_{\text {sectors }} \alpha_{\text {Industries }} D_{\text {industries }}+\varepsilon_{i}$,

where is $\beta_{i}^{\text {Brexit }}$ is the sum of $a_{1}$ and $a_{2}$ in Model (2) estimated respectively for each firm i. $\beta_{i}^{V I X}$ is firm i's reaction to VIX changes. Both $\beta_{i}^{\text {Brexit }}$ and $\beta_{i}^{V I X}$ are normalized using their sample means and standard deviations. The sample period for regression is from February 26, 2016 to June 23, 2016. The regressions are estimated using OLS with the White (1980) heteroskedasticity consistent covariance matrix. Standard errors are shown in parentheses. $*, * *, * * *$ indicate statistical significance at the $10 \%$, $5 \%$, and $1 \%$ level, respectively. 
Table 4 Regression results for Post-referendum Returns

\begin{tabular}{llllllll}
\hline \hline & $6 / 24$ & $6 / 27$ & $6 / 28$ & $6 / 29$ & $6 / 30$ & $7 / 1$ & $6 / 24-7 / 1$ \\
\hline Intercept $\left(\mathrm{a}_{0}\right)$ & -3.68 & -2.67 & 3.59 & 1.93 & 0.25 & 1.84 & -0.26 \\
& $(0.50)^{* * *}$ & $(0.48)^{* * *}$ & $(0.52)^{* * *}$ & $(0.44)^{* * *}$ & $(0.40)$ & $(0.46)^{* * *}$ & $(0.83)$ \\
$\beta^{\text {Brexit }}$ & 1.22 & 1.15 & -0.46 & -0.34 & 0.00 & -0.11 & 1.45 \\
& $(0.22)^{* * *}$ & $(0.18)^{* * *}$ & $(0.17)^{* * *}$ & $(0.11)^{* * *}$ & $(0.10)$ & $(0.15)$ & $(0.35)^{* * *}$ \\
Industry Effect & Yes & Yes & Yes & Yes & Yes & Yes & Yes \\
$\mathrm{N}$ & 499 & 499 & 499 & 499 & 499 & 496 & 496 \\
$R^{2}$ & 0.35 & 0.35 & 0.19 & 0.16 & 0.12 & 0.11 & 0.25 \\
\hline \hline
\end{tabular}

The table reports estimates for the following regression model:

$R_{i t}=\alpha_{0}+\alpha_{1} \beta_{i}^{\text {Brexit }}+\sum_{\text {sectors }} \alpha_{\text {Industries }} D_{\text {industries }}+\varepsilon_{i}$,

where $R_{i t}$ is the S\&P 500 component stock i return on day $\mathrm{t}$ in 2016. $\beta_{i}^{\text {Brexit }}$ is the sum of $a_{1}$ and $a_{2}$ in Model (2) estimated respectively for each firm i, $\beta_{i}^{\text {Brexit }}$ is normalized using their sample means and standard deviations. The regressions are estimated using OLS with the White (1980) heteroskedasticity consistent covariance matrix. Standard errors are shown in parentheses. *, **, *** indicate statistical significance at the $10 \%, 5 \%$, and $1 \%$ level, respectively. 
Table 5 Regression Results for Commodity, Bond and FX markets

\begin{tabular}{|c|c|c|c|c|c|c|}
\hline & Intercept & $\Delta$ Brexit $_{\mathrm{t}}\left(a_{1}\right)$ & $\Delta$ Brexit $_{\mathrm{t}-1}\left(a_{2}\right)$ & $a_{1}+a_{2}$ & $\mathrm{~N}$ & $R^{2}$ \\
\hline \multicolumn{7}{|l|}{ Panel A. FX Markets } \\
\hline Dollar Index & $\begin{array}{l}-0.03 \\
(0.05)\end{array}$ & $\begin{array}{l}0.02 \\
(0.01)^{* * *}\end{array}$ & $\begin{array}{l}0.02 \\
(0.02)\end{array}$ & $\begin{array}{l}0.04 \\
(0.02)^{* *}\end{array}$ & 83 & 0.03 \\
\hline GBP/USD & $\begin{array}{l}0.06 \\
(0.06)\end{array}$ & $\begin{array}{l}-0.12 \\
(0.03) * * *\end{array}$ & $\begin{array}{l}-0.04 \\
(0.03)\end{array}$ & $\begin{array}{l}-0.16 \\
(0.05)^{* * *}\end{array}$ & 84 & 0.24 \\
\hline GBP/JPY & $\begin{array}{l}-0.04 \\
(0.10)\end{array}$ & $\begin{array}{l}-0.15 \\
(0.04)^{* * * *}\end{array}$ & $\begin{array}{l}-0.10 \\
(0.04)^{* *}\end{array}$ & $\begin{array}{l}-0.24 \\
(0.06)^{* * *}\end{array}$ & 84 & 0.19 \\
\hline $\mathrm{GBP} / \mathrm{CHF}$ & $\begin{array}{l}0.01 \\
(0.07)\end{array}$ & $\begin{array}{l}-0.13 \\
(0.04) * * *\end{array}$ & $\begin{array}{l}-0.05 \\
(0.03)\end{array}$ & $\begin{array}{l}-0.18 \\
(0.05) * * *\end{array}$ & 84 & 0.25 \\
\hline \multicolumn{7}{|c|}{ Panel B. Government Bond Yields } \\
\hline UK 10Y & $\begin{array}{l}-0.12 \\
(0.44)\end{array}$ & $\begin{array}{l}-0.34 \\
(0.19) *\end{array}$ & $\begin{array}{l}-0.52 \\
(0.15) * * *\end{array}$ & $\begin{array}{l}-0.86 \\
(0.24)^{* * *}\end{array}$ & 80 & 0.14 \\
\hline EURO 10Y & $\begin{array}{l}-0.12 \\
(0.33)\end{array}$ & $\begin{array}{l}-0.21 \\
(0.10)^{* *}\end{array}$ & $\begin{array}{l}-0.18 \\
(0.10)^{*}\end{array}$ & $\begin{array}{l}-0.39 \\
(0.13) * * *\end{array}$ & 84 & 0.05 \\
\hline US $10 Y$ & $\begin{array}{l}-0.12 \\
(0.43)\end{array}$ & $\begin{array}{l}-0.31 \\
(0.12)^{* *}\end{array}$ & $\begin{array}{l}-0.31 \\
(0.14)^{* *}\end{array}$ & $\begin{array}{l}-0.62 \\
(0.17) * * *\end{array}$ & 82 & 0.08 \\
\hline \multicolumn{7}{|l|}{ Panel C. Commodity Markets } \\
\hline Brent Crude Oil & $\begin{array}{l}0.43 \\
(0.26)\end{array}$ & $\begin{array}{l}-0.08 \\
(0.08)\end{array}$ & $\begin{array}{l}-0.03 \\
(0.09)\end{array}$ & $-0.11(0.10)$ & 83 & 0.01 \\
\hline Bloomberg Commodity Index & $\begin{array}{l}0.19 \\
(0.11)\end{array}$ & $\begin{array}{l}0.00 \\
(0.03)\end{array}$ & $\begin{array}{l}0.01 \\
(0.05)\end{array}$ & $0.02(0.05)$ & 82 & 0.00 \\
\hline Gold & $\begin{array}{l}0.05 \\
(0.11) \\
\end{array}$ & $\begin{array}{l}0.09 \\
(0.03) * * *\end{array}$ & $\begin{array}{l}-0.02 \\
(0.04) \\
\end{array}$ & $0.07(0.05)$ & 77 & 0.05 \\
\hline
\end{tabular}

This table reports results of the following model:

$$
R_{t}=a_{0}+a_{1} \Delta \text { Brexit }_{\mathrm{t}}+a_{2} \Delta \text { Brexit }_{\mathrm{t}-1}+e_{t}
$$

where $R_{t}$ is the daily returns of commodities and exchange rates in percentage points, and first difference of government bond yields in basis points. $\Delta$ Brexit $_{t}$ is the first difference of Leave betting odds, and $\Delta$ Brexit $_{\mathrm{t}-1}$ is its one-day lagged value. The regressions are estimated using OLS with the White (1980) heteroskedasticity consistent covariance matrix. Standard errors are shown in parentheses. *, **, *** indicate statistical significance at the $10 \%, 5 \%$, and $1 \%$ level, respectively. The sample period is from February 26 , 2016 to June 23, 2016. 
Table 6 Regression Results for Financial Assets Returns and Implied Volatilities with an Attention Dummy (Betting Odds Data)

\begin{tabular}{lccccc}
\hline \hline & Intercept & $\Delta$ Brexit $_{\mathrm{t}} D_{t}^{H}$ & $\Delta$ Brexit $_{t}\left(1-D_{t}^{H}\right)$ & $\mathrm{N}$ & $R^{2}$ \\
\hline Panel A. Returns & & & & & \\
\hline FTSE100 & $0.04(0.09)$ & $-0.16(0.05)^{* * *}$ & $0.05(0.09)$ & 81 & 0.14 \\
CAC40 & $0.03(0.12)$ & $-0.22(0.05)^{* * *}$ & $0.00(0.11)$ & 83 & 0.15 \\
DAX & $0.09(0.13)$ & $-0.23(0.06)^{* * *}$ & $0.01(0.10)$ & 82 & 0.13 \\
S\&P500 & $0.09(0.07)$ & $-0.06(0.02)^{* * *}$ & $0.00(0.07)$ & 83 & 0.04 \\
\hline \multicolumn{7}{l}{ Panel B. Implied Volatilities } & & & & \\
\hline FTSE100 & $0.23(0.74)$ & $0.78(0.25)^{* * *}$ & $0.00(0.83)$ & 81 & 0.05 \\
CAC40 & $0.04(0.62)$ & $0.85(0.22)^{* * *}$ & $0.53(0.96)$ & 83 & 0.10 \\
DAX & $0.13(0.59)$ & $0.98(0.25)^{* * *}$ & $-0.10(0.68)$ & 82 & 0.12 \\
S\&P500 & $0.04(0.68)$ & $0.85(0.41)^{* *}$ & $0.68(0.88)$ & 83 & 0.09 \\
\hline \hline
\end{tabular}

Panel A reports results of the following model:

and Panel B reports results of the following model:

$$
R_{t}=a_{0}+a_{1} \Delta \text { Brexit }_{t} D_{t}^{H}+a_{2} \Delta \text { Brexit }_{t}\left(1-D_{t}^{H}\right)+e_{t}
$$

$$
\Delta I V_{t}=a_{0}+a_{1} \Delta \text { Brexit }_{\mathrm{t}} D_{t}^{H}+a_{2} \Delta \text { Brexit }_{\mathrm{t}}\left(1-D_{t}^{H}\right)+e_{t}
$$

where $R_{t}$ is the daily returns of financial assets, $\Delta I V_{t}$ is the daily change in the implied volatility of each of the four stock indices (i.e. the FTSE100, CAC40, DAX and S\&P500). $\Delta$ Brexit $_{\mathrm{t}}$ is the first difference of Leave betting odds, and $\Delta$ Brexit $_{\mathrm{t}-1}$ is its one-day lagged value. $D^{H}$ is a dummy variable equal to one when the number of news about Brexit from Bloomberg is above the sample median and zero otherwise. The regressions are estimated using OLS with the White (1980) heteroskedasticity consistent covariance matrix. Standard errors are shown in parentheses. $*, * *, * * *$ indicate statistical significance at the $10 \%, 5 \%$, and $1 \%$ level, respectively. The sample period is from February 26, 2016 to June 23, 2016. 
Table 7 Regression Results for Financial Assets Returns and Implied Volatilities interacting with Attention Dummy (Polls Data)

\begin{tabular}{lccccc}
\hline \hline & Intercept & $\Delta$ Brexit $_{t-1}^{P} D_{t}^{H}$ & $\Delta$ Brexit $_{t-1}^{P}\left(1-D_{t}^{H}\right)$ & $\mathrm{N}$ & $R^{2}$ \\
\hline Panel A. Returns & & & & & \\
\hline FTSE100 & $0.14(0.20)$ & $-0.10(0.02)^{* * *}$ & $0.01(0.05)$ & 54 & 0.15 \\
CAC40 & $0.20(0.20)$ & $-0.11(0.03)^{* * *}$ & $0.02(0.06)$ & 55 & 0.11 \\
DAX & $0.29(0.21)$ & $-0.12(0.03)^{* * *}$ & $-0.03(0.07)$ & 54 & 0.12 \\
S\&P500 & $0.22(0.10)$ & $-0.05(0.02)^{*}$ & $-0.01(0.06)$ & 53 & 0.07 \\
\hline Panel B. Implied Volatilities & & & & \\
\hline FTSE100 & $0.26(0.98)$ & $0.32(0.28)^{*}$ & $-0.03(0.30)$ & 54 & 0.04 \\
CAC40 & $-0.24(0.90)$ & $0.31(0.16)^{* *}$ & $0.01(0.24)$ & 55 & 0.04 \\
DAX & $-0.09(0.83)$ & $0.44(0.12)^{* * *}$ & $0.05(0.23)$ & 54 & 0.09 \\
S\&P500 & $0.21(0.91)$ & $0.24(0.14)^{*}$ & $-0.02(0.31)$ & 53 & 0.03 \\
\hline \hline
\end{tabular}

Panel A reports results of the following model:

$$
R_{t}=a_{1}+\left(b_{1} \Delta \text { Brexit }_{t-1}^{P}\right) D_{t}^{H}+\left(b_{2} \Delta \text { Brexit }_{t-1}^{P}\right)\left(1-D_{t}^{H}\right)+\varepsilon_{t}
$$

and Panel B reports results of the following model:

$$
\Delta I V_{t}=a_{1}+\left(b_{1} \Delta \text { Brexit }_{t-1}^{P}\right) D_{t}^{H}+\left(b_{2} \Delta \text { Brexit }_{t-1}^{P}\right)\left(1-D_{t}^{H}\right)+\varepsilon_{t}
$$

where $R_{t}$ is the daily returns of financial assets, $\Delta I V_{t}$ is the daily change in the implied volatility of each of the four stock indices (i.e. the FTSE100, CAC40, DAX and S\&P500). $\Delta$ Brexit $_{\mathrm{t}}$ is the first difference of Leave betting odds, and $\Delta$ Brexit $_{\mathrm{t}-1}$ is its one-day lagged value. $D^{H}$ is a dummy variable equal to one when the number of news about Brexit from Bloomberg is above the sample median and zero, otherwise. The regressions are estimated using OLS with the White (1980) heteroskedasticity consistent covariance matrix. Standard errors are shown in parentheses. *, **, *** indicate statistical significance at the $10 \%, 5 \%$, and $1 \%$ level, respectively. The sample period is from February 26, 2016 to June 23, 2016. 
Table 8 Estimated Impact of Increase in the Probability of Brexit (Normalized to cause a 1 basis point drop in 10-year Gilt yield)

\begin{tabular}{lllll}
\hline \hline & FTSE 100 & CAC 40 & DAX & S\&P 500 \\
\hline Market response $(\beta)$ & -0.40 & -0.46 & -0.40 & -0.08 \\
$\lambda$ & $(0.06)^{* * *}$ & $(0.08)^{* * *}$ & $(0.10)^{* * *}$ & $(0.03)^{* * *}$ \\
$\lambda$ & \multicolumn{2}{c}{$15.26(5.01)^{* *}$} \\
Test of overidentifying restrictions & \multicolumn{2}{c}{0.8356} \\
\hline \hline
\end{tabular}

This table reports the change in each of the stock indices caused by a rise in the probability of Brexit that was large enough to cause a one basis point drop in the 10-year UK Gilt yield. The high stock variance sample is from June 10, 2016 to June 23, 2016 and the low stock variance sample is from May 27, 2016 to June 9, 2016. Standard errors are shown in parentheses. $p$-values are shown for the test of overidentifying restrictions. *,**,*** indicate statistical significance at the $10 \%, 5 \%$, and $1 \%$ level, respectively. 
Table 9 Regression Results for the Post Referendum Period

\begin{tabular}{lccccc}
\hline \hline & Intercept & $\Delta \mathrm{A} 50_{\mathrm{t}}\left(a_{1}\right)$ & $\Delta \mathrm{A}_{\mathrm{t}-1}\left(a_{2}\right)$ & $\mathrm{N}$ & $R^{2}$ \\
\hline Panel A. Returns & & & & & \\
\hline FTSE100 & $0.00(0.09)$ & $-0.03(0.02)$ & $-0.07(0.02)^{* * *}$ & 40 & 0.14 \\
CAC40 & $0.06(0.12)$ & $-0.02(0.04)$ & $-0.07(0.03)^{* *}$ & 40 & 0.09 \\
DAX & $0.12(0.13)$ & $-0.03(0.04)$ & $-0.09(0.03)^{* * *}$ & 40 & 0.13 \\
S\&P500 & $0.02(0.05)$ & $-0.00(0.01)$ & $-0.02(0.01)^{* *}$ & 39 & 0.06 \\
\hline Panel B. Implied Volatilities & & & & \\
\hline FTSE100 & $-0.30(1.09)$ & $-0.23(0.42)$ & $0.76(0.35)^{* *}$ & 40 & 0.15 \\
CAC40 & $-0.11(0.76)$ & $0.23(0.15)$ & $0.26(0.17)$ & 40 & 0.04 \\
DAX & $-0.22(0.72)$ & $0.21(0.14)$ & $0.29(0.14)^{*}$ & 40 & 0.05 \\
S\&P500 & $-0.15(0.76)$ & $0.03(0.14)$ & $0.09(0.12)$ & 39 & 0.00 \\
\hline \hline
\end{tabular}

This table reports results of the following model:

$$
R_{t}=a_{0}+a_{1} \Delta \mathrm{A} 50_{\mathrm{t}}+a_{2} \Delta \mathrm{A} 50_{\mathrm{t}-1}+e_{t}
$$

where $R_{t}$ is the daily returns of the four stock indices (i.e. the FTSE100, CAC40, DAX and S\&P500).. $\triangle \mathrm{A} 50_{\mathrm{t}}$ is the first difference of betting odds of the selection that the British government will not trigger Article 50 of the Lisbon treaty in 2016 and $\Delta \mathrm{A}^{2} 0_{\mathrm{t}-1}$ is its one-day lagged value. The regressions are estimated using OLS with the White (1980) heteroskedasticity consistent covariance matrix. Standard errors are shown in parentheses. *, **, *** indicate statistical significance at the $10 \%, 5 \%$, and $1 \%$ level, respectively. The sample period is from February 26, 2016 to June 23, 2016. 
Figure 1 The Probability of Brexit vs. the Level of the Stock Indices
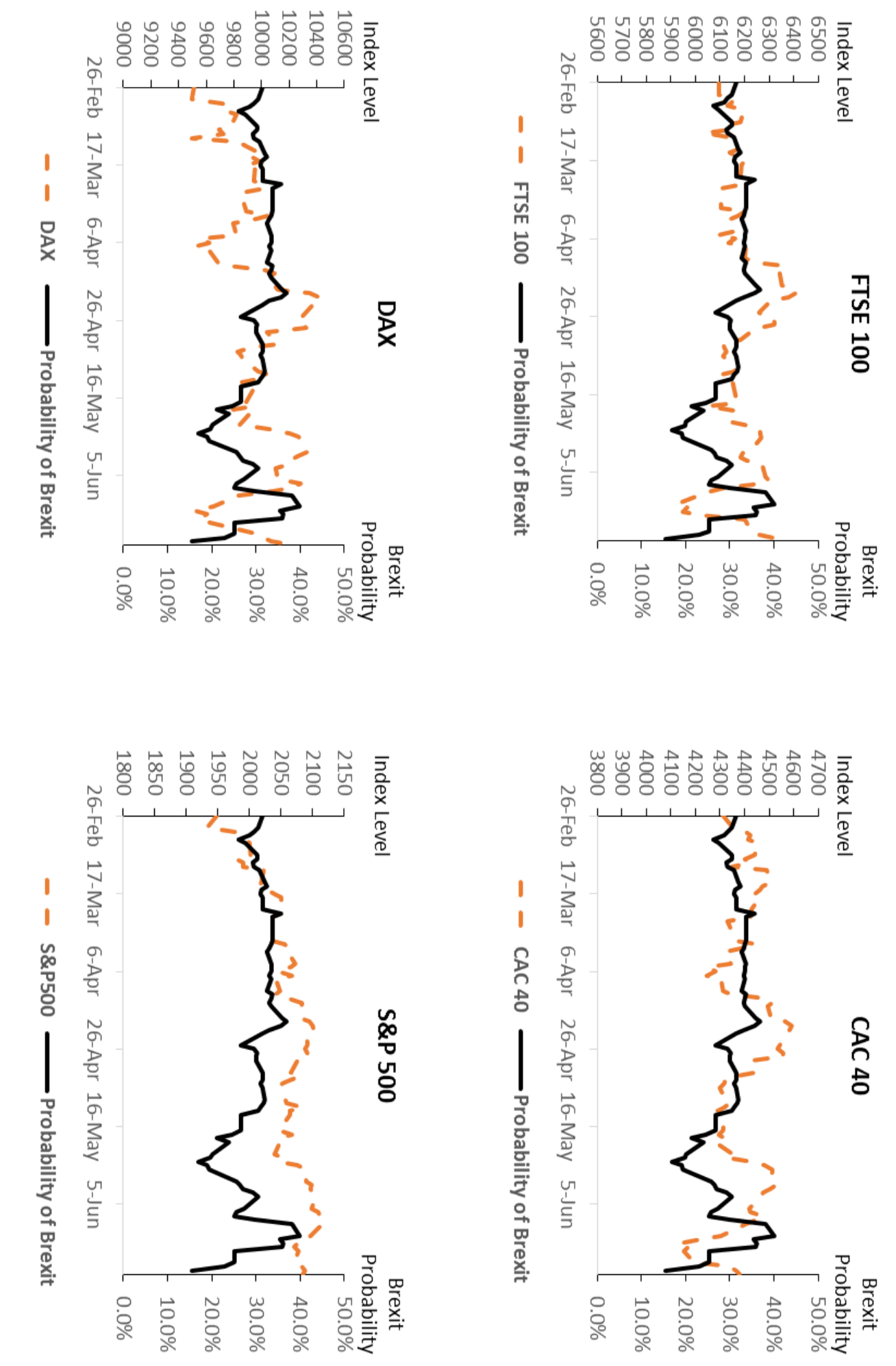

This figure plots the level of the stock indices vs. the probability of Brexit implied from betting odds over time. The sample period is from February 26, 2016 to June 23, 2016. 
Figure 2 Sensitivity of the Slope Coefficient to Sample Period Length
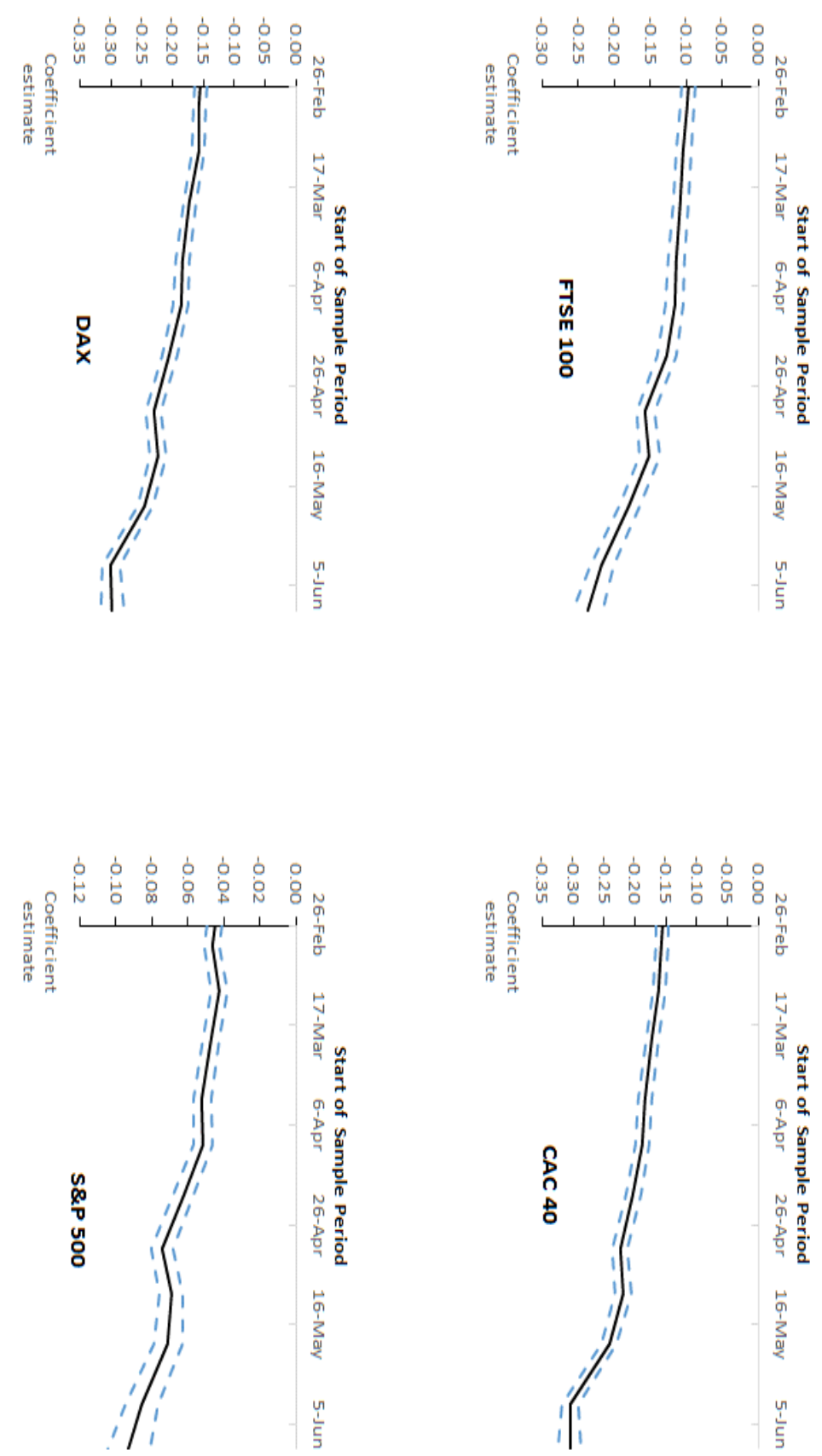

This figure plots the slope coefficient estimates from the OLS regression of stock returns on changes in the probability of Brexit implied from betting odds data. The dashed lines represent $90 \%$ confidence interval. The sample period is from February 26, 2016 to June 23, 2016. 
Figure 3 Daily Realized Volatility of FTSE 100

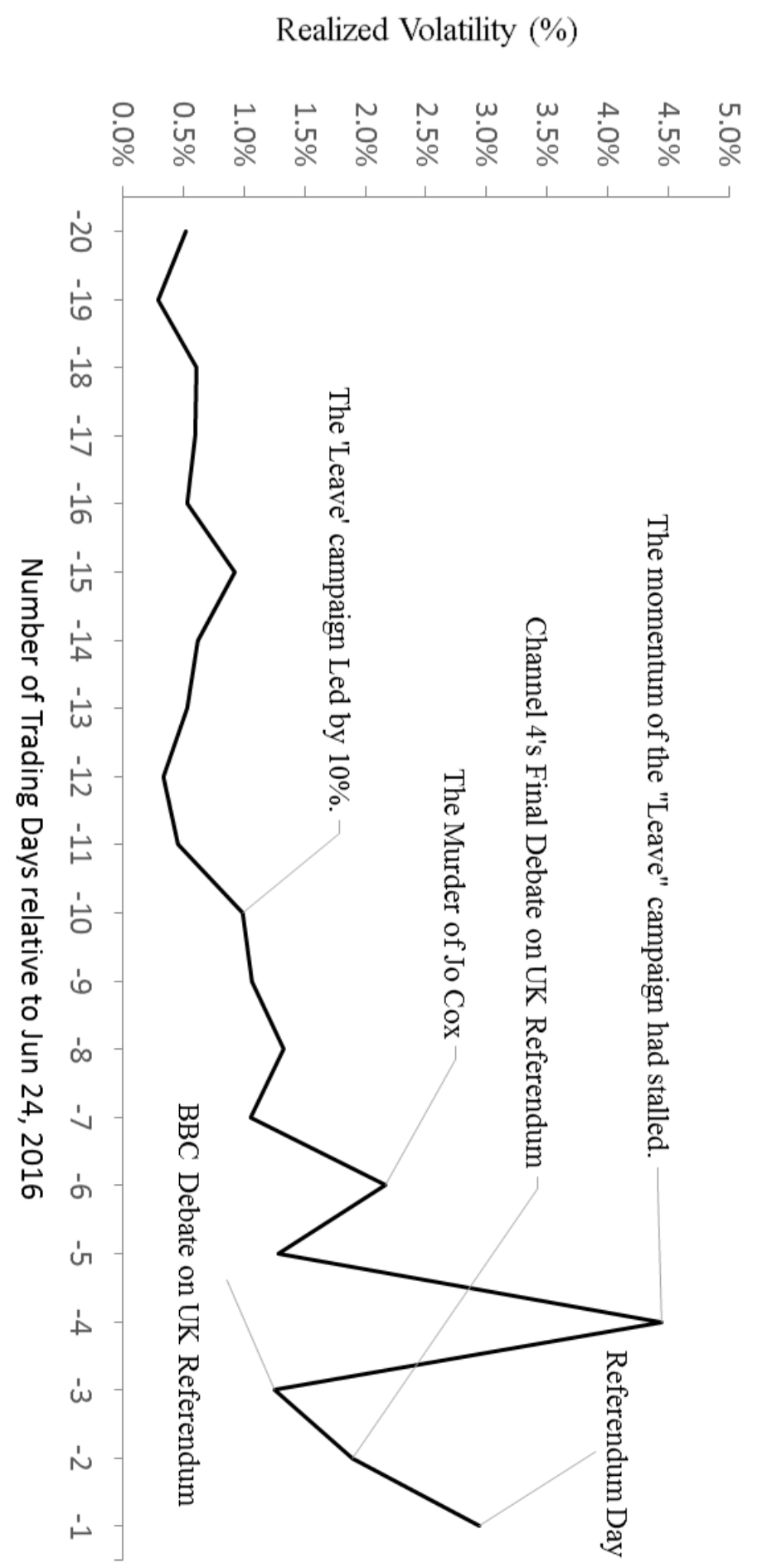

This figure plots the daily realized volatility of the FTSE 100 with important events highlighted during the last 20 trading days before June 24, 2016, the day of the referendum. 


\section{Chapter 3: Informational Role of Social Media: Evidence from Twitter Sentiment ${ }^{51}$}

\subsection{Introduction}

In recent decades, social media, such as Facebook and Twitter, has become a powerful and popular tool in our everyday lives. In financial world, individual investors increasingly rely on information on social media when making trading decisions. For example, on December 6, 2016, Boeing's stock price dipped about $1 \%$ following an early morning tweet from the U.S. President-elect Donald Trump claiming that the cost of new Air Force One planes would exceed $\$ 4$ billion. Calling those costs "out of control," Trump threatened to cancel the order. However, the value of messages on social media platforms is still debatable. Skeptics may argue that Mr. Trump's tweets are a special case. Unlike traditional business column writers and financial analysts, who may have access to new relevant information, most individual social media users are uninformed. Their tweets may be driven by rumors and contain more noise than information relevant for predicting stock price movements. On the other hand, an increasing number of firms adopt social media to communicate with investors and customers. Since April 2013, the SEC has allowed public firms to disclose important news, such as quarterly earnings announcements, to the public via tweeting. At the same time, more and more top investors (for example, Warren Buffett, Carl Icahn, etc.) have also started to use social media to communicate with their thousands of followers.

The aim of this paper is to provide insights into the effect of social media on stock returns and, as a consequence, enhance our understanding of how social media can best be employed as

\footnotetext{
${ }^{51}$ This essay is based on a paper coauthored with Alexander Kurov.
} 
part of an investment strategy. Bollen, Mao and Zheng (2011) provide evidence that the public mood extracted from Twitter feeds predicts daily aggregate stock returns. However, we still know little about how individual stock prices react to firm-specific Twitter sentiment. Our study attempts to shed new light on this issue.

The main challenge faced by researchers who investigate the impact of firm-level Twitter sentiment on financial markets is that discovering and textually analyzing all relevant tweets is difficult, if not impossible. Existing studies mainly investigate tweets around a specific event and perform textual analysis using existing word classifications. Although straightforward, lexiconbased methodologies are subject to significant measurement errors (Loughran and McDonald, 2011). This is especially true for analysis of posts on social media. The content of Twitter messages is likely to be quite different from that of newspapers and corporate documents. Machine learning algorithms trained to imitate linguistics experts in processing textual information are used to digest news on Wall Street trading floors.

This study innovatively uses Bloomberg's firm-specific Twitter sentiment data, which is calculated using tweets from the overall Twitter and StockTwits that Bloomberg classifies as being about a given company. ${ }^{52}$ Bloomberg uses supervised machine learning methodologies that, for example, identifies financial tweets about Apple, determines if the tweet is positive, negative or neutral, and assigns it a confidence score. A firm's daily Twitter sentiment is derived from its weighted average confidence scores in the last 24 hours. The sentiment values are released every morning before the stock market's open. Using Bloomberg's Twitter sentiment data allows us to contribute to the literature on the informational content of Twitter messages without doing

\footnotetext{
${ }^{52}$ StockTwits is a communications platform for the financial and investing community. Today, more than 300,000 investors, market professionals and public companies share information and ideas about the market and individual stocks using StockTwits, producing messages that are viewed by an audience of over 40 million.
} 
daunting and subjective textual analysis of tweet content. This makes it feasible to examine the predictive content of Twitter sentiment for a large number of individual firms over a long sample period. In addition, using Bloomberg's Twitter sentiment makes our study replicable and transparent.

Using Fama-MacBeth type regression, we find that high sentiment predicts high abnormal stock returns. The result is not subsumed by traditional return predictors such as past returns, abnormal volume and volatility, also is not impacted by news sentiment, whose return predictability has been widely documented in the previous literature (e.g., Tetlock, SaarTsechansky and Macskassy, 2008). On average, returns of firms with the most positive sentiment are $0.27 \%$ higher than returns of firms with the most negative sentiment over the next 24 hours. A simple daily long-short strategy using Twitter sentiment would have earned a large annualized Sharpe ratio of 3.17 and an average annual excess return of about 22 percent.

Existing studies have separately examined the ability of sentiment extracted from news stories and Twitter sentiment to forecast stock returns. However, to the best of our knowledge, no study has looked at the two types of sentiment together. It is important to control for news sentiment when testing the predictive ability of Twitter sentiment. Estimating predictive regressions with both news sentiment and Twitter sentiment allows us to examine whether sentiment extracted from social media content provides incremental predictive power for future stock returns relative to that contained in news sentiment. We find that the predictive content of Twitter sentiment for stock returns is not subsumed by news sentiment. This suggests that social media reveals information useful to traders.

Our results for stock returns may be explained by two possible mechanisms. One mechanism is that Twitter sentiment temporarily shifts the demand for stock, even if the Twitter 
sentiment is not informative. In this scenario, high Twitter sentiment produces a short term increase and a later reversal in stock prices. The other mechanism is that Twitter sentiment conveys valuable private signals about prospects of the firms. In this case, Twitter sentiment should have a long term impact on stock prices. Therefore, a possible way to distinguish the first mechanism from the second is to test for return reversals over longer horizons. We find that abnormal stock returns associated with Twitter sentiment are not subsequently reversed. This finding suggests that Twitter sentiment is not a variable that simply reflects sentiment of uninformed traders. Instead, Twitter sentiment contains relevant private information that is incorporated into stock prices with one day delay.

In further analysis, we examine possible sources of the return predictability with Twitter sentiment. Existing literature in this area mainly focuses on specific events. For example, Bartov, Faurel and Mohanram (2017) examine Twitter sentiment around quarterly earnings announcements. In this study, we focus on the informational role of Twitter sentiment by looking at four value relevant events: analyst recommendation releases, initial public offerings (IPOs), analyst target price changes and quarterly earnings announcements. Three sets of findings are documented. First, we find that high Twitter sentiment predicts analyst recommendation upgrades, target price increases and higher firm earnings. Second, we find that the pre-event Twitter sentiment forecasts announcement returns. This indicates that the information contained in Twitter sentiment is not fully reflected in stock prices before these public announcements. Finally, we find that pre-IPO Twitter sentiment is positively related to IPO underpricing. Together these findings show that messages posted on social media contains new information about firm fundamentals. This information drives the return predictability with Twitter sentiment. 
Existing literature on Twitter sentiment can be divided into two strands. The first strand analyzes tweets that discuss broad stock markets (Bollen, Mao and Zheng, 2011; Mao, Counts and Bollen, 2015). The second strand examines the informational role of Twitter sentiment around specific events. For example, Bartov et al. (2017) show that tweets contain information about forthcoming quarterly earnings. Azar and Lo (2016) focus on the Federal Open Market Committee (FOMC) announcements. They show that the content of tweets predicts returns on the FOMC announcement days. In contrast to these studies, we examine the general effect of firm-level Twitter sentiment on stock prices. In our analysis of informational events, we show that, in addition to the information about quarterly earnings, Twitter sentiment contains information about changes in analyst recommendations, target price changes and IPO first opening prices.

The paper proceeds as follows. Section 3.2 provides a review of the related literature. Section 3.3 introduces the key variables. Section 3.4 examines the predictive content of Twitter sentiment for individual stock returns. Section 3.5 investigates potential sources of return predictability. Section 3.6 concludes the paper.

\subsection{Investor Sentiment and Stock Returns}

A large literature examines the effect of investor sentiment on security returns. This literature generally considers sentiment to be a driver of irrational noise trading. For example, Baker and Wurgler (2006) find that difficult-to-arbitrage stocks tend to be more severely mispriced when the market-wide investor sentiment is high. Coreli, Goldreich and Ljungqvist (2006) report evidence of long-run returns reversals for IPO stocks when small investors are overoptimistic before the issue date. The role of investor sentiment in the stock market is difficult to analyze because sentiment is hard to measure. Baker and Wurgler (2006) propose a sentiment proxy constructed 
from historical stock market data and macroeconomic variables. Da, Engelberg and Gao (2015) measure market-wide sentiment using Internet search activity data. Survey-based sentiment measures, such as the University of Michigan Consumer Sentiment and the American Association of Individual Investors (AAII) investor sentiment, are also widely used (e.g., Kurov, 2010; Stambaugh, Yu and Yang, 2012). Survey-based sentiment measures are typically available at low frequencies (weekly or monthly), which limits researchers' ability to analyze the impact of sentiment on daily returns and market activity.

Due to rapid development in textual analysis techniques, a growing literature attempts to directly measure investor sentiment by analyzing the communications of those who are commenting on stocks. One traditional source of such comments is the news media. For example, Tetlock (2007) finds that sentiment extracted from negative words in a column of the Wall Street Journal predicts broad stock market movements. These returns are fully reversed within one week suggesting that market-level news sentiment influences the demand of uninformed traders. In a follow up paper, Tetlock et al. (2008) extend the analysis to stock-specific news sentiment and find that the news sentiment contains information about firms' upcoming quarterly earnings. Garcia (2013) finds that sentiment extracted from financial news stories is a useful predictor of the overall stock market returns and trading activity. The predictive power of news content is concentrated in recessions.

Several studies find some evidence consistent with the view that sentiment extracted from social media messages contain new value-relevant information. Bollen et al. (2011) and Mao et al. (2015) find that market-level investor mood based on tweet content forecasts future aggregate stock returns in the U.S. and other developed countries without subsequent reversals. The permanent impact of sentiment on stock prices indicates potential informational role of investor 
sentiment. Bartov et al. (2017) examine Twitter sentiment for individual firms and show that it contains information about corporate earnings.

The fact that few studies have looked at Twitter sentiment can be explained by the difficulty of extracting information from vast numbers of messages. Most of the existing textual analysis studies use naive dictionary-based (word-count) methods. For example, Tetlock (2007) and Tetlock et al. (2008) compute investor pessimism by counting negative words in major newspapers. Mao et al. (2015) use the relative frequency of terms "bullish" and "bearish" in tweets to measure investor sentiment. Although word-count methods are straightforward, they may lead to large measurement errors because lexicons identify emotional polarity of a word without taking context into account. Some sentiment analysis methods use machine learning to analyze qualitative information. For example, Antweiler and Frank (2004) and Das and Chen (2006) use algorithms, such as Bayesian Classifier and Vector Distance Classifier, to extract investor sentiment from Internet chat room messages. Researchers using machine learning methods first manually classify a large number of stories as positive, negative or neutral. These stories are used to build a statistical model. Then the trained model is used to classify other stories as positive, negative or neutral with a certain probability.

\subsection{Data and Sample Selection}

\subsubsection{Twitter Sentiment Measure}

Bloomberg uses a suite of supervised machine learning methods for social media sentiment analysis. First, Bloomberg lets human experts manually process a large set of tweets. Experts examine the language in a given tweet about a company to determine if the tweet is positive, negative or neutral. The labeling is based on the question "If an investor having a long position in 
the security mentioned were to read this news or tweet, would he/she be bullish, bearish or neutral on his/her holdings?" Bloomberg then feeds the manually classified tweets into machine-learning models that are trained to mimic language experts in analyzing textual information. ${ }^{53}$

Once model training is completed, the models are used to analyze new tweets that reference publicly traded companies in search of sentiment signals distinctive to business and finance. Bloomberg analyzes tweets tagged with tickers and assigns each tweet a story-level sentiment score and associated confidence. The score has three possible values: 1,-1 and 0 , which can be viewed as positive, negative and neutral sentiment, respectively. Confidence ranges from 0 to $100 \%$. It indicates the probability of sentiment being positive, negative or neutral. Hence, the storylevel sentiment varies from -1 to 1 , with -1 representing the most negative sentiment and +1 representing the most positive sentiment. The analysis is done in real time.

Bloomberg computes firm-level daily sentiment using the confidence-weighted average of the past 24 hours' story-level sentiment for Twitter. ${ }^{54}$

$$
\text { Twitter }_{i, t}=\frac{\sum_{k \in P(i, T)} S_{i}^{k} C_{i}^{k}}{N_{i, T}}, \quad T \in[t, t+24 h]
$$

where $S_{i}^{k}$ is the sentiment polarity score of tweet $k$ that references firm $i$. $C_{i}^{k}$ is the confidence of tweet $k$ that references firm $i . P(i, T)$ is the set of all non-neutral Twitter feeds that reference firm $i$ in the 24-hour period T. $N_{i, T}$ is firm $i$ 's total number of positive or negative tweets during period $T$. Daily sentiment is scaled to range from -1 to 1 , similar to story-level sentiment.

\footnotetext{
${ }^{53}$ The models used to measure Twitter sentiment are developed by a team of PhDs, product managers and R\&D professionals using years of Twitter history applied to financial markets. Bloomberg does not disclose details of the models due to their proprietary nature.

${ }^{54}$ Bloomberg does not provide story-level sentiment to subscribers.
} 
Bloomberg updates daily Twitter sentiment data for all U.S. stocks every morning about 10 minutes before the U.S. stock market open. ${ }^{55}$ The calculation is based on the 24-hour period from 9:20 a.m. on the previous day to 9:20 a.m. on the current day. Thus, for example, Twitter sentiment on Friday morning is based on tweets sent from 9:20 a.m. Thursday to 9:20 a.m. Friday. For interpretational convenience, in the following sections we use Twitter $_{i, t}$ to represent stock $i$ 's Twitter sentiment between 9:20 a.m. on day $t$ and 9:20 a.m. on day $t+1$.

\subsubsection{Other Variables}

Besides Twitter sentiment data, we also construct return, volatility and trading volume variables using data from Bloomberg. We use the Rogers and Satchell (1991) extreme value volatility estimator to estimate historical daily volatility. The estimator is computed as follows:

$$
\text { Volatility }_{i, t}=\left(H_{i, t}-C_{i, t}\right)\left(H_{i, t}-O_{i, t}\right)+\left(L_{i, t}-C_{i, t}\right)\left(L_{i, t}-O_{i, t}\right) \text {, }
$$

where $H_{i, t}, L_{i, t}, O_{i, t}$ and $C_{i, t}$ are the log-transformed highest, lowest, opening and closing prices of stock $i$ on day $t$. This approach is widely used in the finance literature and is very efficient when the asset prices follow a geometric Brownian motion with a drift. ${ }^{56}$

We use the abnormal trading volume obtained from Bloomberg in order to make volume comparable across firms with different sizes. ${ }^{57}$ We compute the abnormal trading volume $\left(\right.$ Volume $\left._{i, t}\right)$ by dividing the difference between trading volume for stock $i$ on day $t$ and the mean volume for stock $i$ across the sample period by the mean volume for stock $i$ across the period. So, a positive (negative) Volume $_{i, t}$ indicates that the trading in stock $i$ is more (less) active compared to its sample average. Both abnormal volume and volatility are expressed in percentage points.

\footnotetext{
${ }^{55}$ For companies based in the U.K. and Japan, Bloomberg uses the London and Tokyo opening times, respectively. All other securities are grouped in one of the three categories above based on which time zone they are closer to.

${ }^{56}$ See, for example. Vipul and Jacob (2007)

${ }^{57}$ Due to data availability, we use only the trading volume for the regular trading hours.
} 
Values of Twitter sentiment are released in the morning right before the stock market open. These values cover the after-hours and pre-opening session. Barclay and Hendershott (2003) find that low trading activity after hours generates significant price discovery. To avoid this time overlap between the return and the sentiment measures, we calculate holding period return, $\operatorname{Return}_{i, t}$, from stock i's opening price on day $t$ to the open price on day $t+1$. This approach also theoretically allows one to trade at the 9:30 a.m. market open after observing the Twitter sentiment for the previous day released at 9:20 a.m. and to rebalance his/her holdings at the open on the next trading day when the Twitter sentiment for the current day is released.

\subsubsection{Sample Selection and Summary Statistics}

We analyze Twitter sentiment for the Russell 3000 component stocks. These stocks account for about 99 percent of the total market capitalization of the U.S. equity market. Bloomberg integrated Twitter feeds into its platform in April 2013 and started releasing Twitter sentiment data in January 2015. Our sample period is from January 2015 to February 2017 and contains 535 trading days. In total, we have 1,496,056 stock-day observations and 645,505 non-missing observations of firmspecific Twitter sentiment. ${ }^{58}$

Panel A of Table 1 presents summary statistics for our full sample. The panel shows that the average Twitter sentiment is 0.063 , indicating that on average the content of tweets concerning members of the Russell 3000 index is slightly positive. The mean open-to-open return is about 4.6 basis points, consistent with general upward trend of stock market during our sample period. The

\footnotetext{
${ }^{58}$ The relatively short sample period determined by availability of the Twitter sentiment data is a limitation of our paper. For comparison, Bollen, Mao and Zhen (2011) use Twitter data for a ten-month sample period in 2008. Mao, Counts and Bollen (2015) use data from 2010 to 2012.
} 
mean values of abnormal volume and volatility are $7.79 \%$ and $1.89 \%$, respectively. ${ }^{59}$ Both variables show large cross-sectional variation.

In panel B of the same table, we present sample average conditioning on Twitter sentiment. Subsample Twitter $_{10 \%}$ contains observations with Twitter sentiment in the bottom decile (most negative) every trading day. Subsample Twitter $_{90 \%}$ includes observations with Twitter sentiment in the top decile (most positive) for a given day. The panel indicates that positive sentiment is associated with positive stock returns, whereas negative sentiment is related to negative returns. ${ }^{60}$ Panel B also shows that stock trading volume and volatility in the extreme sentiment deciles are larger than in the full sample. Interestingly, Twitter $_{10 \%}$ has higher volatility and volume than Twitter $_{90 \%}$, although the magnitude of Twitter $_{10 \%}$ reported in Panel A is smaller in absolute value than that of Twitter $_{90 \%}$. This suggests that negative tweets are more strongly related to contemporaneous volume and volatility than positive tweets.

[Insert Table 1 about here]

\subsection{Empirical Results}

This section first shows the Fama-MacBeth regression estimates of the effect of Twitter sentiment on stock returns. Next, we discuss the economic significance of return predictability.

\subsubsection{Predicting Stock Returns Using Twitter Sentiment}

To investigate the impact of Twitter sentiment on stock returns, we use daily cross-sectional regressions similar to those in Fama and MacBeth (1973). Specifically, we first run cross-sectional regressions for each day, and then report the time-series averages of the daily coefficient estimates

\footnotetext{
59 The positive value of the average abnormal volume for days with non-missing Twitter sentiment is reasonable. Stocks tend to be actively traded when they attract investor attention on social media.

${ }^{60}$ Stock returns monotonically increase with Twitter sentiment deciles.
} 
and the corresponding $t$-statistics. The $t$-statistics are robust to heteroskedasticity and autocorrelation for up to five days, using the Newey-West (1987) method. Tetlock (2011) uses a similar method to investigate the impact of firm-specific news on stock returns. We control for return momentum, volatility and abnormal trading volume. These control variables are well-known predictors of returns. The regression specification is:

$$
\begin{aligned}
\text { Return }_{i, t} & =a+\text { bTwitter }_{i, t-1}+\text { cReturn }_{i, t-5: t-1}+\sum_{k=1}^{5} d_{k} \text { Volume }_{i, t-k}+ \\
& +\sum_{k=1}^{5} f_{k} \text { Volatility }_{i, t-k}+\varepsilon_{i, t}
\end{aligned}
$$

where $\operatorname{Return}_{i, t}$ is the holding period return of stock $i$ from market open on day $t$ to open on the next trading day. Twitter ${ }_{i, t-1}$ is the Twitter sentiment of stock $i$ on day $t-1$. As discussed above, Twitter $_{i, t-1}$ measures the sentiment between 9:20 a.m. on day $t-1$ to 9:20 a.m. on day $t$. The coefficient estimate on Twitter $_{i, t-1}$ is our main parameter of interest.

Regression controls include firm i's cumulative return from opening price on day $t-5$ to opening price on day $t\left(\right.$ Return $\left._{i, t-5: t-1}\right)$, five lags of daily volatility and abnormal trading volume. It is important to control for return momentum, since return autocorrelation in conjunction with contemporaneously correlated returns and sentiment can generate spurious evidence of lead-lag relationships (e.g., Chordia and Swaminathan, 2000; Rapach, Strauss and Zhou, 2013). The abnormal trading volume is included to control for the high-volume return premium of Gervais, Kaniel, and Mingelgrin (2001). Following Ang et al. (2006), the regression also controls for volatility.

Column 1 of Table 2 reports the impact of Twitter sentiment on subsequent returns. As discussed above, the return is computed from 9:30 a.m. on the current day to 9:30 a.m. on the following day. As seen in the column, the coefficient estimate on Twitter $_{i, t-1}$ is positive and statistically significant. On average, the stock return over the next 24 hours for firms with most 
positive Twitter sentiment $($ Twitter $=1$ ) is about 27 basis points higher than the return for firms with most negative Twitter sentiment (Twitter $=-1$ ).

[Insert Table 2 about here]

One may argue that this positive relation between Twitter sentiment and subsequent stock returns may be driven by systematic risks. For example, if small firms unconditionally have higher Twitter sentiment than large firms, the predictive power of Twitter sentiment could be driven by the size factor. To address this concern, we re-estimate the regression above using abnormal returns, defined as the residuals of the Fama-French-Carhart four-factor model ${ }^{61}$ In other words, we risk-adjust the returns using the market factor, the size factor, the value factor and the momentum factor. ${ }^{62}$ If the return predictability of Twitter sentiment is related to any of these factors, the coefficient estimate on Twitter $_{i, t-1}$ should become smaller, if not insignificant. As seen in Column 2 of Table 2, the coefficient estimate of Twitter sentiment remains positive and significant at the $1 \%$ level. The size of this coefficient estimate is very close to that reported in Column 1 of the table. This suggests that the predictive value of Twitter sentiment for stock returns is largely independent of the commonly used risk factors.

\subsubsection{Is Twitter Sentiment Informative?}

The predictive power of Twitter sentiment for individual stock returns may be explained by its information content. If Twitter sentiment contains useful fundamental information about stocks, its effect on returns should be permanent. Mao et al. (2015) find that the effect of market-wide

\footnotetext{
${ }^{61}$ Daily risk factor data are obtained from Ken French's data library.

${ }^{62} \mathrm{We}$ acknowledge that using risk factors based on close-to-close returns to risk-adjust open-to-open returns may lead to biased excess returns. Price does move after market close and before the market open. However, the overnight price variation is much smaller than that during the regular trading hours. Thus, it is reasonable to assume that values of risk factors based on opening prices would be close to those based on closing prices provided in the historical factor data. As a robustness check, we alternatively use the difference between individual firms' open-open returns and concurrent Russell 3000 index returns as a proxy for risk adjusted returns. The results, available upon request, are similar to those based on raw returns.
} 
Twitter sentiment on stock indices is permanent. On the other hand, if Twitter sentiment simply reflects sentiment of uninformed traders, the impact of Twitter sentiment on stock returns should be reversed over the next few trading days. We test whether the positive influence of Twitter sentiment on returns is temporary or permanent by including Twitter $_{i, t-2}$, Twitter $_{i, t-3}$, Twitter $_{i, t-4}$, Twitter $_{i, t-5}$ in the model in equation (2). ${ }^{63}$ We run regressions for raw returns as well as risk-adjusted returns. Table 3 shows that controlling for lags of Twitter sentiment influences predictive value of Twitter sentiment for stock returns very slightly. The coefficient estimate on w witter $_{i, t-1}$ does not decrease significantly. Moreover, the values of the coefficient estimates on lags of Twitter sentiment are trivial and statistically insignificant. All these findings are consistent with the notion that Twitter sentiment contains some fundamental information that has not been incorporated into stock prices.

[Insert Table 3 about here]

\subsubsection{Twitter Sentiment vs. News Sentiment}

Tetlock et al. (2008) find that the firm-level news sentiment predicts stock returns. Specifically, there is a significant negative relation between the percentage of negative words in firm-specific news reported by the Dow Jones News Service and firms' next day returns. In this subsection, we test whether Twitter sentiment has predictive value for stock returns incremental to that of news sentiment. We do so by adding news sentiment as an additional regressor to equation (2). This specification allows us to compare the return predictability of Twitter sentiment to that of news sentiment. If fundamental information diffuses from traditional media to social media, we should

\footnotetext{
${ }^{63}$ The results are not sensitive to the number of lags.
} 
expect the predictive power of Twitter sentiment for stock returns to disappear after controlling for news sentiment.

We obtain firm-specific news sentiment from Bloomberg. It is measured by following the same procedure as the one used to calculate Twitter sentiment, and is based on all news published on Bloomberg. The value of news sentiment ranges from +1 to -1 and is updated before the market open every trading day. The regression results are reported in Table 4. Column (1) and (3) present the news sentiment's predictive value for raw and excess returns. Consistent with Tetlock et al. (2008), we find that firm-level news sentiment predicts future returns. One can expect to earn 26 basis point over the next 24 hours by buying stocks with the most positive news sentiment (news sentiment=1) and selling stocks with the most negative news sentiment (news sentiment $=-1)$ right before the market open.

\section{[Insert Table 4 about here]}

Column (2) and (4) show results for regressions including both Twitter sentiment and news sentiment. As seen in the columns, the predictive power of Twitter sentiment is not subsumed by that of news sentiment and vice versa. Combining the low correlation between news sentiment and Twitter sentiment, this finding suggests that social media contains information that is generally innovative to the information in traditional news media known to have predictive power for stock returns. ${ }^{64}$ Moreover, we find that the difference in predictive value of news sentiment and Twitter sentiment for future returns is not statistically significant.

Overall, the above three subsections show that Twitter sentiment predicts stock returns over the next 24 hours without subsequent reversals. This indicates that Twitter sentiment contains

\footnotetext{
${ }^{64}$ The average daily cross-sectional correlation between news sentiment and Twitter sentiment is about 0.17 .
} 
value-relevant information. In addition, we provide evidence that information in Twitter messages is incremental to that contained in traditional news media.

\subsubsection{Economic Significance of Return Predictability}

The positive relation between Twitter sentiment and subsequent returns suggests that a simple long-short trading strategy could earn positive risk-adjusted returns. In this subsection, we examine this possibility by estimating trading profits of a simple daily strategy using Twitter sentiment. Specifically, we form two equally-weighted portfolios at the market open right after Twitter sentiment release. The long portfolio includes all firms with Twitter sentiment in the top decile. The short portfolio contains all firms with Twitter sentiment in the bottom decile. We hold both the long and short portfolios for 24 hours and rebalance at the beginning of the next trading day. This strategy can be employed every trading day. The portfolio performance is reported in Table 5.

Column 1 shows that, ignoring transaction costs, the daily average raw return of this longshort strategy is 8.6 basis points. This translates into average annual raw return of approximately 21.5 percent. The strategy produces an annualized Sharpe ratio of 3.17. ${ }^{65}$

[Insert Table 5 about here]

Columns 2, 3 and 4 in Table 5 report risk-adjusted excess returns of this daily trading strategy based on Twitter sentiment. We use the CAPM, the Fama-French (1993) three-factor and Carhart (1997) four-factor models and regress the raw portfolio returns on the contemporaneous factor returns. The intercepts of the regressions represent the portfolio alphas, or the average riskadjusted excess returns.

\footnotetext{
${ }^{65}$ The annualized Sharpe ratio is calculated by multiplying the daily Sharpe ratio by the square root of the number of trading days per year.
} 
Similar to the raw returns in Column 1, the excess returns reported in the other three columns are positive and statistically significant. This suggests that, ignoring transaction costs, the daily Twitter-based trading strategy would generate positive risk-adjusted returns. Specifically, CAPM, three-factor and four-factor alphas are 8.7, 8.9, 8.8 basis points, respectively. These riskadjusted returns are close to the raw returns. Interestingly, the return from Twitter-based trading is strongly related to the momentum factor. The predictive ability of Twitter sentiment is likely driven by the market's sluggish reaction to the fundamental information contained in Twitter sentiment data. The positive loading on the momentum factor indicates that past stock returns influence current Twitter sentiment. The non-trivial regression $R^{2}$ estimates show that some of the risk of the Twitter-based long-short trading strategy is not firm-specific. This finding suggests that firm-specific tweets are partly based on market-level information. ${ }^{66}$

Table 5 shows that the returns of a simple trading strategy based on Twitter sentiment are substantial. But, the high profits may be driven by extremely high returns earned in a few good months. To address this concern, we measure monthly returns of our trading strategy. Figure 1 depicts the monthly returns over our sample period. As seen in the figure, in 22 out of 26 months, the Twitter-based strategy would have earned positive trading returns. To put this perspective, if the unconditional likelihood of obtaining a positive trading return were 0.5 , the probability of getting 22 or more positive returns in 26 independent periods would be less 0.001 . This result indicates that the Twitter sentiment based trading strategy was consistently profitable in our sample period.

\footnotetext{
${ }^{66}$ Howe, Unlu and Yan (2009) find that analysts use industry-level and market-level information besides firm-level information when updating their recommendations. If the market-level information contains past market-wide returns, the significant predictive value of Twitter sentiment for analyst recommendation change, which is documented in subsection 5.1, provides an explanation of the significant relation between returns of the Twitter-based trading strategy and the momentum factor.
} 
Another result that emerges from Figure 1 is that monthly trading returns vary significantly over time with the highest return of over 6 percent and the largest loss of over 3 percent. Although, our short sample period prevents us from doing a statistically meaningful time variation analysis, the monthly return pattern suggests that predictive value of Twitter sentiment for return is not constant. Similarly, Garcia (2013) shows the return predictability of news sentiment is depends of the state of the macroeconomy.

\section{[Insert Figure 1 about here]}

Bloomberg measures sentiment using tweets from Twitter and from StockTwits. It is very likely that some Twitter feeds contain more information than others and deserve more attention. Sophisticated traders may be able to trade more profitably by following more informative Twitter feeds or by constructing better trading strategies ${ }^{67}$ Several additional issues need to be considered. First, the trading strategy returns discussed above are computed without taking into account transaction costs. High per-transaction costs combined with high trading turnover may make the strategy much less profitable. Most of the new information from social media is likely incorporated into current day's stock prices, which may explain why the trading returns discussed above are small. Secondly, stocks in the long portfolio may be riskier than the stocks in the short portfolio. Buying high-risk securities and selling low-risk securities increases trading risks. Finally, based on our estimates, the strategy may produce negative returns in some periods.

\footnotetext{
${ }^{67}$ For example, if the long portfolio includes all firms with Twitter sentiment in the top percentile and the short portfolio contains all firms with Twitter sentiment in the bottom percentile, the average daily excess return of the long-short trading strategy is about 21 basis points.
} 


\subsection{Fundamentals Reflected in Twitter Sentiment}

In the above section, we provide evidence that tweets contain some relevant information about corporate fundamentals. In this section, we investigate potential sources of this information by focusing on four important events. We find that Twitter sentiment predicts analyst recommendation changes, target price changes, IPO underpricing and quarterly earnings.

\subsubsection{Analyst Recommendation Changes}

Extensive literature finds that analyst recommendations contain valuable information that moves market prices (Womack, 1996). Howe et al. (2009) further report that besides firm-level information, market-level and industry-level information is also reflected in analyst recommendations. In this subsection, we investigate whether Twitter sentiment contains information about analyst recommendation changes using the following regression model:

$$
\begin{aligned}
\text { RecChng }_{i, t}= & a+\text { bTwitter }_{i, t-2}+\text { cReturn }_{i, t-6: t-2}+\sum_{k=2}^{6} d_{k} \text { Volume }_{i, t-k}+ \\
& +\sum_{k=2}^{6} f_{k} \text { Volatility }_{i, t-k}+\varepsilon_{i, t},
\end{aligned}
$$

where $\operatorname{RecChng}_{i, t}$ is the change in firm i's consensus recommendation on day $t$.

Jegadeesh et al. (2004) argue that consensus recommendation changes are more informative relative to the level of the consensus. ${ }^{68}$ The consensus recommendations for Russell 3000 component stocks are obtained from Bloomberg. Bloomberg offers a consensus ranging from one to five (strong sell to strong buy) that reflects the aggregate opinion of equity analysts. When an analyst upgrades (downgrades) his or her recommendation for a firm's stock, Bloomberg adjusts the firm's consensus upward (downward). Control variables included in the model are past return, abnormal volume and volatility.

\footnotetext{
${ }^{68}$ Jegadeesh et al. (2004) find that stock returns are significantly affected by analyst consensus recommendation changes but are not associated with the consensus recommendation levels.
} 
Analysts may release their recommendations before the market open. Hence, it is possible that recommendations announced on day $t$ could affect Twitter $_{i, t-1}$, which measures firm i's Twitter sentiment from market open on day $t-1$ to market open on day $t$. To rule out such reverse causality, we use Twitter sentiment released on day $t-1\left(\right.$ Twitter $\left._{i, t-2}\right)$ as a proxy for prerecommendation Twitter sentiment. ${ }^{69}$

Following previous literature, we estimate the regression in equation (3) using pooled OLS with standard errors clustered by calendar day to account for cross-correlation between firms. ${ }^{70}$ The results are presented in Table 6 . Column 1 of Table 6 shows that Twitter sentiment positively predicts forthcoming recommendation changes. As expected, upgraded stocks are more likely to have positive Twitter sentiment prior to the recommendation release. This suggests that tweets contain information about analyst recommendation changes.

\section{[Insert Table 6 about here]}

If the information contained in Twitter sentiment is not fully incorporated into prices before the recommendation release, the ability to predict recommendation consensus also should also be reflected in an ability to forecast the price reaction to the release. To test this, we regress the riskadjusted return around the recommendation announcement on the pre-release Twitter sentiment. The return is measured by taking the sum of the risk-adjusted returns on day $t-1$ and on day $t$. This window captures the stock price reaction to analyst recommendations on the announcement day and the potential pre-announcement effect. ${ }^{71}$

Column 2 of Table 6 documents that Twitter sentiment predicts the response of stock prices to analyst recommendation changes. High pre-event Twitter sentiment forecasts high event return.

\footnotetext{
${ }^{69}$ The results based on Twitter $_{i, t-1}$, available upon request, are qualitatively similar.

${ }^{70}$ See, for example, Tetlock et al. (2008) and Loh (2010).

${ }^{71}$ Irvine, Lipson and Puckett (2006) document informed trading before recommendation announcements.
} 
It indicates that information about analyst recommendations contained in Twitter sentiment is not fully reflected in stock prices before the recommendation announcement.

\subsubsection{IPO Underpricing}

IPO underpricing has been widely studied in finance literature. Recent studies investigate the relation between IPO initial returns and investor sentiment. Cornelli, Goldreich, and Ljungqvist (2006) find that higher pre-IPO retail investor sentiment, measured by pre-IPO market prices, can lead to higher first trading day returns. ${ }^{72}$ Liu, Sherman, and Zhang (2008) document that news sentiment is related to IPO underpricing. In this subsection, we test the effect of Twitter sentiment, a different type of investor sentiment, on IPO underpricing.

Loughran and Ritter (2002) show that IPO offering prices only partially incorporate available public information. If Twitter sentiment contains relevant information not incorporated in IPO prices, it should have predictive value for the difference between the offering prices and the first day opening prices. To illustrate this point, suppose that an analyst, who is active on social media, estimates that the fair offering price of an upcoming IPO is $\$ 20$, whereas the actual offering price is $\$ 15$. The analyst would share his/her optimism about the success of the IPO on social media, such as Twitter. This would lead to a positive relation between pre-IPO sentiment and IPO underpricing. Moreover, when pre-IPO sentiment provides incremental information, we would not expect a significant price reversal after the opening.

To construct our sample of IPOs, we first obtain from Bloomberg a list of IPOs whose first trading days were between January 2015 and February 2017. We then exclude IPOs with missing

\footnotetext{
${ }^{72}$ Pre-IPO (grey) markets allow investors to trade based on their expectations on stock prices of firms that are going to be listed in exchanges. Grey markets only exist in Europe, and most traders are individual investors with little capital (Cornelli et al., 2006).
} 
Twitter sentiment before the first opening prices. Finally, we remove IPOs with offer sizes of less than $\$ 50$ million. The final sample consists of 128 IPOs.

To examine the relation between pre-IPO Twitter sentiment and IPO Performance, we regress the return from the offering price to the first opening price (Offer_To_1 ${ }^{\text {st }}$ Open) and return from the first opening price to the first close price (Open_To_ $1^{\text {st }}$ Close) on Twitter ${ }_{i, t-1}$. The regressions are estimated using OLS regression with the White (1980) heteroskedasticity consistent standard errors and using the MM estimator of Yohai (1987). The MM estimator is robust to the presence of outliers. The regression results are reported in Table 7.

[Insert Table 7 about here]

Both OLS and robust regression estimates show a significant positive relation between preIPO Twitter sentiment and Offer_To_ $1{ }^{\text {st }}$ _Open but no significant relation between pre-IPO Twitter sentiment and Open_To_1 ${ }^{\text {st }}$ CClose. These findings are consistent with our hypothesis that Twitter sentiment contains information about IPO underpricing.

\subsubsection{Analyst Target Price Changes}

Another important value-relevant information event is analyst target price revisions. Brav and Lehavy (2003) document a significant price reaction to target price announcements. In this subsection, we use Twitter sentiment to forecast upcoming target price changes using a regression with clustered standard errors that is similar to that in equation (3). We first download target price data for Russell 3000 component stocks from Bloomberg. We then compute target price return $\left(\right.$ TargetChng $\left._{i, t}\right)$ and use it as the main dependent variable. Twitter $_{i, t-2}$ is used as the main independent variable to address the possible reverse causality discussed in subsection 3.5.1.

[Insert Table 8 about here] 
Column 1 of Table 8 shows the regression results. The positive and significant coefficient on Twitter $_{i, t-2}$ confirms that Twitter sentiment predicts target price changes. An increase in a firm's target price is more likely to occur after Twitter users express positive views about the firm. We also estimate a similar regression where the main dependent variable is the stock return around target price changes. The results reported in column 2 of Table 8 show that Twitter sentiment before target price announcements helps predict returns after the announcement. We conclude that target price changes represent another example of relevant information contained in Twitter sentiment.

\subsubsection{Quarterly Earnings}

Bartov, Faurel and Mohanram (2017) show that Twitter sentiment forecasts quarterly earnings between January 2009 and December 2012. ${ }^{73}$ However, since recent years have seen a large increase in the amount of information and number of users on Twitter, it is worthwhile to revisit the relation between Twitter sentiment and firms' earnings using a more recent sample period. Moreover, the results in this subsection can be viewed as test of the quality of Twitter sentiment constructed by Bloomberg.

To measure earnings surprises, we use the standardized unexpected earnings (SUE), computed as follows:

$$
S U E_{i, q}=\left(A_{i, q}-F_{i, q}\right) / \sigma_{i, q},
$$

where $A_{i, q}$ is the actual earnings per share reported by firm $i$ for quarter $q, F_{i, q}$ is the $\mathrm{I} / \mathrm{B} / \mathrm{E} / \mathrm{S}$ consensus forecast of quarterly earnings per share just prior to the earnings announcement date, and $\sigma_{i, q}$ is the cross-sectional standard deviation of analyst forecasts comprising the consensus.

\footnotetext{
${ }^{73}$ Bartov et al. (2017) measure sentiment using the proportion of negative words in each tweet.
} 
Following the existing literature, we estimate the regression in equation (4) using pooled OLS regressions with standard errors clustered by calendar quarter.

Table 9 shows that Twitter sentiment released one day before earnings reports predicts earnings surprises, and is positively related to the stock price reaction to the earnings releases. These findings are similar to those documented in Bartov et al. (2017), suggesting that Twitter sentiment contains information about firms' quarterly earnings.

[Insert Table 9 about here]

\subsection{Conclusion}

Social media has recently become one of the main communication channels for information about financial markets. However, the role of social media in finance is still not well understood due to the difficult task of analyzing massive amounts of social media content. This study uses firmspecific Twitter sentiment data provided by Bloomberg to investigate the impact of social media on the stock market. Although most Twitter users are believed to be uninformed, our findings show that the daily firm-level Twitter sentiment contains information that is useful for predicting future stock returns. In particular, we document that Twitter sentiment contains information about analyst recommendation changes, IPO first opening prices, target price changes and quarterly earnings surprises. These findings are consistent with the notion of the "wisdom of crowds" (Surowiecki, 2004). Our study contributes to a better understanding of how social media affect stocks.

Our findings have important implications for market participants. The predictive power of Twitter sentiment for stock returns gives traders a strong incentive to analyze social media content carefully. Social media content may influence asset allocation decisions. The role of Twitter 
sentiment documented in our paper also indicates that business entities may be able to improve transparency and market efficiency by using social media. 
Table 1 Summary Statistics

\begin{tabular}{llllll}
\hline \hline \multicolumn{2}{l}{ Panel A. Cross Sectional Summary Statistics } \\
\hline & Mean & Median & Std & P10 & P90 \\
\hline Twitter & 0.063 & 0.033 & 0.246 & -0.180 & 0.367 \\
Open-to-open return & 0.046 & 0.031 & 2.943 & -2.624 & 2.664 \\
Volume & 7.793 & -12.446 & 111.614 & -53.034 & 75.370 \\
Volatility & 1.892 & 1.399 & 1.649 & 0.618 & 3.645 \\
\hline Panel B. Sample Averages conditioned on Twitter Sentiment & \multicolumn{3}{c}{ Twitter $_{90 \%}$} \\
\hline \multicolumn{3}{r}{ Twitter } \\
Open-to-open return & -0.862 & \multicolumn{2}{c}{0.670} \\
Volume & 20.286 & & 13.485 \\
Volatility & 2.141 & \multicolumn{3}{c}{1.918} \\
\hline \hline
\end{tabular}

Panel A reports cross sectional Summary Statistics for the daily Twitter sentiment, return (in percent), abnormal volume (in percent) and volatility (in percent) for Russell 3000 component stocks for the period from January 2015 to February, 2017. The abnormal volume is computed by dividing the difference between trading volume for stock $i$ on day $t$ and the mean volume for stock $i$ in the sample period by the mean of volume for stock $i$ in the sample period. Daily volatility is estimated using the approach of Rogers and Satchell (1991). P10 contains observations with selected variables in the bottom decile for every trading day, and P90 includes observations with selected variables in the top decile in a given day.

Panel B provides the means conditioned on daily twitter sentiment. Twitter ${ }_{10 \%}$ contains stocks with Twitter sentiment in the bottom decile (most negative) for every trading day. Twitter ${ }_{90 \%}$ contains stocks with Twitter sentiment in the top decile (most positive) for every trading day. 
Table 2 Predicting Stock Returns Using Twitter Sentiment

\begin{tabular}{ccc}
\hline \hline & Raw Return & Risk-Adjusted Return \\
& $(1)$ & $(2)$ \\
\hline Intercept & $0.022(-0.63)$ & $0.012(0.35)$ \\
Twitter $_{i, t-1}$ & $0.135(7.83)^{* * *}$ & $0.134(8.51)^{* * *}$ \\
Controls & Yes & Yes \\
$N$ & 645,505 & 645,505 \\
$R^{2}(\%)$ & 7.8 & 4.7 \\
\hline \hline
\end{tabular}

The table presents results from the following regression estimated using the Fama-MacBeth approach:

$$
\begin{gathered}
\text { Return }_{i, t}=a+\text { bTwitter }_{i, t-1}+\text { cReturn }_{i, t-5: t-1}+\sum_{k=1}^{5} d_{k} \text { Volume }_{i, t-k}+ \\
\sum_{k=1}^{5} f_{k} \text { Volatility }_{i, t-k}+\varepsilon_{i, t},
\end{gathered}
$$

where Return $_{i, t}$ is the raw holding period return or risk-adjusted return from the open on day $t$ to the open on day $t+1$. Risk-adjusted returns are computed as the residuals from the Fama-French-Carhart four-factor model. Twitter $r_{i, t-1}$ is stock $i$ 's specific Twitter sentiment on day $t-1$. Control variables include the return from the open on day $t-5$ to the open on day $t-1$, lagged abnormal volume and volatility. The abnormal volume is computed by dividing the difference between trading volume for stock $i$ on day $t$ and the mean volume for stock $i$ in the sample period by the mean of volume for stock $i$ in the sample period. Daily volatility is estimated using the approach of Rogers and Satchell (1991). The sample period is from January 2015 to February 2017. $t$-statistics based on Newey-West standard errors are shown in parentheses. * **, *** indicate statistical significance at $10 \%, 5 \%$, and $1 \%$ levels, respectively. 
Table 3 Predicting Stock Returns Using Lagged Twitter Sentiment

\begin{tabular}{ccc}
\hline & Raw Return & Risk-Adjusted Return \\
& $(1)$ & $(2)$ \\
\hline Intercept & $0.021(0.61)$ & $0.011(0.42)$ \\
Twitter $_{i, t-1}$ & $0.142(8.30)^{* * *}$ & $0.138(8.59)^{* * *}$ \\
Twitter $_{i, t-2}$ & $-0.014(-0.69)$ & $-0.005(-0.25)$ \\
Twitter $_{i, t-3}$ & $0.026(1.50)$ & $0.031(1.20)$ \\
Twitter $_{i, t-4}$ & $0.00(0.01)$ & $-0.002(-0.11)$ \\
Twitter $_{i, t-5}$ & $-0.022(-1.25)$ & $0.022(-1.38)$ \\
Controls & Yes & Yes \\
$N$ & 645,505 & 645,505 \\
$R^{2}(\%)$ & 8.2 & 4.8 \\
\hline \hline
\end{tabular}

The table presents results from the following regression estimated using the Fama-MacBeth approach:

$$
\begin{gathered}
\text { Return }_{i, t}=a+\sum_{k=1}^{5} b_{k} \text { Twitter }_{i, t-k}+\text { cReturn }_{i, t-5: t-1}+\sum_{k=1}^{5} d_{k} \text { Volume }_{i, t-k}+ \\
\sum_{k=1}^{5} f_{k} \text { Volatility }_{i, t-k}+\varepsilon_{i, t},
\end{gathered}
$$

where $\operatorname{Return}_{i, t}$ is the raw holding period return or risk-adjusted return from the open on day $t$ to the open on day $t+1$. Risk-adjusted returns are computed as the residuals from the Fama-French-Carhart four-factor model. Twitter $r_{i, t-1}$ is stock $i$ 's specific Twitter sentiment on day $t-1$. Control variables include the return from the open on day $t-5$ to the open on day $t-1$, lagged abnormal volume and volatility. The abnormal volume is computed by dividing the difference between trading volume for stock $i$ on day $t$ and the mean volume for stock $i$ in the sample period by the mean of volume for stock $i$ in the sample period. Daily volatility is estimated using the approach of Rogers and Satchell (1991). The sample period is from January 2015 to February 2017. $t$-statistics based on Newey-West standard errors are shown in parentheses. $*, * *, * * *$ indicate statistical significance at $10 \%, 5 \%$, and $1 \%$ levels, respectively. 
Table 4 Predicting Stock Returns Using Twitter Sentiment and News Sentiment

\begin{tabular}{|c|c|c|c|c|}
\hline & \multicolumn{2}{|c|}{ Raw Return } & \multicolumn{2}{|c|}{ Risk-Adjusted Return } \\
\hline & (1) & (2) & (3) & (4) \\
\hline Intercept & $0.020(0.57)$ & $0.014(0.39)$ & $0.010(0.38)$ & $-0.005(-0.54)$ \\
\hline Twitter $_{i, t-1}\left(b_{1}\right)$ & & $0.121(7.06)^{* * *}$ & & $0.119(7.45)^{* * *}$ \\
\hline$N e w s_{i, t-1}\left(b_{2}\right)$ & $0.132(5.90)^{* * *}$ & $0.111(5.00)^{* * *}$ & $0.131(6.56)^{* * *}$ & $0.111(5.51)^{* * *}$ \\
\hline Controls & Yes & Yes & Yes & Yes \\
\hline$b_{1}-b_{2}$ & & $0.010(0.39)$ & & $0.008(0.53)$ \\
\hline$N$ & 645,505 & 645,505 & 645,505 & 645,505 \\
\hline$R^{2}(\%)$ & 7.8 & 7.9 & 4.7 & 4.8 \\
\hline
\end{tabular}

The table presents results from the following regression estimated using the Fama-MacBeth approach:

Return $_{i, t}=a+b_{1}$ Twitter $_{i, t-1}+b_{2}$ News $_{i, t-1}+$ cReturn $_{i, t-5: t-1}+\sum_{k=1}^{5} d_{k}$ Volume $_{i, t-k}+$ $\sum_{k=1}^{5} f_{k}$ Volatility $_{i, t-k}+\varepsilon_{i, t}$,

where Return $_{i, t}$ is the raw holding period return or risk-adjusted return from the open on day $t$ to the open on day $t+1$. Risk-adjusted returns are computed as the residuals from the Fama-French-Carhart four-factor model. Twitter $r_{i, t-1}$ is stock $i$ 's specific Twitter sentiment on day $t-1$. News $s_{i, t-1}$ is stock i's specific news sentiment on day $t-1$. Control variables include the return from the open on day $t-5$ to the open on day $t-1$, lagged abnormal volume and volatility. The abnormal volume is computed by dividing the difference between trading volume for stock $i$ on day $t$ and the mean volume for stock $i$ in the sample period by the mean of volume for stock $i$ in the sample period. Daily volatility is estimated using the approach of Rogers and Satchell (1991). The sample period is from January 2015 to February 2017. $t$-statistics based on NeweyWest standard errors are shown in parentheses. *,**,*** indicate statistical significance at $10 \%, 5 \%$, and $1 \%$ levels, respectively. 
Table 5 Returns of Twitter-Based Trading Strategy

\begin{tabular}{ccccc}
\hline \hline & $(1)$ & $(2)$ & $(4)$ & $(5)$ \\
\hline Raw Return & $0.086(4.65)^{* * *}$ & & & \\
Alpha & & $0.087(4.66)^{* * *}$ & $0.089(4.88)^{* * *}$ & $0.088(5.11)^{* * *}$ \\
Market & & $-0.001(-049)$ & $-0.005(-0.26)$ & $0.033(0.1,63)$ \\
SMB & & & $-0.018(-0.50)$ & $0.056(1.61)$ \\
HML & & & $-0.168(-4.99)^{* * *}$ & $-0.037(-1.05)$ \\
UMD & 537 & 537 & & $0.186(8.38)^{* * *}$ \\
Trading Days & & 0.14 & 537 & 537 \\
$R^{2}(\%)$ & & & 3.97 & 15.02 \\
Sharpe Ratio & 3.17 & & \\
\hline \hline
\end{tabular}

This table shows the daily returns from a Twitter-based trading strategy. We assemble the portfolio for the trading strategy at the beginning of each trading day. We form two equal-weighted portfolios based on each firm's recent Twitter sentiment. The long portfolio includes all firms with Twitter sentiment in the top decile (most positive). The short portfolio contains all firms with Twitter sentiment in the bottom decile (most negative). We hold both the long and the short portfolios for 24 hours and rebalance at the beginning of the next trading day. We use the CAPM, Fama-French (1993) three-factor model and Carhart (1997) four-factor model, respectively, to adjust the trading strategy returns for the impact of contemporaneous market (Market), size (SMB), book-to-market $(H M L)$, and momentum (UMD) factors. Sharpe ratio is the annualized Sharpe ratio. The sample period is from January 2015 to February 2017. $t$-statistics computed using the White (1980) heteroskedasticity-consistent covariance matrix are in parentheses. *, **, *** indicate statistical significance at $10 \%, 5 \%$, and $1 \%$ levels, respectively. 
Table 6 Predicting Analyst Recommendation Changes and Event Returns Using Twitter Sentiment

\begin{tabular}{ccc}
\hline \hline & RecChng (t) & Risk-Adjusted Announcement Return \\
& $(1)$ & $(2)$ \\
\hline Intercept & $-0.003(-4.66)$ & $0.012(0.11)$ \\
Twitter $i, t-2$ & $0.013(2.68)^{* * *}$ & $0.375(2.81)^{* * *}$ \\
Controls & Yes & Yes \\
$N$ & 27,366 & 27,366 \\
Clusters & 535 & 535 \\
$R^{2}(\%)$ & 0.165 & 0.147 \\
\hline \hline
\end{tabular}

Column (1) presents estimation results for the following regression:

RecChng $_{i, t}=a+$ bTwitter $_{i, t-2}+$ cReturn $_{i, t-6: t-2}+\sum_{k=2}^{6} d_{k}$ Volume $_{i, t-k}+$ $\sum_{k=2}^{6} f_{k}$ Volatility $_{i, t-k}+\varepsilon_{i, t}$,

Column (2) presents estimation results for the following regression:

Return $_{i, t-1: t+1}=a+$ bTwitter $_{i, t-2}+$ cReturn $_{i, t-6: t-2}+\sum_{k=2}^{6} d_{k}$ Volume $_{i, t-k}+$ $\sum_{k=2}^{6} f_{k}$ Volatility $_{i, t-k}+\varepsilon_{i, t}$,

where $\operatorname{RecChng}_{i, t}$ is the change in firm $i$ 's consensus analyst recommendation on day $t$. Return $_{i, t-1: t+1}$ is firm $i$ 's risk-adjusted return from the market open on day $t-1$ to market open on day $t+1$. The two-day riskadjusted returns are computed as the sum of two daily risk-adjusted returns. Risk-adjusted returns are computed as the residuals from the Fama-French-Carhart four-factor model. Twitter ${ }_{i, t-2}$ is stock $i$ 's Twitter sentiment on day $t-2$, released on day $t-1$ before the market open. Control variables include the return from the open on day $t-6$ to the open on day $t-2$, lagged abnormal volume and volatility. The abnormal volume is computed by dividing the difference between trading volume for stock $i$ on day $t$ and the mean volume for stock $i$ in the sample period by the mean of volume for stock $i$ in the sample period. Daily volatility is estimated using the approach of Rogers and Satchell (1991). The sample period is from January 2015 to February 2017. The regression is estimated with OLS using standard errors clustered by calendar day. The corresponding $t$-statistics are shown in parentheses. $*, * *, * * *$ indicate statistical significance at $10 \%, 5 \%$, and $1 \%$ levels, respectively. 
Table 7 Predicting IPO Underpricing Using Twitter Sentiment

\begin{tabular}{ccccc}
\hline \hline & \multicolumn{2}{c}{ Offer_To_1 ${ }^{\text {st }}$ Open } & \multicolumn{2}{c}{ Open_To_1 ${ }^{\text {st }}$ Close } \\
\hline OLS & MM & OLS & MM \\
\hline Intercept & $18.14(8.22)^{* * *}$ & $14.95(8.69)^{* * * *}$ & $2.168(1.88)^{* * *}$ & $1.00(1.20)$ \\
Twitter $_{i, t-1}$ & $28.34(10.78)^{* * *}$ & $26.30(3.18)^{* * *}$ & $-4.06(-0.72)$ & $-6.40(1.60)$ \\
$N$ & 128 & 128 & 128 & 128 \\
$R^{2}(\%)$ & 5.20 & 4.13 & 0.41 & 0.94 \\
\hline \hline
\end{tabular}

The table presents results from the following regression:

Return $_{i, t}=a+$ bTwitter $_{i, t-1}+\varepsilon_{i, t}$,

where Return $_{i, t}$ is firm $i$ 's return on the first trading day. We report results for the return from the offering price to the first opening price (Offer_To_1st_Open) and return from the first opening price to the first close price (Open_To_1st_Close). Twitter ${ }_{i, t-1}$ is stock $i$ 's Twitter sentiment for the 24-hour period before the IPO. The sample period is from January 2015 to February 2016. The regressions are estimated using (1) OLS with the White (1980) heteroskedasticity consistent covariance matrix and (2) robust MM-estimator of Yohai (1984). The corresponding $t$-statistics are shown in parentheses. *, **, *** indicate statistical significance at $10 \%, 5 \%$, and $1 \%$ levels, respectively. 
Table 8 Predicting Target Price Changes and Event returns Using Twitter Sentiment

\begin{tabular}{ccc}
\hline \hline & TargetChng $(\mathrm{t})$ & Risk-Adjusted Announcement Return \\
& $(1)$ & $(2)$ \\
\hline Intercept & $0.777(14.44)^{* * *}$ & $0.041(0.51)$ \\
Twitter $i, t-2$ & $1.09(15.65)^{* * *}$ & $0.388(6.28)^{* * *}$ \\
Controls & Yes & Yes \\
$N$ & 106,692 & 106,692 \\
Clusters & 535 & 535 \\
$R^{2}(\%)$ & 4.885 & 0.068 \\
\hline \hline
\end{tabular}

Column (1) presents results from following regression:

TargetChng $_{i, t}=a+$ bTwitter $_{i, t-2}+$ cReturn $_{i, t-6: t-2}+\sum_{k=2}^{6} d_{k}$ Volume $_{i, t-k}+$ $\sum_{k=2}^{6} f_{k}$ Volatility $_{i, t-k}+\varepsilon_{i, t}$,

Column (2) presents results from following regression:

Return $_{i, t-1: t+1}=a+$ bTwitter $_{i, t-2}+$ cReturn $_{i, t-6: t-2}+\sum_{k=2}^{6} d_{k}$ Volume $_{i, t-k}+$ $\sum_{k=2}^{6} f_{k}$ Volatility $_{i, t-k}+\varepsilon_{i, t}$,

where TargetChng $_{i, t}$ is the change in firm $i$ 's target price on day $t$. Return $n_{i, t-1: t+1}$ is firm $i$ 's riskadjusted return from the market open on day $t-1$ to market open on day $t+1$. The two-day risk-adjusted returns are computed as the sum of two daily risk-adjusted returns. Risk-adjusted returns are computed as the residuals from the Fama-French-Carhart four-factor model. Twitter ${ }_{i, t-2}$ is stock $i$ 's Twitter sentiment on day $t-2$, released on day $t-1$ before the market open. Control variables include the return from the open on day $t-6$ to the open on day $t-2$, lagged abnormal volume and volatility. The abnormal volume is computed by dividing the difference between trading volume for stock $i$ on day $t$ and the mean volume for stock $i$ in the sample period by the mean of volume for stock $i$ in the sample period. Daily volatility is estimated using the approach of Rogers and Satchell (1991). The sample period is from January 2015 to February 2017. The regression is estimated with OLS using standard errors clustered by calendar day. The corresponding $t$-statistics are shown in parentheses. *, **, *** indicate statistical significance at $10 \%, 5 \%$, and $1 \%$ levels, respectively. 
Table 9 Predicting Earnings Surprises and Event returns Using Twitter Sentiment

\begin{tabular}{ccc}
\hline \hline & SUE $(\mathrm{t})$ & Risk-Adjusted Announcement Return \\
& $(1)$ & $(2)$ \\
\hline Intercept & $1.673(12.95)^{* * *}$ & $0.099(0.56)$ \\
Twitter $_{i, t-2}$ & $0.681(2.20)^{*}$ & $0.426(2.32)^{* *}$ \\
Controls & Yes & Yes \\
$N$ & 11,435 & 11,435 \\
Clusters & 8 & 8 \\
$R^{2}(\%)$ & 0.568 & 0.201 \\
\hline \hline
\end{tabular}

Column (1) presents results from following regression:

SUE $_{i, t}=a+$ bTwitter $_{i, t-2}++$ cReturn $_{i, t-6: t-2}+\sum_{k=2}^{6} d_{k}$ Volume $_{i, t-k}+$

$\sum_{k=2}^{6} f_{k}$ Volatility $_{i, t-k}+\varepsilon_{i, t}$,

Column (2) presents results from following regression:

Return $_{i, t-1: t+1}=a+$ bTwitter $_{i, t-2}+$ cReturn $_{i, t-6: t-2}+\sum_{k=2}^{6} d_{k}$ Volume $_{i, t-k}+$ $\sum_{k=2}^{6} f_{k}$ Volatility $_{i, t-k}+\varepsilon_{i, t}$,

where $S U E_{i, t}$ is the standardized earning surprise announced on day t. $\operatorname{Return}_{i, t-1: t+1}$ is firm $i$ 's riskadjusted return from the market open on day $t-1$ to market open on day $t+1$. The two-day risk-adjusted returns are computed as the sum of two daily risk-adjusted returns. Risk-adjusted returns are computed as the residuals from the Fama-French-Carhart four-factor model. Twitter ${ }_{i, t-2}$ is stock $i$ 's Twitter sentiment on day $t-2$, released on day $t-1$ before the market open. Control variables include the return from the open on day $t-6$ to the open on day $t-2$, lagged abnormal volume and volatility. The abnormal volume is computed by dividing the difference between trading volume for stock $i$ on day $t$ and the mean volume for stock $i$ in the sample period by the mean of volume for stock $i$ in the sample period. Daily volatility is estimated using the approach of Rogers and Satchell (1991). The sample period is from January 2015 to February 2017. The regression is estimated with OLS using standard errors clustered by calendar day. The corresponding $t$-statistics are shown in parentheses. $*, * *, * * *$ indicate statistical significance at $10 \%, 5 \%$, and $1 \%$ levels, respectively. 
Figure 1 Time series of monthly returns for the trading strategy based on Twitter sentiment

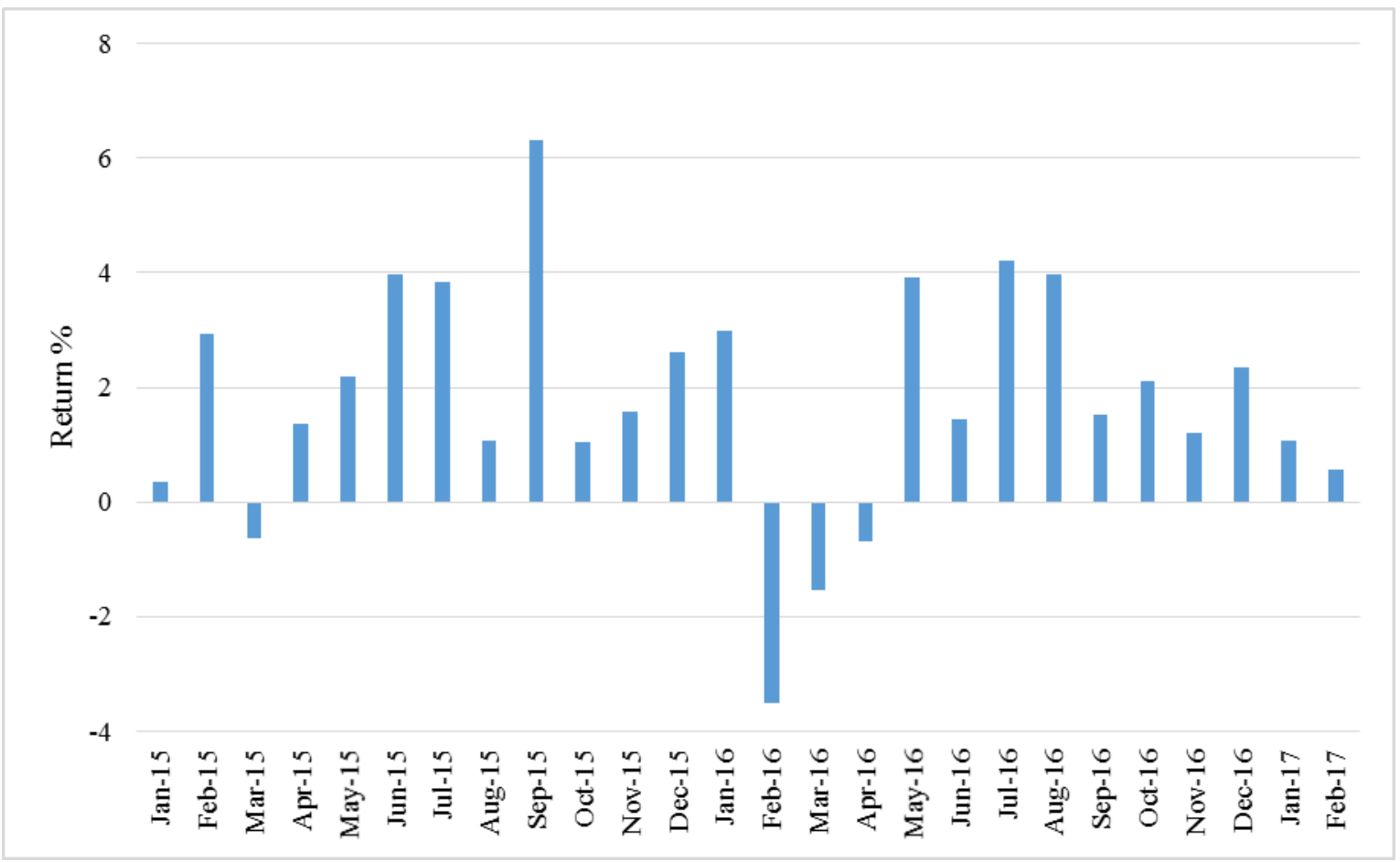

The figure shows monthly returns for the trading strategy based on Twitter sentiment over our sample period. We assemble the portfolio for the trading strategy at the beginning of each trading day. We form two equal-weighted portfolios based on each firm's recent Twitter sentiment. We include all firms with Twitter sentiment in the top decile (most positive) in the long portfolio and all firms with Twitter sentiment in the bottom decile (most negative) in the short portfolio. We hold both the long and the short portfolios for 24 hours and rebalance at the beginning of the next trading day. The sample period is from January 2015 to February 2017. 


\section{BIBLIOGRAPHY}

Admati, A., \& Pfleiderer, P. (1988) A theory of intraday patterns: Volume and price variability. Review of Financial Studies 1, 3-40.

Amihud, Y., \& Wohl, A. (2004). Political News and Stock Prices: The Case of Saddam Hussein Contracts. Journal of Banking and Finance, 28, 1185-2000.

Ang, A., Hodrick, J., Xing, Y., \& Zhang, X., (2006). The cross-section of volatility and expected returns. Journal of Finance, 61, 259-299.

Antweiler, W., \& Murray, Z. F., (2004). Is all that talk just noise? The information content of Internet stock message boards. Journal of Finance, 59, 1259-1294.

Azar, D. P., \& Lo, W. A., (2016). The wisdom of Twitter crowds: Predicting stock market reactions to FOMC meeting via Twitter feeds. Journal of Portfolio Management, 42, 123-134.

Baker, M., \& Wurgler, J., (2006). Investor sentiment and the cross-section of stock returns. Journal of Finance, 61, 1645-1680.

Barclay, J.M., \& Hendershott, T., (2003). Price discovery and trading after hours. Review of Financial Studies, 16, 1041-1073.

Bartov, E., Faurel, L., \& Mohanram, P., (2017). Can Twitter help predict firm-level earnings and stock returns? Accounting Review, forthcoming.

Barber, B. M., Lehavy, R., \& Trueman, B., (2010). Ratings changes, ratings levels, and the predictive value of analysts' recommendations. Financial Management, 39, 533-553.

Basistha, A., Kurov, A., \& Wolfe, H., M. (2016). Volatility forecasting: the role of internet search activity and implied volatility. Working Paper.

Brav, A., \& Lehavy, R., (2003). An empirical analysis of analysts' target prices: Short-term informativeness and long-term dynamics. Journal of Finance, 58, 1933-1967.

Bernanke, B. S. (1983). Irreversibility, Uncertainty, and Cyclical Investment, Quarterly Journal of Economics, 85-106.

Ben-Rephael, A., Da, Z., \& Israelsen, R. D. (2017). It depends on where you search: Institutional investor attention and under-reaction to news. Review of Financial Studies, 30, 3009-3047.

Bernile, G., Hu, J., \& Tang, Y. (2016). Can information be locked-up? Informed trading ahead of macro-news announcements. Journal of Financial Economics, 121, 496-520.

Binham, C. Tyrie calls for probe into market moves before UK data releases. Financial Times, March 15, 2017. Retrieved from www.ft.com on April 15, 2017.

Bird, M. Market swings hint at data leaks. Wall Street Journal, March 14, 2017. 
Bollen, J., Mao, H., \& Zheng, X., (2011). Twitter mood predicts the stock market. Journal of Computational Science, 2, 1-8.

Boutchkova, M., Doshi, H., Durnev, A., \& Molchanov, A. (2012) Precarious politics and return volatility. Review of Financial Studies, 25(4), 1111-1154.

Caballero, R. J., \& Krishnamurthy, A. (2008). Collective risk management in a flight to quality episode. Journal of Finance, 63, 2195-2230.

Campbell, S. D., \& Sharpe, S. (2009). Anchoring bias in consensus forecasts and its effect on market prices. Journal of Financial and Quantitative Analysis, 44, 369-390.

Carhart, M. M., (1997). On the persistence of mutual fund performance. Journal of Finance, 52, $57-82$.

Chang, C., Daouk, H., \& Wang, A. (2009). Do investors learn about analyst accuracy? A study of the oil futures market. Journal of Futures Markets, 29, 414-429.

Chordia, T., \& Swaminathan, B., (2000). Trading volume and cross-autocorrelations in stock returns. Journal of Finance, 55, 913-935.

Cieslak, A., Morse, A., \& Vissing-Jorgensen, A. (2016). Stock returns over the FOMC cycle. NBER Working paper.

Clark, T. E., \& West, K. D. (2007). Approximately normal tests for equal predictive accuracy in nested models. Journal of Econometrics, 138, 291-311.

Collin-Dufresne, P., \& Fos, V. (2015). Do prices reveal the presence of informed trading? Journal of Finance, 70, 1555-1582.

Collin-Dufresne, P., \& Fos, V. (2016). Insider trading, stochastic liquidity, and equilibrium prices. Econometrica, 84, 1441-1475.

Cornelli, F., Goldreich, D., \& Ljungqvist, A., (2006). Investor sentiment and pre-IPO markets. Journal of Finance, 61, 1187-1216.

Cutler, D.M., Poterba, J.M., \& Summers, L.H. (1989). What moves the stock market? Journal of Portfolio Management, 15 (Summer), 4-11.

Da, Z., Engelberg, J., \& Gao, P. (2011). In search of attention. The Journal of Finance, 66, 14611499.

Da, Z., Engelberg, J., \& Gao, P., (2015). The sum of all FEARS: Investor sentiment and asset prices. Review of Financial Studies, 28, 1-32.

Das, S., \& Chen, M., (2007), Yahoo! for Amazon: Sentiment extraction from small talk on the web. Management Science, 53, 1375-1388. 
DiColo, J. A., \& Rogow, G. Gas market stung by rapid traders. Wall Street Journal, October 16, 2012.

Dellavigna, S., \& Pollet, M. J. (2009). Investor inattention and Friday earnings announcements. Journal of Finance, 64,709-749

Fama, E. F., \& French, R. K., (1993). Common risk factors in the returns of stocks and bonds. Journal of Financial Economics, 33, 3-56.

Fama, E. F., \& Macbeth, J.D., (1973). Risk, return, and equilibrium: empirical tests. Journal of Political Economy, 81, 607-636.

Flynn, P. Gas traders say HFT's are banging the beehive. Wall Street Journal, October 19, 2012.

French, K. R., \& Roll, R. (1986). Stock return variances: The arrival of information and the reaction of traders. Journal of Financial Economics, 17, 5-26.

Garcia, D., (2013). Sentiment during recessions. Journal of Finance, 68, 1267-1300.

Gay, G. D., Simkins, B. J., \& Turac, M. (2009). Analyst forecasts and price discovery in futures markets: The case of natural gas storage. Journal of Futures Markets, 29, 451-477.

Gemmill, G. (1992). Political risk and market efficiency: tests based in British stock and options markets in the 1987 election. Journal of Banking and Finance, 16, 211-231.

Gervais, S., Kaniel, R., \& Mingelgrin, H. D., (2001). The high-volume return premium. Journal of Finance, 56, 877-919.

Grisse, C., \& Nitschka, T. (2015). On financial risk and the safe haven characteristics of Swiss franc exchange rates. Journal of Empirical Finance, 32, 153-164.

Goodell, J. W., \& Vähämaa, S. (2013). US presidential elections and implied volatility: The role of political uncertainty, Journal of Banking and Finance, 27, 1108-1117.

Halova, M. W., Kurov, A., \& Kucher, O. (2014). Noisy inventory announcements and energy prices. Journal of Futures Markets, 34, 911-933.

Hendershott, T., Livdan, D., \& Schürhoff, N. (2015). Are institutions informed about news? Journal of Financial Economics, 117, 249-287.

Hess, D., \& Orbe, S. (2013). Irrationality or efficiency of macroeconomic survey forecasts? Implication from the anchoring bias test. Review of Finance, 17, 2097-2131.

Holden, C. W., \& Subrahmanyam, A. (1992). Long-lived private information and imperfect competition. Journal of Finance, 47, 247-270.

Howe, J. S., Unlu, E., \& Yan, X. S., (2009). The predictive content of aggregate analyst recommendations. Journal of Accounting Research, 47, 799-821. 
Huberman, G., \& Regev, T. (2001). Contagious Speculation and a Cure for Cancer: A Nonevent that Made Stock Prices Soar, Journal of Finance, 56, 387-396.

Irvine, P., Lipson, M., \& Puckett, A., 2006. Tipping. Review of Financial Studies, 20, 741-768.

Jegadeesh, N., Kim, J., Krische, S. D., \& Lee, C., (2004). Analyzing the analysts: When do recommendations add value? Journal of Finance, 59, 1083-1124.

Julio, B., \& Yook, Y. (2012). Political uncertainty and corporate investment cycles. Journal of Finance, 67, 45-83.

Kacperczyk, M., Van Nieuwerburgh, S., \& Veldkamp, L. (2016). Rational attention allocation over the business cycle. Econometrica, 84, 571-626.

Kim, O., \& Verrecchia, R. (1994). Market liquidity and volume around earnings announcements, Journal of Accounting and Economics, 17, 41-67.

Kurov, A., (2010). Investor sentiment and the stock market's reaction to monetary policy. Journal of Banking and Finance, 34, 139-149.

Kurov, A., Sancetta, A., Strasser, G., \& Wolfe, M. H. (2017). Price drift before U.S. macroeconomic news: Private information about public announcements? Journal of Financial and Quantitative Analysis, forthcoming.

Kuttner, K. N. (2001). Monetary policy surprises and interest rates: Evidence from the Fed funds futures market. Journal of Monetary Economics, 47, 523-544.

Leigh, A., Wolfers, J., \& Zitzewitz, E. (2003). What do financial markets think of war with Iraq? NBER Working Paper.

Li, J., \& Born, J.A. (2006). Presidential election uncertainty and common stock returns in the United States. Journal of Financial Research, 29, 609-622.

Linn, S. C., \& Zhu, Z. (2004). Natural gas prices and the gas storage report: public news and volatility in energy futures market. Journal of Futures Markets, 24, 283-313.

Liu, L. X., Sherman, A. E., \& Zhang, Y., (2014). The long-run role of the media: Evidence from initial public offerings. Management Science, 60, 1945-1964.

Loh, R. K., (2010). Investor inattention and the underreaction to stock recommendations. Financial Management, 39, 1223-1252.

Loughran, T., \& Ritter, J. R., (2002). Why don't issuers get upset about leaving money on the table in IPOs? Review of Financial Studies, 15, 413-444.

Loughran, T., \& McDonald, B., (2011). When is a liability not a liability? Textual analysis, dictionaries, and 10-Ks. Journal of Finance, 66, 35-65. 
Lucca, D. O., \& Moench, E. (2015). The pre-FOMC announcement drift. Journal of Finance, 70, 329-371.

Mao, H., Counts, S., \& Bollen, J., (2015). Quantifying the effects of online bullishness on international financial markets. European Central Bank working paper.

$\mathrm{Mu}, \mathrm{X}$. (2007). Weather, storage, and natural gas price dynamics: Fundamentals and volatility. Energy Economics, 29, 46-63.

Newey, W. K., \& West K. D., (1987). A Simple positive semi-definite, heteroskedasticity and autocorrelation consistent covariance matrix. Econometrica, 29, 229-256.

Pastor, L., \&Veronesi, P. (2012). Uncertainty about government policy and stock prices, Journal of Finance, 67, 1219-1264.

Pastor, L., \& Veronesi, P. (2013). Political uncertainty and risk premia. Journal of Financial Economics, 110, 520-545.

Rapach, D. E., Strauss, J. K., \& Zhou, G. (2010). Out-of-sample equity premium prediction: combination forecasts and links to the real economy. Review of Financial Studies, 23, 821862.

Rapach, D., Strauss, J., \& Zhou, G., (2009). International stock return predictability: What is the role of the United States? Journal of Finance, 68, 1633-1662.

Rigobon, R., \& Sack, B. (2005). The effects of war risk on U.S. financial markets. Journal of Banking and Finance, 29, 1769-1789.

Rogers, L.C.G., \& Satchell, S.E., (1991). Estimating variance from high, low and closing prices. Annals of Applied Probability, 1, 504-512.

Seasholes, M., \& Wu, G. (2007). Predictable Behavior, Profits, and Attention. Journal of Empirical Finance, 14, 590-610.

Stambaugh, F. R., Yu, J., \& Yuan, Y., (2012). The short of it: Investor sentiment and anomalies. Journal of Financial Economics, 104, 288-302.

Tetlock, P. C., (2007). Giving content to investor sentiment: the role of media in the stock market. Journal of Finance, 62, 1139-1168.

Tetlock, P. C., Saar-Tsechansky, M., \& Macskassy, S., (2008). More than words: Quantifying language to measure firms' fundamentals. Journal of Finance, 63, 1437-1467.

Tetlock, P. C., (2011). All the news that's fit to reprint: do investors react to stale information? Review of Financial Studies, 24, 1481-1512.

Surowiecki, J., (2004). The wisdom of crowds: Why the many are smarter than the few and how collective wisdom shapes business, economies, societies and nations. Doubleday. 
Vipul, Jocob, J., (2007). Forecasting performance of extreme-value volatility estimators. Journal of Futures Markets, 27, 1085-1105.

Vlastakis, N., \& Markellos, R. N. (2012). Information demand and stock market volatility. Journal of Banking \& Finance, 36, 1808-1821.

Welch, I., \& Goyal. A. (2008). A Comprehensive look at the empirical performance of equity premium prediction. Review of Financial Studies, 21, 1455-508.

White, H., (1980). A heteroskedasticity-consistent covariance matrix estimator and a direct test for heteroskedasticity. Econometrica, 48, 817-838.

Womack, K. L., (1996). Do brokerage analysts' recommendations have investment value? Journal of Finance, 51, 137-167.

Yohai, V. J., (1987). High breakdown-point and high efficiency robust estimates for regression. The Annals of Statistics, 15, 642-656.

Zhou, J., (2015). Sophisticated trading and market efficiency: evidence from macroeconomic news announcements. Working paper. 